\title{
The Meaning of Success
}
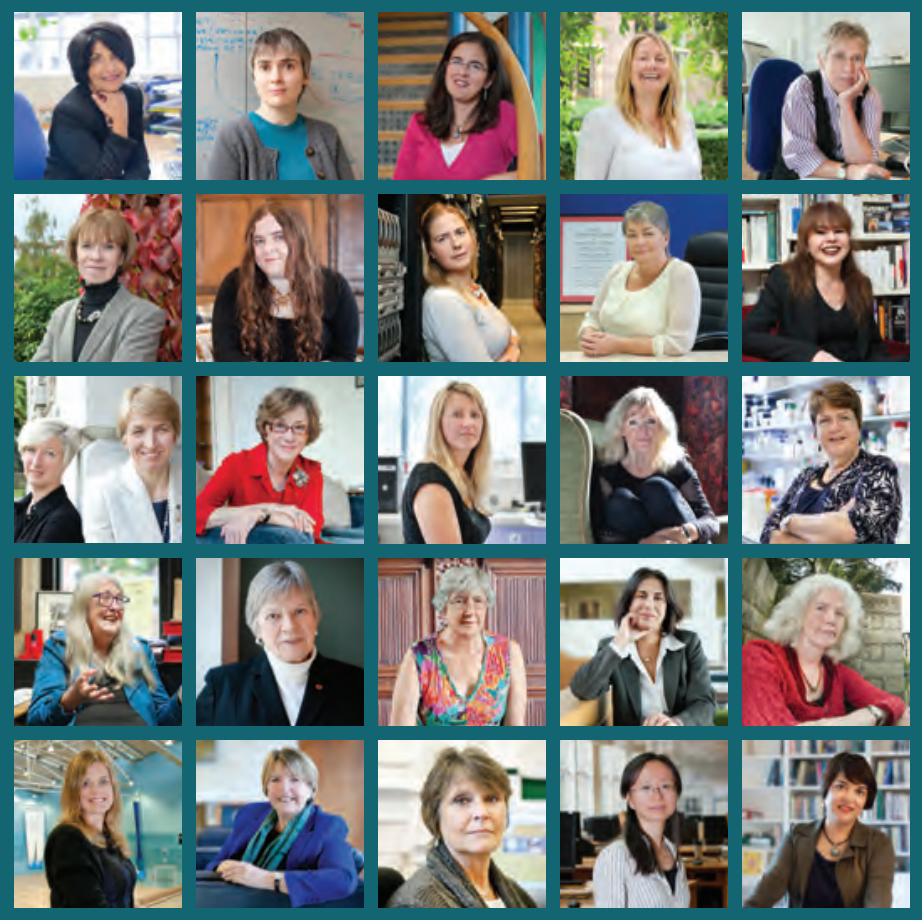

\section{Insights from \\ Women at Cambridge}



The Meaning of Success

\author{
Insights from \\ Women at Cambridge
}




\section{CAMBRIDGE \\ UNIVERSITY PRESS}

University Printing House, Cambridge св2 8в , United Kingdom

Cambridge University Press is part of the University of Cambridge.

It furthers the University's mission by disseminating knowledge in the pursuit of education, learning and research at the highest international levels of excellence.

www.cambridge.org

Information on this title: www.cambridge.org/9781107428683

(C) The Chancellor, Masters and Scholars of the University of Cambridge 2014

This publication is in copyright. Subject to statutory exception and to the provisions of relevant collective licensing agreements, no reproduction of any part may take place without the written permission of The Chancellor, Masters and Scholars of the University of Cambridge.

First published 2014

Printed in Poland by Opolgraf

A catalogue record for this publication is available

ISBN 978-1-107-42868-3 Paperback

Additional resources for this publication at www.cam.ac.uk/womenatcambridge

The Chancellor, Masters and Scholars of the University of Cambridge have no responsibility for the persistence or accuracy of URLs for external or third-party internet websites referred to in this publication, and do not guarantee that any content on such websites is, or will remain, accurate or appropriate. 


\section{Acknowledgements}

Starting as an idea to create a publication that would increase the visibility of women at Cambridge, it soon became clear that there was scope to achieve much more than that, and there are many people to thank for this development.

Thanks go to those whose vision in the early days shaped the direction of the project's exploration: the University's Gender Equality Champion Professor Dame Athene Donald, Pro-Vice-Chancellor Jeremy Sanders, Head of Equality \& Diversity Sigrid Fisher, and Jo Bostock of Pause Consultancy. Jo's expertise, authenticity and unwavering commitment have been fundamental to the book's formation and it has been an inspiration to work with her.

Thanks go to Gina Warren and Vivien Hodges who helped gather together and analyse the material from all the nominees, and to Jeanette Ward of McHale Ward Associates for her refreshing design concept and endless patience.

Thanks too to Pari Naderi for her brilliant photography that brought the book to life.

The help of those from the E\&D team who kept the project on track was invaluable, so thanks go to Claire Hogg for all things finance and Kevin Coutinho for the checks and double-checks. Particular thanks are extended to Diane Jeffery for her constant and unflappable project management.

Invaluable feedback and shaping of draft chapters came from Sigrid Fisher and Tammy Parlour, both of whom helped to identify and hone the main themes of the book.

The careful eyes of copy-editor Caroline Howlett and proofers Rachel Wood and Melanie Gardner provided reassurance at the later stages of writing the book. Guidance from Andrew Aldridge in the Office of Communications and Professor Ottoline Leyser was much appreciated, helping us to maintain clarity as the book developed.

Sincere thanks go to Cambridge University Press for their financial support for this book and their professional advice throughout its formation, particularly to Claudia Bickford-Smith, Heidi Mulvey, Jillian Cheshire and Elaine Allwright.

The generosity of Professor Jeremy Sanders is also much appreciated for his support in securing the finances needed to deliver this project.

And finally, the biggest thanks go to the University of Cambridge colleagues who nominated their peers for this book, and to the women who responded so positively to the invitation to be seen and to be heard. Thank you for making this book a reality. 



\section{Contents}

Foreword

Introduction

Questioning the meaning of success

Ottoline Leyser

Shima Barakat $\quad 14$

Carol Black 16

Laurie Friday $\quad 18$

$\begin{array}{ll}\text { Sarah Teichmann } & 20\end{array}$

\section{Chapter 1}

The achievements that matter most, and why

Suzy Stoodley

Joya Chatterji

Nicky Clayton

Sheila Scarlett

\section{Chapter 2}

The challenges experienced by women

working at Cambridge

Mary Beard

Kusam Leal

Sandra Waterhouse

Nicky Athanassopoulou

Chapter 3

Gender and its effect on working life

Jane Clarke

Penny Hubbard

Shery Huang

Karen Pearce

\section{Chapter 4}

Admired qualities and role models

Emma Wilson

Joanna Cheffins \& Helen Jackson

Rebecca Simmons

Kate Pretty

Chapter 5

Advice, insights and learning from experience

Ann Louise Kinmonth

Rachel Fogg

Philippa Steele

Barbara Stocking 


\section{Foreword}

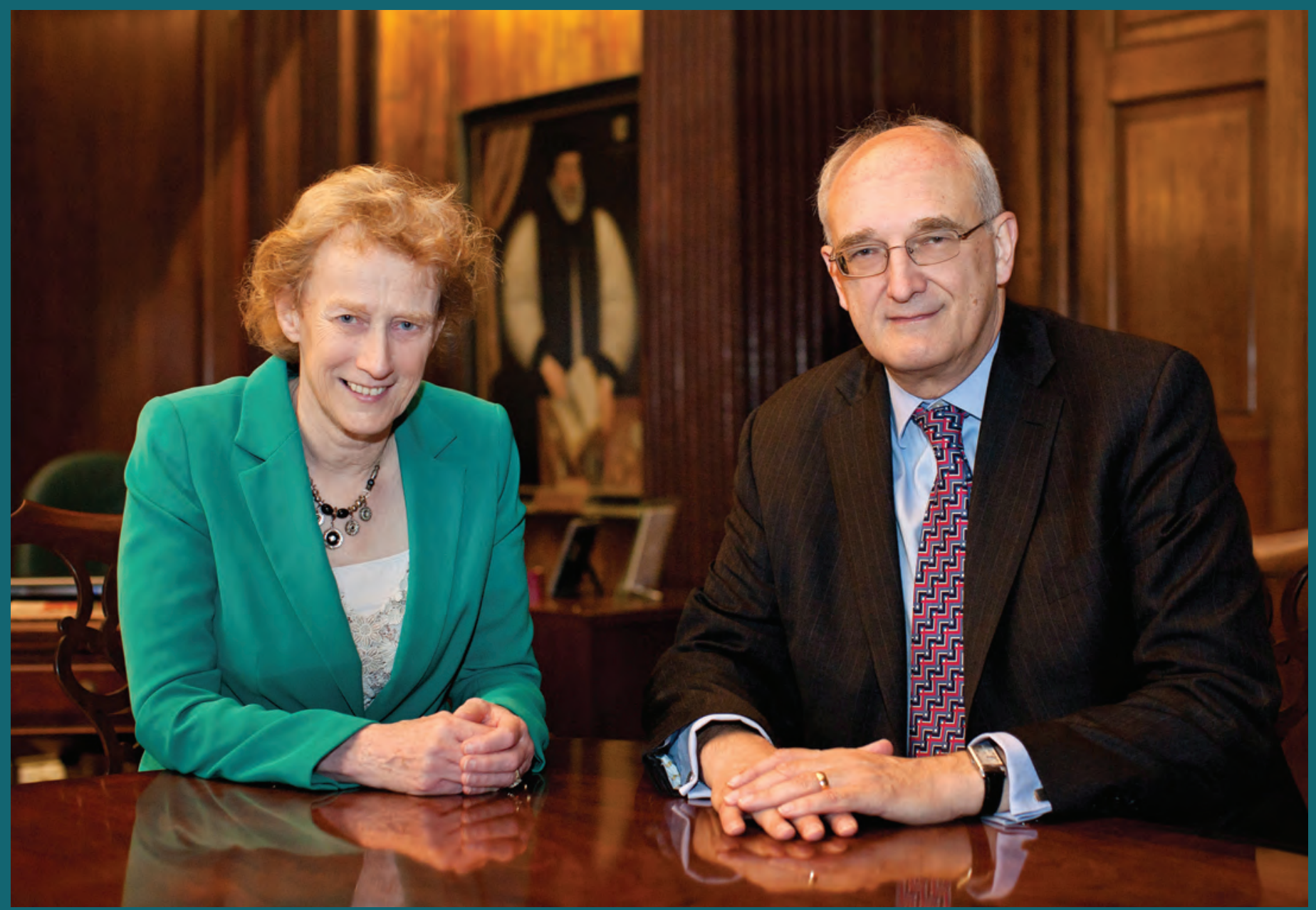

"The Meaning of Success brings together the stories and life experiences of women from across the collegiate University. This investigation provides a rare opportunity to reconsider what success means by sharing the contributors' distinct and very individual life journeys that have led them to Cambridge.

All the women featured in the book are successful. It is apparent however, from the unacceptably low numbers of women in senior roles across the University and in society more generally, that the traditional understanding of success can often disadvantage women. By exploring these inspirational stories, this book reminds the reader that talent and excellence can be found across the University and in every walk of life. It provides an opportunity to reflect on how success is recognised and rewarded, giving us scope to redefine and extend the qualities and attributes we associate with being successful.

I am quite sure that the University is not unique in having so many talented women amongst its workforce. But I am equally sure that this book will inspire others to realise their potential and question the meaning of success both for themselves and in others." 
As I came up through the Cambridge system it was certainly the case that I did not always feel I fitted in with those around me. It is never possible to tell whether such a sensation is gender-related or not, but being in such a male-dominated field as physics it was hard not to think that my gender may at least have been relevant. Back then I would have loved to hear how other women charted a path through the University system and hierarchy, a place where I could feel uncertain, confused and unsupported.

This book is a celebration of the life stories of many remarkable women across the University. It is also a potent reminder that there is no unique path to success; indeed, that success is not a single thing that we can all agree on. Instead, for all these different women - both those who are interviewed at length and those whose voices are heard through selected quotations - what really matters to them is a complex multi-dimensional set of factors which are frequently different from those commonly ascribed to the successful in life. These factors may even shift over time, but they must always be consistent with the woman's own belief systems if they are to provide fulfilment. Only then can they ensure the woman herself believes in her 'success'. For these women it is clear that success comes from within at least as much as from any external recognition. This is an important lesson for us all, men and women, to remember.

This book has evolved substantially over its gestation. Starting off as an idea to celebrate and highlight women who might serve as visible role models to those coming after them, it has transformed into something more subtle but, I believe, more powerful. It isn't just a book that may inspire younger women. It is now equally a book that can inform anyone who works with women - in other words, everyone within the University (and beyond). It shows how ensuring that a woman's sense of inner integrity is satisfied generates a powerful driving force for her. Alongside a decent work-life balance, this contributes to her ability to feel successful. In other words we glimpse insights into what success means to each of the individuals represented here.

As I read the stories these women reveal, I was moved and I was excited. Within an academic environment, too often the individual stories and voices are lost. Here we can reclaim a few of these and profit from what we hear. For those setting out, I hope this book will act as an inspiration and give them much food for thought. For those already working their way up the ladder, I hope the messages conveyed will provide both validation of choices they are making or have made, as well as an element of recognition of themselves in the stories told so that they feel empowered. For managers and leaders within the University and elsewhere, perhaps particularly but not solely the men, I hope the book will provide a resource for reflection about what really makes the women in their institutions tick. This may be not at all what they assumed or what works for them personally. Difference and diversity matter. Success has many faces, and supporting those whose meaning of success is not necessarily the same as one's own is a crucial part of good leadership.

Having risen through the ranks I feel an obligation to contribute towards making life that bit easier for the next generations of women. I should like to think that the work the University is now doing, and my own role as Gender Equality Champion, are starting to transform our working environment. By opening up dialogues about what matters to each of us, about our working culture and about what is going right and what is going wrong, I hope that everyone, male and female, will feel better able to achieve their potential and to do so without compromising their own integrity. There will always, for the academics amongst us, be hard-core metrics, such as grants or prizes won and books and papers published, that matter. But there is more to life than these (or their equivalents for other tracks), and this book is a powerful reminder of that fact.

The Meaning of Success is part of ongoing gender-related activities in Cambridge. The University has changed massively since I was an undergraduate in the 1970s. Some of this has come about through overall societal changes, but many small internal changes I trust are opening up a much more equal world for all our employees and students. These include support for those applying for promotion, and slight shifts in emphasis in promotion criteria and opportunities for academic-related staff to 'act up' to gain experience. Much more formalised equality training has been introduced for all involved in recruitment, which should bring into the open the pernicious habit we all tend to have of undervaluing women through unconscious bias; and there is now an explicit requirement for appointment committees to carry out active searches to ensure there is an appropriately diverse field of applicants. We have most certainly not yet achieved all we must and can do, as the low numbers of women in the highest grades make all too plain, but there is a tangible momentum and statement of intent that has not been present up until recently.

I hope readers of this book, whatever their gender, will feel as enthusiastic and moved as I do as they read the personal stories and grand themes that are covered here. This book is just one small contribution to the conversation we all need to have - with ourselves and with others - to make sure every employee in the University is able to fulfil their potential and to feel comfortable and supported as they do so.

Professor Dame Athene Donald DBE FRS
Gender Equality Champion, University of Cambridge 


\section{Questioning the meaning of success}

"Be really hungry for success - but be brave enough to know that success can be measured in many different ways."

Nicola Padfield

\section{Why attempt to redefine success?}

The way that success is defined shapes our working lives. It affects how organisations perform, who progresses within them and how power is exercised. It is a brutal fact that fewer women than men are recognised as successful based on current standards and value judgements. This book therefore sets out to question our assumptions about what success is and how this impacts on the progression of men and women in the workplace. Our wider ambition is to stimulate a rethink about who and what we value, why and how. This will enable us to imagine and then create more inclusive workplaces, which can in turn influence progress towards a fairer society.

The ideas and insights in the book are based on a series of questionnaires and interviews conducted with women at the University of Cambridge who were identified as successful by their peers. What emerged from this enquiry was a pressing need to broaden and redefine the term success in order for it to be more meaningful, relevant and accessible to women, as well as men. This redefinition is not about lowering standards but actually about enhancing them. A more sophisticated notion of what constitutes success acknowledges the range of behaviours and competencies necessary for the University, and society more broadly, to prosper.

An institution like the University is almost entirely dependent on the quality of its research and teaching for its reputation. It needs highly able people at all levels and in all areas to inspire, stretch, encourage, test, disagree with and support one another in order for the institution to continue to flourish. It also needs a diverse range of visible role models to attract the best new people and to provide tangible evidence of what it's possible to achieve. Such aspirations require the active participation of both women and men.

A meaningful definition of success that works for the organisation, whilst also being personally engaging for both genders, starts to change the game, rather than tinkering around the edges. In commissioning this book, the University is demonstrating a determination to achieve change on this scale. The book provides a platform for stories by and about successful women at the University, so that they can influence thinking in this area. These insights could also provide encouragement to women looking to shape their own working lives, as well as valuable guidance for those responsible for developing or managing others.

There is an implicit acknowledgement that gender progression across all sectors of the workplace has been achingly slow in recent years. This is despite ample research showing the positive impact that gender diversity has on the performance of organisations. There are also countless cautionary tales that link a lack of diversity with poor risk assessment, wasted talent, limited innovation and poor decision-making.

It seems that the case for gender equity may be compelling, but measures to address it have yet to achieve real traction. With leaders across sectors clamouring to publicly state their support for women coming through the talent pipeline and on to top tables, we might reasonably expect to be seeing radical improvements in the metrics that indicate progression. We're not. Something isn't working. Girls are still opting out of STEMM subjects, equal pay seems a distant prospect, the talent pipeline for women is notoriously leaky at mid to senior levels and leadership remains a predominantly male preserve. The rules of the game need to change. Success as it is currently framed around factors such as seniority, remuneration and personal status is neither equally appealing to both genders, nor does it fully recognise or reward their contributions.

We need to challenge some of the myths about meritocracy that put women in a double-bind of wanting to advance based on their competence rather than a quota, whilst at the same time being judged against subjective criteria with an inbuilt gender bias. Unconscious bias can also be detected in the subtleties of who is invited for interview, assessments about readiness for promotion, restricted exposure to stretch assignments and prizing individual attainment over collegiate contribution.

In addition to any talent and performance argument there is also an ethical aspect to making a case for a more inclusive definition of success. At the most basic level, you can only defend a status quo where men statistically dominate the leadership ranks by also buying into the deeply uncomfortable position that they are just better and smarter than women. This is clearly not a view we share, and there is a need to evolve the systems of reward and recognition that result in 
such an imbalance. Having more women integrated at all levels of organisations is vital, and the book looks to point to ways this can be achieved. It seeks to identify the individual and organisational behaviours that get in the way of an inclusive workplace, as well as the ones that enable diverse talent to thrive.

We know of course that success means many different things to many different people. It may therefore seem futile to attempt to redefine it to give it more meaning and efficacy; but we must try if we are serious about creating more inclusive workplaces. If the way of valuing and promoting others is too narrow then we shall never see the systemic change necessary for real gender equity. A broader, richer definition of success makes it far more likely that diverse talent will be recognised. These talented people - both men and women - can then progress through their organisations and shape them for the better along the way.

\section{Success and its relationship to gender}

"Success is measured in many ways - the most important of which is how you feel about yourself."

During the interviews for this book, there was often palpable discomfort when participants heard themselves described as successful women. This discomfort ranged from such remarks as 'are you sure you have the right person?' through to an active dislike about what this term might imply about who they were and how they worked. Some expressed fears that they would be viewed as self-aggrandising or arrogant if they were to accept the label 'successful'. Whilst there were examples of people who were much more at ease with being seen as successful, they were not in the majority.

In accounting for this broad aversion to the notion of success, it would be all too easy to jump to glib conclusions about women having a lack of confidence, feeling a disinclination to promote themselves in a highly competitive environment or perhaps preferring to choose to opt out because of the complexities of combining work and childcare. Based on the actual data emerging from the interviews, this would be to miss the point entirely.

"We don't all have to aspire to the top job just because we think we ought to; but equally we shouldn't set our sights too low, just because it's what other people expect."

Margaret Robinson

The women who contributed to this book are all members of an elite institution - the University of Cambridge. By some measures, simply being part of the University would have them viewed as success stories. Any one of them could lay claim to several of the following adjectives - smart, eloquent, gutsy, powerful, influential, funny, insightful, pioneering, supportive, demanding and driven. They are also flawed, human and as susceptible to imposter syndrome as the next person. But they are not women who shied away from being seen as successful because they felt 'less than'. Instead, they just didn't seem to buy a more traditional interpretation of success forged over centuries in workplaces that were shaped by and for men. There was a general sense that ideas about success had not yet caught up with the societal changes that had brought far more women into the workplace.

The women who participated in the book embraced success, but only when it was reframed to have more relevance and meaning to them. If success was seen to be primarily about status, remuneration, prizes, papers in esteemed journals or the corner office then it was not sufficiently appealing for them. Personal success or acknowledgement was most valued when it came as a by-product or consequence of having got something important done, or as a result of having contributed to others' achievements. Similarly, influence or power was often embraced, but only in so far as it enabled a person to instigate an important change, conduct an interesting piece of research or set up a new project. The research evidenced no real sense that power, prestige or status had an appeal independent of what one could do with it.

"I have learned to define success on my own terms and to focus my work where possible on the areas where I can make most effective contributions."

Ruth Cameron

It is also important to say that many of the women interviewed for this book did not directly correlate seniority with success. Traditional career advancement was not the goal for all - indeed many put far greater stock in having the freedom to pursue deeply interesting work for which they felt a real passion.

"I am clearly not successful in the way that most academics set out to succeed and that does not faze me one bit. I am touched that someone nonetheless saw that by some other measure I might be considered successful."

Terri Apter

A clear theme emerged about the importance of who you were and how you behaved in relation to others, as well as the outcomes you achieved. An ability to work collaboratively was strongly linked with a more meaningful definition of success. There was an interest in having a decent process and doing high-quality work as part of an effective team rather than just getting individual credit. Along with this came a general aversion to jockeying for personal promotion which, whilst laudable in many ways, also carried the risk of being overlooked. There was a clear wish to be viewed as having behaved in a way that was characterised by integrity and healthy working relationships. This naturally leads to an active engagement with others to get the job done. The relational aspect of this evolved definition of success also emerged in the emphasis that participants put on developing those around them. There was a sense of vicarious pleasure in the success of others that often seemed to be more easily embraced than success solely for oneself. 
"Not only is my 'success' measured by the number of publications I have had that reflect the quality of the work, but also by my willingness to help other scientists where I can."

Jennifer Hirst

It was notable that the achievements that mattered to participants often had an everyday feel to them, rather than just being showstopping, big-ticket items. There was clear value in the simple daily practice of engaging constructively with colleagues to do work that was of a high standard and on topics that held a real fascination. This took place in arenas as diverse as running the library, leading a team working on medical research, running the administration for graduate applications or building a major new sports complex.

"If I were to articulate what l'm most proud of, it would be in terms of really small, incremental improvements in my ability to do the various jobs I undertake."

Corinna Russell

The other dominant theme that came through the various conversations with women at Cambridge was the extent to which they saw themselves as having rounded working lives that encompassed both family, in all sorts of forms, and some kind of hinterland. Being rounded also meant more than family - it related to sporting endeavour, gardening, being a justice of the peace, a school governor, playing in an orchestra or even refurbishing a lifeboat to live on. This all gives a clue that the women of Cambridge have a multi-dimensional rather than one-dimensional sense of what it is to be successful.

"I very much support the notion that 'success' has a million definitions."

Joanna Cheffins

\section{Structure of the book}

This book is based on an assumption that there is real value in tuning into interesting stories from a range of women who are viewed by their colleagues as being successful. Its approach is therefore qualitative and looks to describe the phenomenon that is success.

The content is a blend of two main elements. There are five chapters that draw on the questionnaire submissions of 126 women to explore the themes of achievement, challenge, gender, role models and learning from experience. The remainder of the book comprises firstperson narratives and full-page photographic portraits. These are based on interviews with twenty-six of the participants, who represent a diverse range of perspectives, ages, backgrounds, levels of seniority and views on their working lives.

\section{Approach and demographics}

The Meaning of Success book project is linked to the University of Cambridge's wider activities and aspirations for gender equity. This work is led by Professor Dame Athene Donald and Pro-ViceChancellor Professor Jeremy Sanders, with the active support of the Vice-Chancellor Professor Sir Leszek Borysiewicz.

Jo Bostock was working with the University's Senior Gender Equality Network (SGEN). This group had identified the importance of visible women role models and wanted to explore how success is recognised and rewarded, from a gender perspective. The book project grew from these two starting points and was developed, coordinated and delivered in conjunction with the University's Equality \& Diversity (E\&D) team, part of the HR Division.

In order to identify potential participants, senior members of the University were asked to nominate colleagues who they felt to be successful, inspirational women who may have an interesting story to share. From the outset there was a clear intent to involve women from all levels, all grades, all staff groups and from across the whole University. Nominations of women from the lower staff grades and younger in age were particularly encouraged to ensure that the project reflected the wider cohort of women at Cambridge.

Nominated participants were sent an online survey featuring the questions you can see opposite.

The responses were reviewed to identify themes and illustrative quotes which form the basis for the chapters of the book. Of the respondents, twenty-six were then invited to participate in a one-to-one interview with the author and a photographic portrait session. These individuals were selected to reflect both the breadth and diversity of the women involved and also their ability to illustrate the strongest themes that emerged from the questionnaires. An advisory team consisting of senior University members involved in the project guided the short-listing process.

In total, 195 women were nominated by their peers, with 126 returning a questionnaire. For those respondents for whom we held demographic information, 2 per cent had disclosed a disability, 15 per cent were of foreign nationality and 15 per cent were of ethnicities other than White-British. The age of participants ranged from the late twenties to the late sixties, with an average age of fifty. 


\section{Online survey questions}

- What would you point to as the achievements that have mattered most to you, and why? (These can be large or small, personal or professional)

- What are some of the challenges you have faced, and how have you handled these?

- How do you think your gender has affected your working life?

- Which other woman/women at the University of Cambridge do you admire/ inspire you, and why?

- Having been nominated by colleagues for this project celebrating a diverse range of successful women at Cambridge, what is your best guess about why they rate you in this way?

What have you learnt from your experiences that you would like to pass on to others?

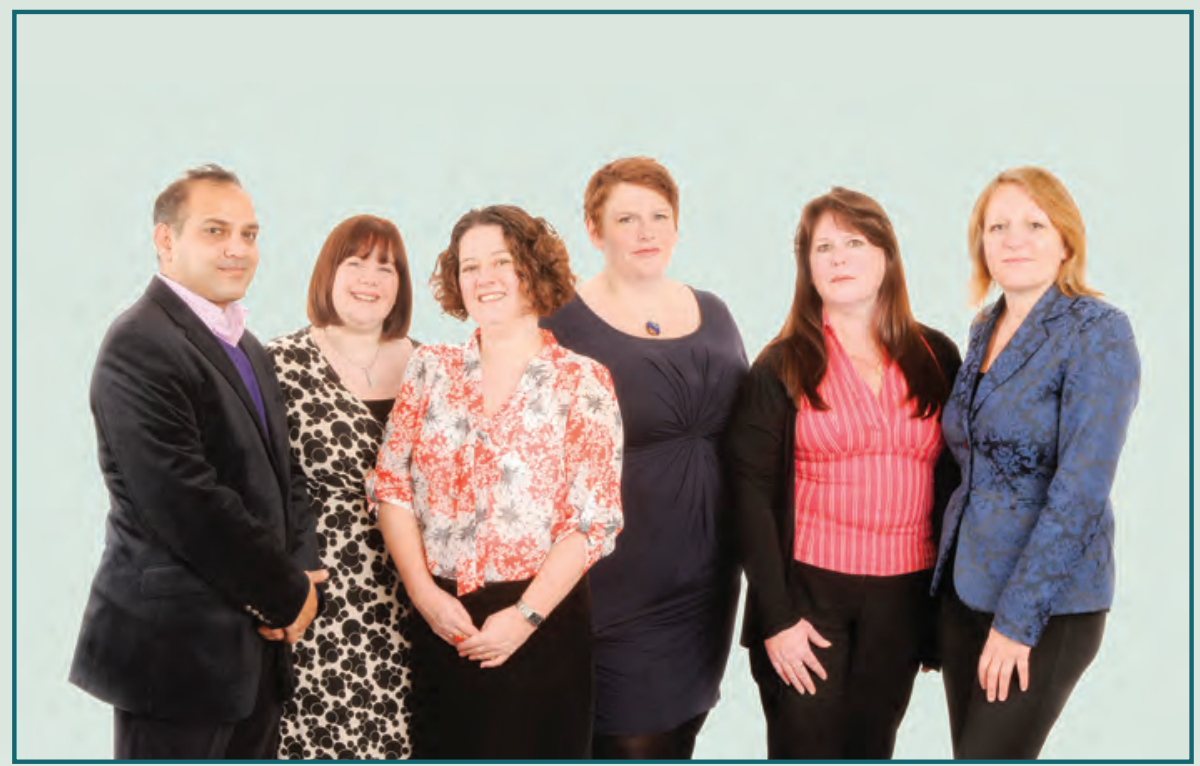

Members of the E\&D team, University of Cambridge

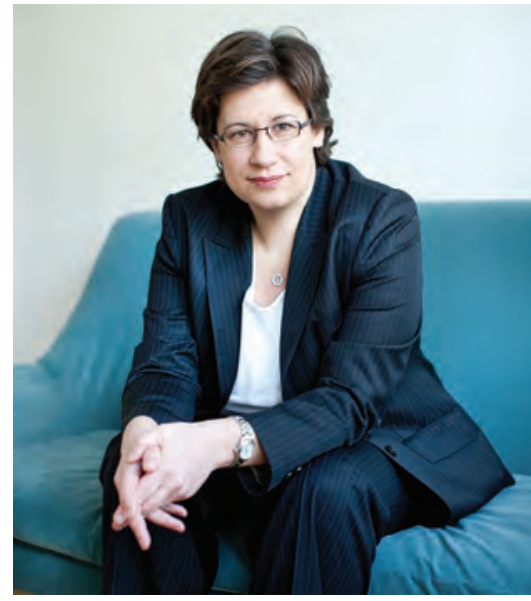

\section{Author Jo Bostock}

Jo runs Pause Consultancy, a leadership development business that advises global organisations, top teams and senior individuals on how to achieve diverse and inclusive workplaces. Jo is also co-founder of the Women's Sport Trust, a charity that encourages gender equality through sport.

www.pauseconsultancy.com

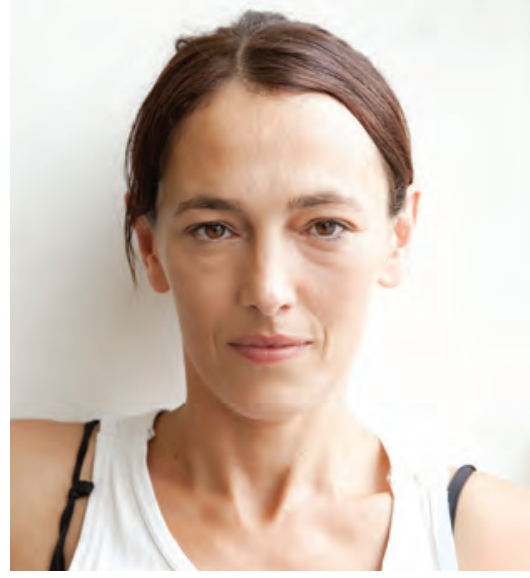

\section{Photographer Pari Naderi}

Following an internationally distinguished career as a dance artist, Pari Naderi has pursued a fascination with the image as an articulate expression of performance, place and person. Pari regularly lectures in photography and has lead numerous collaborative arts projects.

www.parinaderi.co.uk 
Professor Ottoline Leyser CBE FRS is the Director of the Sainsbury Laboratory and a Fellow of Clare College. Among her honours are the Society of Experimental Biology's President's Medal (2000), the Royal Society Rosalind Franklin Award (2007) and the International Plant Growth Substance Association's Silver Medal (2010).

As a developmental biologist, the whole basis of my science is about seeing patterns. I am a 'connector-upper' of things. There's a kind of magpie collection of information and ideas, and then you stick them together in different ways and see what it looks like.

I've noticed myself doing the same thing when l'm sitting on committees. I can see the complex system and I can see the interactions going on which generate a pattern. If you want to change that pattern - perhaps because it's not supportive of women - then you have to find the levers that will shift it.

"If the overall culture of an organisation is constructed by individual interactions at different levels, then everybody really does have power."

My mum is a big influence on me, and she has the view that if something's not right, then you do something about it. It's completely normal and it's almost required. There's a kind of responsibility to act, especially if you have any kind of influence and actually all of us have more than we think. In science there's a lot of, 'Oh we're under terrible pressure to do this and that' and 'I'll never get a job unless I have this kind of CV.' Everybody complains about it, but we're the people sitting on panels, making judgements and shaping the system. I think if everybody were just a little bit more positive about what they could do, it would make a big difference. If the overall culture of an organisation is constructed by individual interactions at different levels, then everybody really does have power.

Although I have a strong belief in the importance of exercising influence, I still have quite a hard time with the idea of being successful or important. Acknowledging that you're important is inherently un-British! But at the same time, you have to admit it, because people respond differently to you because of your position. I hope that I just get on and do things, and I don't think my ego is particularly invested in my own ideas. Of course it's nice if you have a good idea and you might well feel pleased with it, but that's not the point. It should be completely about the outcome. I don't care whose idea it is as long as we get the right outcome and I do think there's some connection to gender here. When you sit on a committee, people seem to be absolutely astonished if you say their ideas are better than yours. That's not the rules - you are meant to fight hell for leather to hold your position.
I want to break the mould of what you need to be like to be successful. I think success needs to be about collegiality and recognising that the whole should be far more than the sum of the parts. Of course it's nice if you're elected to the Royal Society, but it's a by-product, not the object of the exercise. The current system favours the individual agenda, so you wind up with people with big grants and fancy publications, who can be doing very little for the system as a whole. I want this place to be different. I want it to be a really exciting, collaborative, open place to do science. I dislike the hoarding of ideas and unhelpful competitiveness - these are behaviours that to me are totally antithetical to what science should be about. I want to prove that by working together you can be even more successful in terms of what you actually deliver and the impact you have on your discipline.

I hate this notion of work-life balance; I just can't see that segregation. The idea of conflict being all about your family versus your job doesn't work for me. I really do feel that they can feed into one another in a positive way. Of course there are only twenty-four hours in the day - I get that, and you have constant time pressures and competing priorities. But I have time conflicts within my job and within my family, not just between them. You know, should I do the washing up or should I play Scrabble? I chose to buy a dishwasher and stopped buying clothes that needed ironing! My feeling is, if you can work out what matters most to you, which isn't always straightforward, then it's not so hard to know where to make the compromises. For me it was everywhere else except those two things - family and work. If it's you and your partner and it's a good relationship, I think you should be able to work it out, even if you're both pushing careers. It's very personal and at some level it's about what you want out of your life.

"I hate this notion of work-life balance; I just can't see that segregation." 


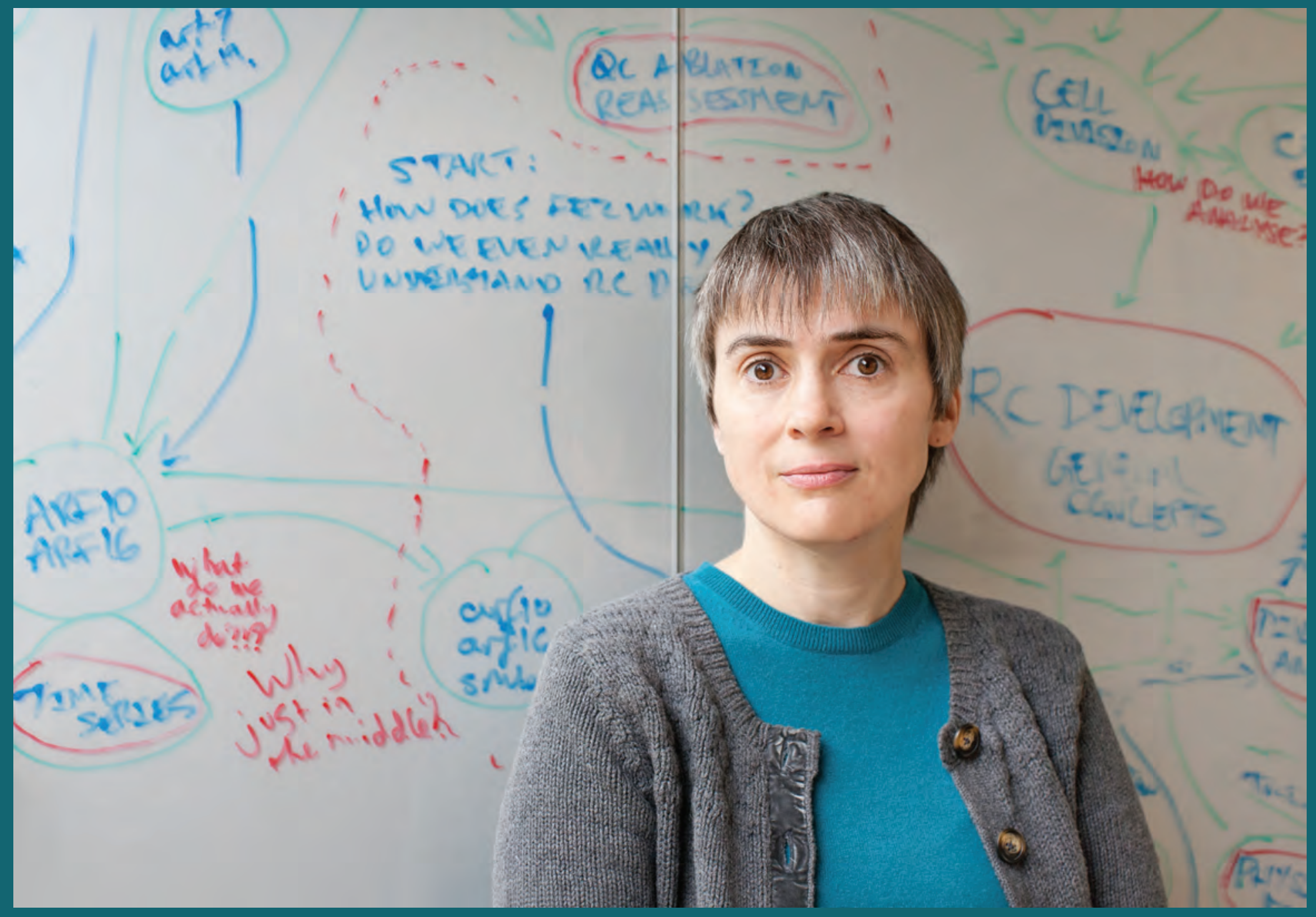

"I want to break the mould of what you need to be like to be successful." 


\title{
Shima Barakat
}

\author{
Dr Shima Barakat is a Research and Teaching Fellow in Enterprise and Entrepreneurship at the Cambridge \\ Judge Business School. She started her career as a construction engineer, which led to an interest in how \\ organisations understand and act in relation to the natural environment and global issues, and ultimately to \\ inspiring and supporting entrepreneurialism and business 'not as usual'.
}

I have polarised parents. My mother is as risk averse as you can possibly get, whilst my father breaks all the rules. Actually, he doesn't even acknowledge they exist and just goes about his life getting into a whole heap of trouble.

He's an entrepreneur, so we've had our highs but we've also had bailiffs at the door. Unlike my father I'm aware of boundaries but I'm also very willing to question them. If I don't think a rule is valid, I'll choose to either push back or go round it.

I think this attitude has helped me, particularly as a woman in engineering. I went to university when I was sixteen and was one of only three girls in a large class. The boys kept telling me I couldn't do things because I was a girl and I got so fed up I told the professor I was thinking of quitting. His response was perfect: 'You don't strike me as a person who walks, so what else could you do?' I decided to take charge, marched straight back to the boys and told them how things were going to be from now on. It was fine after that.

"My starting point is that I have the power to change something and I go from there."

When I graduated I worked on the construction of the Cairo Metro; it was 400 men and me. I didn't even have a toilet, so I commandeered the men's when needed and put up a sign 'occupied for feminine use'. That's illustrative of a broader mind-set, where if a situation doesn't work, l'll try to improve it. You don't just sit there complaining and wallowing in your misery. My starting point is that I have the power to change something and I go from there.

I think I have the genes of a planner and I apply this to the chaos and uncertainty of the entrepreneurial world that I now work in. I get energy from making order out of mess. I realise that people don't tend to deal well with chaos and that gives me an edge. At work we often get very short lead times for our programmes, so it can feel quite chaotic but I take real pleasure in making the whole system come together out of nothing.

It's interesting that the belief I can shape and order the world sits alongside fears associated with imposter syndrome. I suspect I'm typical in that I don't think of myself as a particularly successful woman. Most of the time I question whether I've done enough or if I'm at the level I should be for my age. I keep thinking I'm going to be found out and I imagine people reading this and asking 'Why her?'
Despite this perfectionist streak, I also know l'm at my best when I'm involved in an interesting variety of things, rather than singularly focused on one. At university I was actually happy to come second; it was good enough and meant that I got to do so much more.

I like breadth and when I look at what impresses me in other people, it's when they manage to strike a balance that enables them to spend time with their kids, fit in sports or a hobby and do good quality work at the same time. That roundedness is something that I value.

"Our systems are inconsistent and based on a masculine world view. We need to question them because they determine who gets recognised as successful."

What I find frustrating in most workplaces is that success is often based on the sheer quantity of work. It's often the person who puts in huge hours that makes it to professor early. Women tend to buy into the myth of the 'good academic' which emphasises citizenship, helping students, being on committees and so on. Then you see younger men who don't collaborate, focus totally on their own research and make it to professor before they're forty. Our systems are inconsistent and based on a masculine world view. We need to question them because they determine who gets recognised as successful. And it's not just about women 'leaning in' more: that's throwing the problem back on women when there are structural and organisational issues going on.

When thinking about gender, it's interesting to step away from 'man' and 'woman' as categories and look instead at femininity and masculinity. There was a lot about me growing up that was very masculine. I'm dressed in pink now and l've gone through my career looking very much like a girl but the rest of me didn't conform to standard notions of femininity. I made the Egyptian national team for taekwondo, had male friends and chose to study engineering. There is pressure to conform to stereotypes and they apply to men too.

We need to break down these stereotypes and there are some hints we are heading in the right direction. I had a lovely moment last week when two people Skyped in for a board meeting. I thought great: we're getting away from this obsession with travelling to meetings just to be seen. The two people who dialled in were both men and one showed up with his baby. This is where we need to get to, the system needs to be family friendly for both men and women; it needs to be human friendly. 


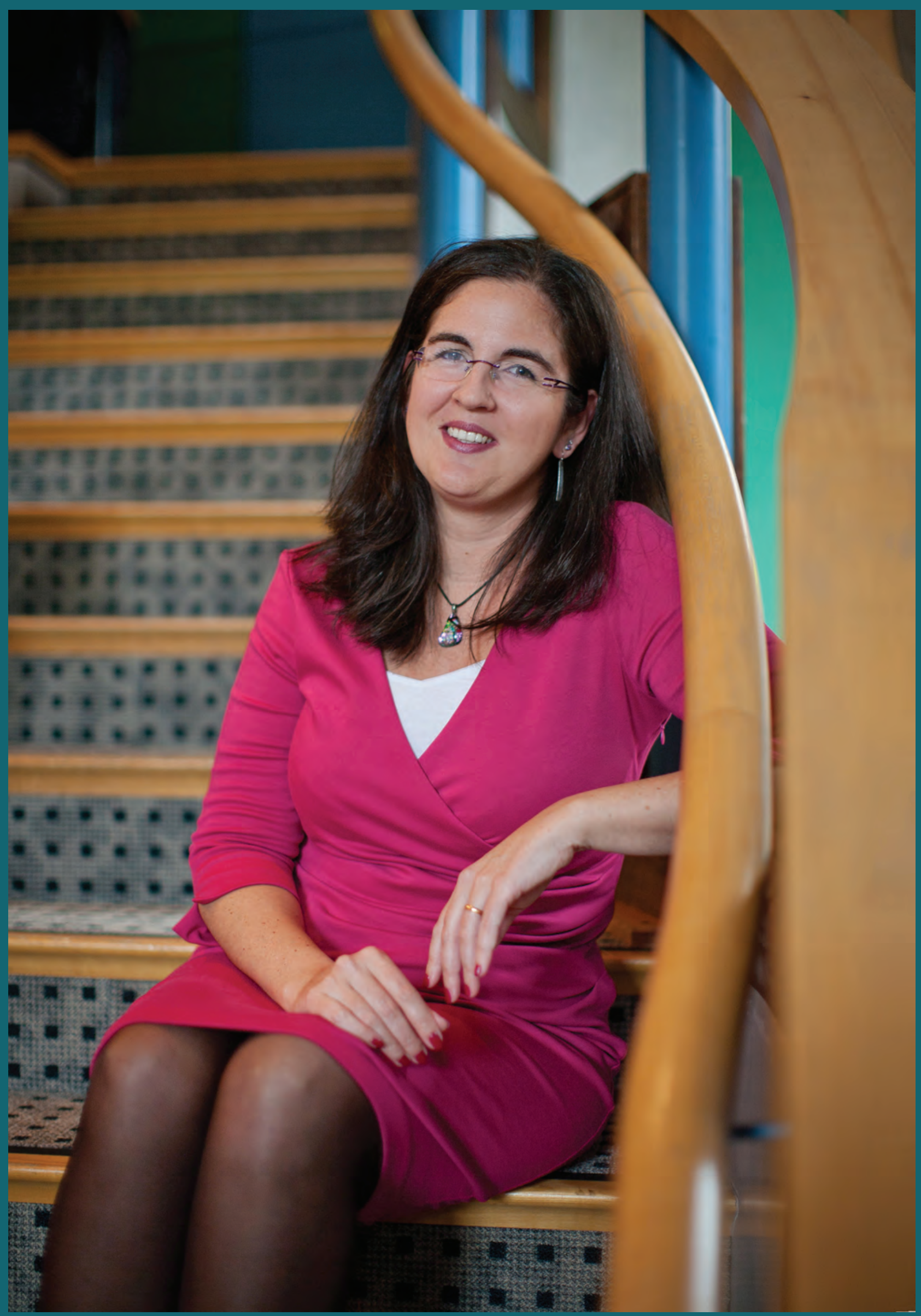


Professor Dame Carol Black FRCP FMedSci is Principal of Newnham College. She has held top positions in medicine and now holds high-level policy advisory positions on health and work. She was included in the 2013 BBC Woman's Hour Power List of 100.

Perhaps my earliest achievement was to defy limited family expectations. I was meant to stay living in my home town and work in a shoe factory or shop; but I had a stubborn belief that more was possible.

Both my parents were part of huge Victorian working-class families. After marrying late in life, they found it difficult to have children, and I eventually arrived when my mother was in her mid forties. Possibly in an attempt to keep me in good health, they fed me - and fed me a great deal. As a child I was a little, round Michelin person with masses of blond curls.

I scraped through the eleven-plus and went to a local grammar school. It was a huge shock to the system at first but as time progressed I became more and more dissatisfied with my circumstances at home. I didn't really know what university was but it seemed to be a very good thing because I would be able to escape. That sense of wanting to become something more probably comes from my father. He had a superb voice and as a young man won a scholarship to the Royal Academy of Music. He wasn't able to go, and later became deeply resentful about the life he never had.

"Of course I worry about things, but if you're going to succeed you must somehow develop the resilience to recover quickly from setbacks."

I was Head Girl at school, then Head of my hall of residence before being elected President of the Student Union at Bristol. As President I only had a year in post and I remember my absolute determination to make the most of it. Even then I demonstrated a steeliness that characterises my leadership now. It means I'm not going to be put off if I think a thing is worth doing. The other quality l've relied on is resilience. It doesn't matter how bad a day is, I will go to bed, sleep pretty well and tomorrow will be a new day. Of course I worry about things, but if you're going to succeed you must somehow develop the resilience to recover quickly from setbacks. My starting premise is always to try to achieve progress consensually, but if there is going to be a battle about something important then I will put on my tin helmet and Teflon coat; I won't avoid it.
I was eight years older than most of my peers before I started studying medicine, so what matters most to me about my career is that I was able to have one in the first place. I just love medicine and I suppose I became a workaholic, but then it never felt like work to me. In time I discovered that I knew how to build really good clinical or research departments and I was able to attract the best people to work in them. But I never expected to become President of the Royal College of Physicians. When that happened it did feel like a success, especially as I was only the second woman to hold the post.

I realised that I had the influence to effect change and I didn't shy away from the difficult things because I knew if I did, I wouldn't be able to look myself in the face.

"If you're leading an organisation, your job is to guide it, care for it, protect it as best you can and try to make sure good things happen to it."

I have a belief in the importance of stewardship and that applies to my position here at Newnham too. If you're leading an organisation, your job is to guide it, care for it, protect it as best you can and try to make sure good things happen to it. As a leader it's very easy to become arrogant or self-serving but it's awful to do things that diminish an organisation. If you do a good job, people will come to respect you and you'll be asked to go for other things; so personal success comes as a by-product of making a positive difference.

In order to have this sort of career, I've had to get over low expectations of what women could do and be. It took me a while to realise that it was perfectly all right to want to be a Medical Director or lead a unit. As a result I'm very interested in mentoring women towards leadership positions and I actively encourage them to simply have a go. Even if they don't get what they are going for, they'll still learn from the experience. Many women walk away when they look at what it takes to make it to the top. I know there are people who say you can have it all, but I'm not convinced; something has to give. The important thing is that it's a choice. A mentor can help you to decide what you really want and how to get over those final humps if you choose not to walk away. I'm all in favour of adequate crèches and all those practical things, but finding the right support at critical decision times is crucial.

With my own career, it matters to me terribly that I try and that I take risks. I would rather say, 'I had a go and it didn't work', than look in the mirror and realise I didn't put myself in the race. 


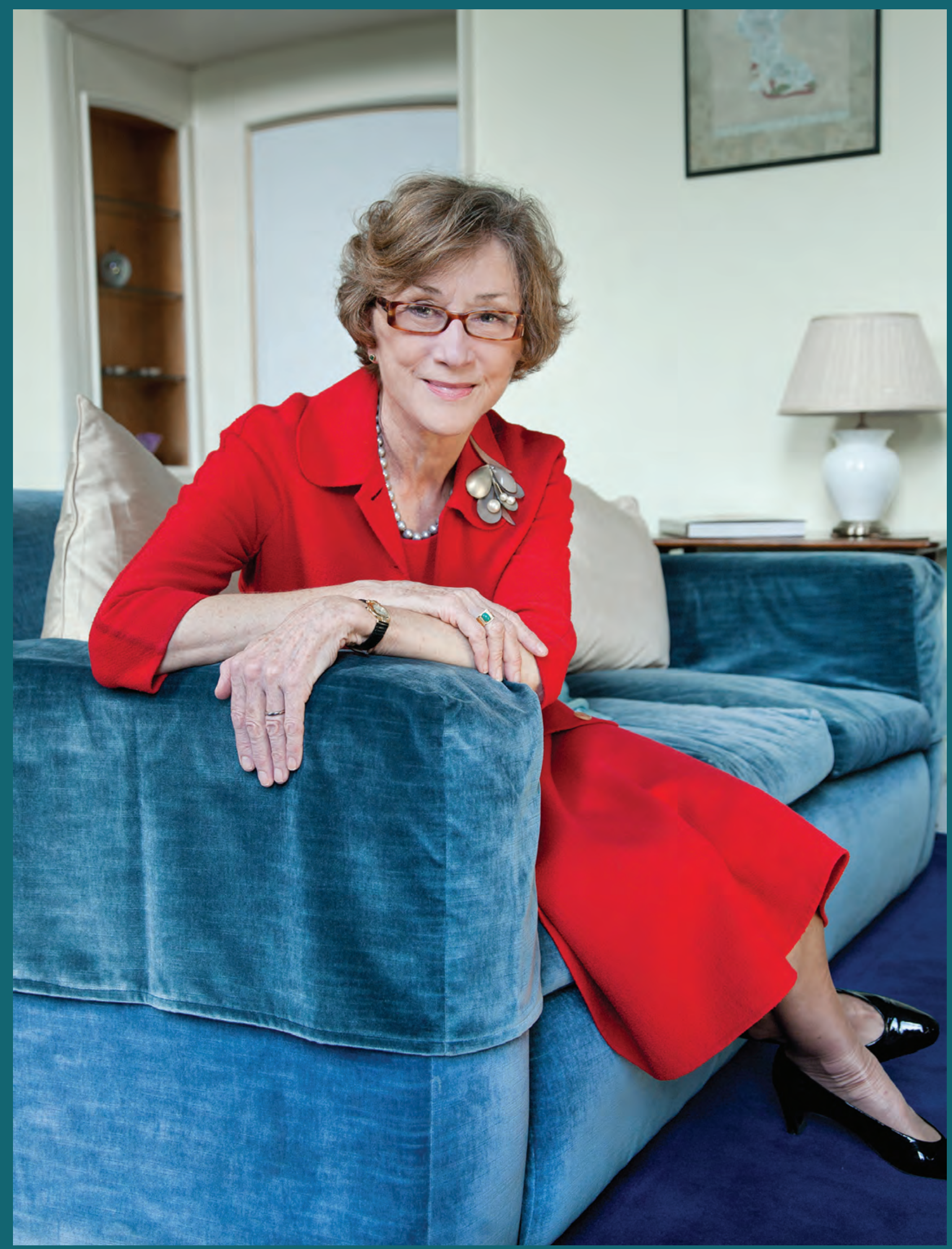


Dr Laurie Friday is the Degree Committee Senior Administrator in the School of Physical Sciences, and Secretary of the Degree Committees for Earth Sciences \& Geography and Physics \& Chemistry. A Zoology graduate of Clare College and a former Fellow of Darwin and Newnham Colleges, she has moved from research and academic roles into graduate administration.

I didn't think too deeply about my education when I was at school and I certainly didn't read when I was at home.

My mother heroically bought me a full set of the Encyclopaedia Britannica, which I studiously ignored. I found lessons a bit too easy and ended up spending most of my time playing music, or in the garden digging and pollinating pansies. My hands were always dirty and as a very small child I was quite fond of eating mud; I've grown out of that now! But l'm still happiest when I'm playing with soil and water and it's no surprise that my research has been on freshwater and fenland ecology.

When it came to A Levels, I disappointed my teachers woefully but was still offered a place at Clare College. I was one of the first women to go there, which was completely wonderful. I did a pretty useless Biology paper for the entrance exam but what got me in was an essay on Copernicus. Even though I didn't know a huge amount about him, it must have showed that I was able to put ideas together in interesting ways and Cambridge still values this kind of thinking.

"Thank goodness we're not all the same: it would be incredibly boring and we would never get anything done."

As an ecologist I am pretty much obsessed with the diversity of living things; most ecologists are. If you take the river in front of us, it's absolutely full of life that you can only see at a microscopic level. In a similar way, diversity amongst people excites me a great deal. Thank goodness we're not all the same: it would be incredibly boring and we would never get anything done. People bring different talents to the same problem and I'm looking at how to do more of this across departments. In academic circles it's fairly new to bring together insights from different disciplines, but you can get so much further that way. That's exactly how the natural environment works, lots of different species interacting together.

You need to appreciate the complexity of a system to effect change. The University is like a huge Meccano set that people have been adding to for centuries, so having a bit of experience and insight can really help. I also think my approach is distinctly female in that I prefer to solve problems by consensus (where possible) or dogged persuasion (where consensus is impossible). I have disarmed College Bursars and senior academics by offering them more cooperation than they could reasonably have expected.
What I do for work is enlivened enormously by the fact that I can go home and get stuck into the garden, or rehearse Shostakovich. I've never seen work as the main element in my life. It's very important and I give it my all when I'm there, but life is about much, much more. There are things I am deeply proud of that have nothing to do with my working life, for example conquering crippling performance nerves to play the horn in an orchestra. If work excludes anything that you would otherwise love to do then that's a bit sad.

"I'm pretty sure success is not just about climbing to the top of a greasy pole."

I've been incredibly fortunate that work has not simply been about making a living and that my husband was willing to support me in what I wanted to do. But it took me a long time to give myself permission to think this way. I used to believe that I had to have a full-time job because that's what 'proper people' did. I assumed I ought to get a university lectureship and I tried to get one until it became evident that it wasn't going to happen for me. At that stage I decided there was no point in becoming deeply frustrated about it. I chose to step back and ask myself, 'What else would I like to do?' Going from A to B might seem to be desirable, but actually $\mathrm{C}$ can turn out to be a far better option.

This led me to a career in administration, which has given me a slightly unusual take on success. I started at the top and then just gently slid downwards. Few people would countenance that. I had very good reasons for not staying in my most senior role longer than seven years. Once I made sure the department and the people in it were in a good place for me to leave, I was very glad to move on. It enabled me to re-engage with other things that were important to me.

I think progressing upwards matters for a lot of people; you earn more but you also get more responsibility and have to put in much more time. It's at least worth asking the question, 'Do I really want to do that?' I'm pretty sure success is not just about climbing to the top of a greasy pole. I think you can be deeply successful at the bottom of the greasy pole, providing others view you as somebody who can be trusted to do your job really well. For me that's far more important than somebody saying, 'Goodness me, how much do you earn? Really?' 


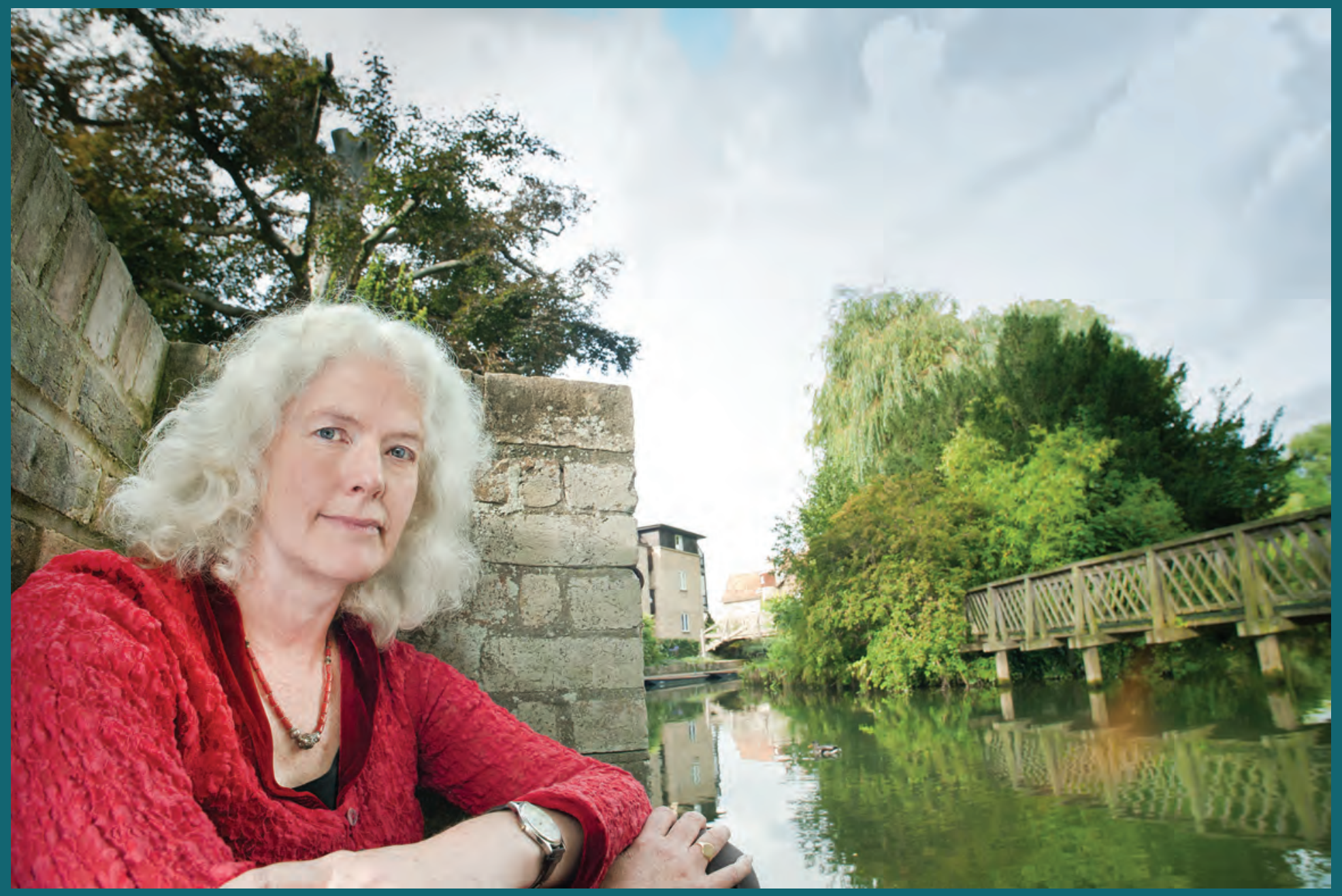

"I've never seen work as the main element in my life. It's very important and I give it my all when I'm there, but life is about much, much more." 


\section{Sarah Amalia Teichmann}

Dr Sarah Amalia Teichmann is a Principal Research Associate in the Department of Physics and a Group Leader, EMBL-European Bioinformatics Institute \& WT Sanger Institute. A computational biologist who has discovered global principles of protein complex assembly and gene expression regulation, her work has been awarded several prizes, including the Royal Society Francis Crick Lecture and EMBO membership.

I think it's a bit over-ambitious and actually unnecessary to attempt to completely change how success is measured within the academic system.

There are already objective measures like publications, prizes and scientific discoveries, as well as obvious indicators like leadership position, salary and the allocation of resources. But we do need to see a more diverse range of people embodying that success.

"If a woman wants to be successful in her workplace, she should have that opportunity and the freedom to choose to do that."

For me it's more important to focus on equality of opportunity and the freedom of an individual to make choices. If a woman wants to be successful in her workplace, she should have that opportunity and the freedom to choose to do that. However, when you look at the statistics, she can 'lean in' as much as possible but she is very unlikely to make it to the top, because institutional recognition and support is required in addition to achievements and a skill set. It's equally unlikely that a man would really be able to choose to stay at home and look after the kids, as society would question his choices and there's little financial support for paternity.

We need to look at how people inhabit the work and domestic spheres and challenge some of the historical assumptions about how men and women are attached to each. We are constrained in these boxes that we've constructed for ourselves. Nobody really gets to choose, and it's a tremendous waste of human resources and capital. This isn't just about women; it's about aspiring to make things better for society as a whole.

"We are constrained in these boxes that we've constructed for ourselves."
I am passionate about using policies to bring about progress and believe that shifting from maternity or paternity leave to parental leave could be a real game-changer. This could transform the culture for everybody, not just those who have children. If both men and women were equally likely to take time out, it would change the way hiring decisions were made. It would move us from talking about childcare as a women's issue and start us thinking about how to effectively employ parents. I'd also like to bounce around the idea of some form of affirmative action. The current gender imbalance is so enormous that linking funding to target figures in some sensible way could sharpen people's attention.

We need to enable women to keep working as efficiently as possible if they do have children. There are very simple things that are already embedded in UK law but need to be applied more consistently, such as removal of administrative duties while on leave. There are other things that are not a legal requirement but could make a huge difference. For instance, if you are a senior academic in the sciences, your research-group members can be significantly affected if you just disappear for months, so having meeting spaces where you can bring a child if on parental leave is critical.

It's important to retain and develop women who can then become powerful role models for others. In psychology, it's been shown that we overestimate the probability of unlikely events, as discussed by Daniel Kahneman in his recent book Thinking, Fast and Slow. So even if you only have a few women in senior positions, the benefit of them being there as role models for other women outweighs the actual statistics. They show that it's not totally impossible for a woman to achieve that sort of success, even if it is unlikely.

Why was I able to make it as a senior scientist? From the very beginning, l've had all the academic badges of success with publications, discoveries, prizes and so on, but at the same time there were people who recognised this. Both my PhD and my postdoc advisors were extremely supportive and these people are key. They are the ones who write references, get phoned up for opinions and provide advice on which jobs to go for. They can also help to counter the potential for unconscious bias that seems to creep in at the postdoc level. That's the stage where people are invited to apply for more senior roles, and perhaps fewer women are encouraged to do so. 


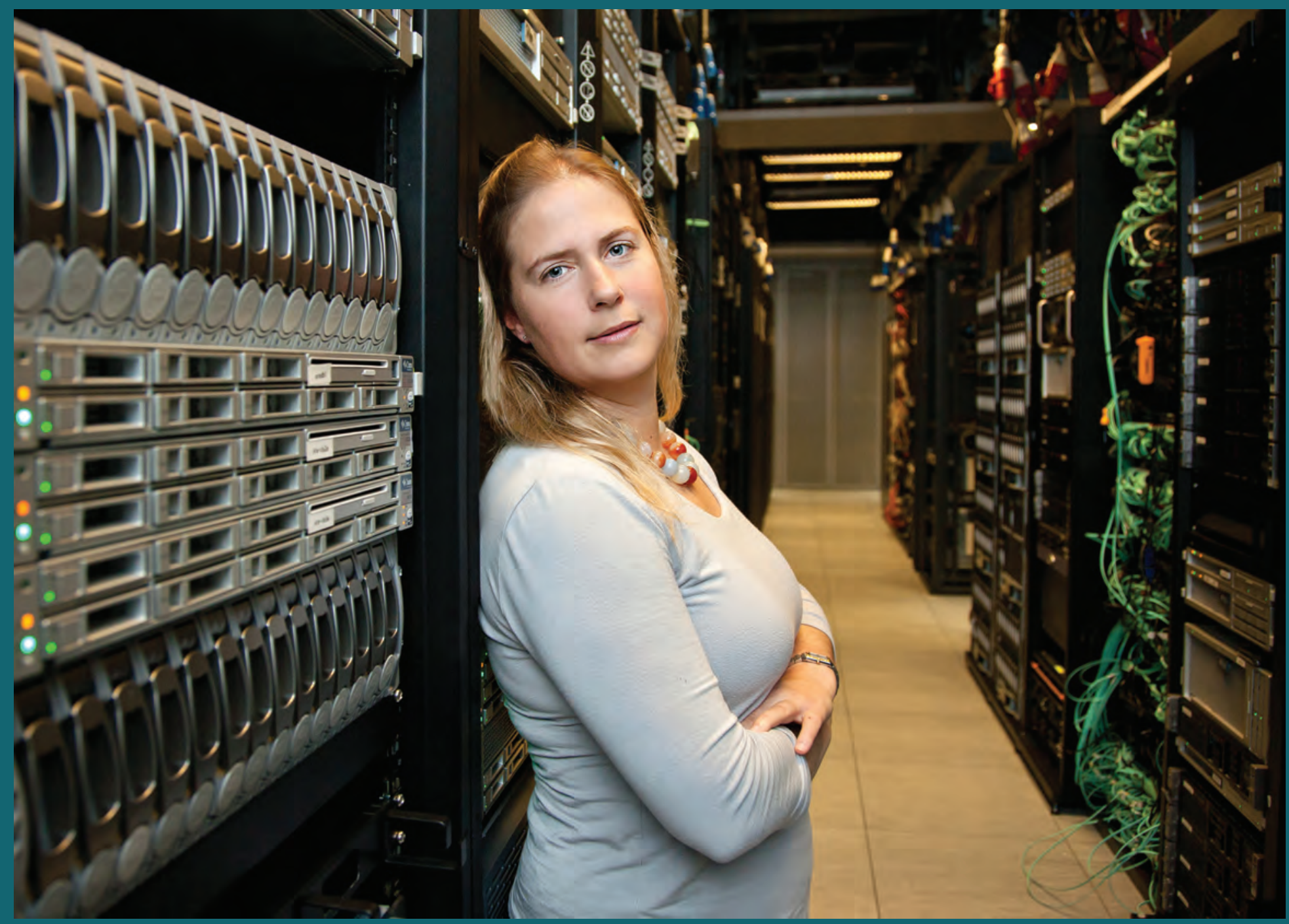

Contribution to the progression of others is not part of the conventional definition of success, but l've learnt that it's really important to me. I wouldn't be able to look at myself in the mirror if I was trampling on anyone. I have had fantastic experiences with my mentors, and I want to be that person for my group members. Irrespective of whether it makes me more successful or not, I think it's part of my role to train the next generation of scientists who can think independently, come up with their own ideas and who really make their science part of who they are.
"Contribution to the progression of others is not part of the conventional definition of success, but I've learnt that it's really important to me."

Speaking up in this way is not really about me or my situation. I'm at a different life stage and in a sense l've been there, done that, so there is a genuine altruism in wanting to change things for the next generation as quickly as possible. I feel I have a responsibility to influence my environment for the better. I have two daughters, and I also have my academic sons and daughters, and I want the system to work better for all of them. 


\section{The achievements that matter most, and why}

Achievements are the building blocks that enable someone to construct a sense of themselves as a success. The achievements that matter most combine to form a version of success that has meaning and substance for the individual. Achievements also provide tangible evidence that colleagues, competitors and the wider world use to judge a person as more or less successful.

Different people find different evidence compelling, so it is no surprise that there was variance in the achievements that were seen to hold greatest weight for women at Cambridge. There was also a recognition that achievements could be ephemeral, highly personal and evolve over time or in relation to context. Nonetheless, clear patterns did emerge. These patterns, which are outlined below, point to potential mismatches between the achievements that are traditionally viewed as markers of success and the ones that participants valued the most. As such they indicate areas that organisations might want to consider if they are interested in developing a more sophisticated and gender-inclusive sense of what it means to be successful.

\section{Being able to pursue interesting, high-quality work that has a positive impact}

The vast majority of participants wrote about the importance of having interesting, stimulating work that gave them a sense of pleasure, pride and even joy. Constructing careers in which it was possible to have the freedom and autonomy to pursue work that mattered was an achievement in itself.

"There is nothing more exhilarating than to find out something for the first time - something that may have existed for over a billion years, but was never known before."

Margaret Robinson

The women we spoke to took great pleasure in the quality of their work, whether that meant pride in the elegance and clarity of a piece of research or reorganising an administrative system in a way that actively contributed to the effectiveness of a department. Work was particularly prized if it demonstrated a creativity that took people or ideas to the next level and raised the standard of what was possible. Many participants still seemed to retain a sense of 'wide-eyed wonder' in relation to their work, and talked about the enduring memories of early breakthroughs. If they got external recognition, these achievements became even more tangible and helped to build self-confidence.

There was an awareness of the world beyond Cambridge, and many people talked about wanting to connect, using everything from blogging, lecturing and conferences, through to the more conventional route of publication. Participants talked about becoming part of a wider intellectual or professional community, which then became a source of support, acknowledgement and stimulation. It was clear that they had an appetite to keep learning and developing throughout their careers.

"My previous jobs had always been 'just a job', but I feel that the role I hold now is more important than that; it has purpose and gives me a lot of satisfaction."

Helen Marshall

Work was almost always seen as a core part of the participants' lives. Many of them found that it gave them a clear sense of purpose and was fundamental to their sense of who they were. Whilst work was rarely pursued to the exclusion of all else, it was nonetheless a central part of their existence. Some people talked about putting their heart and soul into their work, and also described the often gruelling journey they had undertaken to achieve a particular outcome.

The appetite to make a tangible impact through their work was clearly discernible. Inevitably, the type of impact participants were able to achieve varied considerably, depending on their specific areas of expertise, their seniority and the scope of their role. Although the nature and scale of the impact varied, the need to have an impact didn't. Some participants took simple pleasure in the incremental improvements that were the fabric of their daily work, or in the persistent effort necessary to land vital grants and donations. Others pointed to keynote moments such as coordinating the press conference for a Nobel Prize winner from the University, or securing a medical breakthrough that would help to address a life-threatening illness. Several participants talked about taking pride in having changed their field with a particular discovery, but they did so with no more or less pride than those in service or support roles who helped to create the conditions for such a breakthrough, for example by ensuring a lab was safe and fully resourced. 


\section{Securing awards, promotions and other acknowledgements of achievement}

The vast majority of participants had a healthy interest in securing acknowledgement for their efforts, particularly if it came from individuals or institutions that they themselves rated. In contrast, little value was attached to being able to secure the corner office or a larger desk with each new job. Promotion was an important marker of success for many, although it was more noticeable as a theme amongst academics than non-academics. For those for whom promotion was a factor, it signified vindication for hard work and validation from one's peers.

"Gaining personal promotion was a real vindication of the effort that I had put in - despite one colleague telling me 'it was just because they needed to promote women."

Anon

Getting a professional qualification, degree or doctorate was clearly valued by both academics and non-academics. This was even more the case when it had been achieved whilst under significant pressure, perhaps as a result of studying as a part-time or mature student. For some there was a sense of achieving second time around, perhaps after a less successful first degree, re-qualifying for a new career or after having left school early.

For many it was important to be acknowledged within their professional sphere beyond Cambridge. As well as the obvious indicator of being widely published, such acknowledgement could take the form of fellowships, prizes and medals, or becoming chair of an influential body outside the University. The elected nature of many of these achievements gave them additional validity, as it constituted feedback from one's peers. Additional sheen was added if they were the first or one of very few women to have secured such recognition.

"To have the respect of my friends and colleagues because of the work I do gives me a sense of achievement."

Helena Earl

There were also roles and achievements beyond those directly related to people's careers that held great significance, such as being a part-time judge or a school governor, leading a Brownie troop or being awarded a Blue in a particular sport.

\section{Maintaining a happy and healthy family life as well as a career}

This particular achievement, and its centrality to the participants' notion of what it meant to be successful, was commented on more than any other. Participants would not view themselves as an overall success if their achievements in the work sphere fundamentally undermined family life. If they could see themselves as having integrated their work and home lives in a way that was broadly healthy and viable, then it was an achievement based on deeply held beliefs about what mattered most to them in life.
"I am very fortunate in being able to combine all the things I love most. They are my husband and children, pursuing the questions in science that excite me and being able to help others to do the same."

Ottoline Leyser

The topic of gender, family and work will be explored in more detail in a subsequent chapter, but in terms of being an 'achievement', it is this sense of being able to have both a career and a family that stands out. The equation really seemed to work when people challenged the framing of an 'either/or situation', where either work or home life had to pay an extortionate price to allow the other aspect to thrive. Both were essential and needed to be integrated, rather than compartmentalised. This is not to say that tension and tough choices were eradicated, but for the people who saw this as an area of personal achievement those choices were managed in a way that broadly worked. Compromises were made, and few if any of the participants espoused the idea that you could have everything you wanted all the time. Pragmatism, informed by a clear sense of what really mattered, was the order of the day.

Being a good parent and grandparent was of paramount importance to many, as was maintaining enduring and mutually supportive partnerships. Whilst family life took many different shapes, there remained a consistent message about how vital it was. Many people talked about family indirectly feeding into their achievements in the work sphere by bringing a greater focus or a different perspective. Making time to enjoy one's family despite time pressures was seen as an achievement in itself.

"With the demands of motherhood I needed to restrict my time in the lab, and this increased my focus and resulted in my science really taking off."

Gillian Griffiths

For those with children, seeing them thrive and turn out well was a source of great pride - although many were wary of claiming this as their own achievement. Several pointed to the basic accomplishment of surviving the sleepless nights and energy-depleted years that come with very young children, whilst others enjoyed the fact that their teenagers would still talk to them!

It's a truism to say that families are complicated, and for some people surviving unhappy childhoods, divorce or illness within the family was an achievement in its own right. Being able to secure an education despite family obstacles or to hold down a job whilst coping with a relationship breakdown both counted as achievements in the family sphere.

"I have recovered from an unhappy childhood and an unsuccessful marriage to a position where I feel happy and valued."

Patricia Fara 


\section{Handling challenge, complexity and change}

Achievement is not just about the happy, shiny things - it is also about withstanding tough times and challenging situations.

Resilience demonstrated under pressure is perhaps the darker side of achievement, but is in many ways just as important as the more obvious markers of success.

"I am very proud of the fact that I have been able to pick myself up when things have gone wrong - as they have, not infrequently."

Athene Donald

No career is a seamless progression upwards, and many of the participants were able to process the inevitable bumps in the road in a positive way. There was pride in having withstood a range of setbacks, from failing to secure a particular promotion or having a grant application turned down through to conquering debilitating performance anxiety as a musician. The capacity to pick oneself up, bounce back and carry on regardless was something that participants clearly valued in themselves and others. This was also evident amongst those who talked about forging a career whilst having a chronic illness or depression, or providing support to a family member who was experiencing difficulties. Navigating adversity seems to have had the effect of sweetening subsequent achievements.

"My greatest achievements are often directly related to my greatest challenges."

Kirsty Allen

There was also a link with boldness and risk-taking that suggested many people weren't just coping with challenge but were being actively stimulated by it. There were individuals who seemed to thrive under arduous field conditions without running water or electricity, whilst others jumped into the unknown by taking a job in a different discipline or on a different continent. There was an appetite to seek out situations that were scary because they offered the promise of new learning opportunities and excitement.

"I think one reinvents oneself each time one makes a serious move; it is very rewarding to be able to make major changes, stand back from the process and reassess." Wendy Pullan

\section{Being a role model or pioneer}

To be a pioneer is also to take on the challenges associated with being the first, or one of a small number of trailblazers. This pioneering spirit showed up in various ways, including being the first in their family or school to attend university, being the first woman in a particular post, being the lone woman round a corporate board table or defying expectations by succeeding despite a lack of formal qualifications.
Being a pioneer was not exclusively linked to gender, but was often accentuated by the limited numbers of women in certain positions or subject areas. Some women also became more conspicuous having had a non-linear or unusual career pattern, such as pursuing academia late in life, making a significant career change, returning to work after many years away or being a senior woman in a successful job share.

Visibility brings with it a degree of scrutiny. It brings a sense of being a role model whether you like it or not, simply based on the fact that your colleagues, both men and women, will be aware of what you do. Some of the women we spoke to were more at ease with this notion than others. At their best, role models provide evidence of what can be achieved, for example as a mother returning to work, a mature student, a woman in science or coming from a working-class background. Some participants talked about wanting to set an example for their own children, or wanting to have a tangible impact by making a particular subject more accessible to a diverse range of students.

"As someone with a state school background who read Modern Languages at Jesus in the early nineties, encouraging talented students from all backgrounds to consider applying to Cambridge is important to me."

Nicola Hardy

\section{Exercising leadership, authority and influence}

"That my seniority as an academic has enabled me to work with others to facilitate steps towards significant culture change within the University has heartened me greatly."

Athene Donald

Many of the women at Cambridge expressed a sense of achievement when talking about the effective use of power and influence. Whilst there was clear frustration about obstacles in the way of securing leadership roles, when they got to positions of influence they wanted to do something constructive with their authority. They felt a pride in not shirking the responsibility that comes with leadership at all levels. This showed up in a range of ways, including stepping up as spokesperson for a major project like the Large Hadron Collider (LHC), establishing a new programme for entrepreneurs, setting up a flagship clinical unit, leading an institution to full college status and helping to get a new sports centre built.

"Being influential in something bigger than my personal research agenda means being a part of delivering change."

Sarah Worthington 
Leadership was not just found at the most senior levels or in the highest-profile projects. It was equally vital in the day-to-day exercise of influence to improve the working conditions of others, for example, by actively mentoring young women, turning around a failing department, bringing in technological advances or making sure a redundancy situation was handled fairly.

\section{Having a positive effect on and engagement with others}

Linked to the idea of exercising effective leadership was a strong interest in enabling the progression of others. People described the vicarious thrill that came with helping team members, or junior colleagues, to establish themselves as successes. Offering support could take the form of mentoring, helping people to identify their strengths, creating a good working environment, inspiring passion in a subject, enabling someone to cope with a setback or simply being a great teacher. It was seen as a privilege to be in a position to develop others and as such was not something to be taken lightly.

"I encourage people to develop themselves and not to be held back by feelings that, first, it's not their place to develop themselves beyond their prescribed role and second, that it's something beyond them."

Susie White

Several women mentioned the pleasure of being thanked by those they had helped, but at the same time they were not dependent on such gestures of appreciation. It seems that this area of achievement is one that can be understated, and one that is experienced both privately and through the successes of others.

Engagement with people was not just to do with helping more junior colleagues but also about developing a robust network of supportive friends and peers. This was seen by many as both an achievement and a necessity. Good friendships that sustained over time, and despite geographical separation, were a source of great mutual support and fun. They frequently led to positive professional collaborations and encouraged the establishment of successful teams. Many of these collaborations extended beyond Cambridge and as such actively contributed to the University maintaining its global reputation. Making a difference through having a positive effect on others also fed into thoughts about leaving a legacy that would extend beyond an individual's own career or lifetime.

\section{Demonstrating authenticity, integrity and roundedness}

"Work(ing) collaboratively with the various personalities one encounters whilst retaining the integrity of one's own values and instincts."

Corinna Russell
The women we spoke to were adamant that who they were and how they worked mattered as much as the tangible outcomes they achieved. The ends did not justify the means. Integrity and authenticity were standards that they used to measure both themselves and others. They wanted to be known for behaving in a way that gained them a reputation for fairness and decency. They repudiated the idea that you could only be nice or competent but not both. Being thought of as 'nice' can be a way of damning with faint praise, but when reframed by participants it came to be associated with things like highly effective interpersonal skills, consistency of behaviour, clear communication and articulation of purpose. Participants tended to express real distaste for people who intentionally trampled others underfoot. They felt that something could only really be claimed as an achievement if it was secured without compromising themselves or their values.

In talking about authenticity, participants emphasised the importance of doing things their own way, not mimicking others. There was particular mention of not imitating men in order to get on, and being able to write, talk and act in a way that was recognisably their own. They also valued being able to pursue their own ideas and finding a niche that was suited to their particular attributes. Securing a situation where they could do work they really cared about meant they were more likely to perform well, rather than wasting energy bending themselves out of shape to fit in.

"I am pleased that I found a way to talk and write that felt as if it was me." Mary Beard

Achieving in a way that was authentic also made it easier to claim success rather than seeing it as down to luck. It underpinned the self-confidence that comes with feeling responsible for shaping one's own career and having taken or created opportunities. Several women talked about having achieved through their own determination and often in the face of opposition.

"The achievement that means most to me in life is my garden. It is my creative outlet and my sanctuary. I'm proud of the fact that I have managed to retain a creative outlet in my administrative career."

Isobel Humphrey

Authenticity also implied a sense of roundedness and breadth, which meant that the women valued other aspects of their being, not just their work. Music, gardening, photography, fundraising and sport were all mentioned as important pursuits, not just hobbies. Achievement at the expense of having this kind of hinterland was not generally seen as a price worth paying. 


\section{Suzy Stoodley}

Suzy Stoodley is the BBSRC Doctoral Training Partnership (DTP) Programme Administrator within the Department of Plant Sciences. A mother of three, she has combined a successful career at the University with a busy family life.

From a young age all I really wanted was to be happy, have a family and to be a decent person. I try to treat people the way l'd like to be treated, and that comes from my upbringing.

My parents weren't well off, but I always felt very secure and loved. My mum became poorly when I was about eleven; she deteriorated quite quickly and passed away when I was sixteen, three weeks before my GCSE exams. Although it was a hugely difficult time, I do think I was fortunate because I have such a close family and we support each other. I went to a good college but only stayed there a few months; my head just wasn't in it so I decided to leave and get a job. My dad was really supportive of my decision, and because he didn't force me to stay I didn't feel like I was letting him down.

I've had all sorts of jobs before I came here. I've been a dental nurse, purchaser for a computer business and handled escalated calls for a telephone company. I was the one who dealt with people when they got really cross. I loved it. When people shout and rant, I just let them get it off their chest because nine times out of ten they're pretty stressed and just want to vent. Eventually they run out of steam. It's the quiet ones you need to watch out for!

I knew I wanted three or four children quite close together. When I became pregnant with my second child it wasn't financially viable for me to go back to work, but I think I was really lucky to get to spend time at home. After a while I ended up getting a job in a supermarket stacking shelves three nights a week. My brain wasn't exercised at work, but my focus was on the family and I absolutely love watching the three of them evolve and grow. Life is never dull in our house; this morning the youngest woke me up at 5 am to tell me his tooth had come out, then I had to dress them all as pirates for school, and later we're going to bake carrot cake. I just think they're pretty cool and we make each other laugh. I don't experience a tension between being a mum and my working life, but it's been a slow, evolving process; I have a very supportive husband and we've worked out what we need to make it work as a family.

"I don't experience a tension between being a mum and my working life, but it's been a slow, evolving process."
It was pretty daunting when I got this job after being out of the 'real' working world for so long. It meant moving back into an office environment and thankfully I was given a chance to show what I'm capable of. I don't want to be an administrator who does the bare minimum. I like instigating and improving things, for example building a new website and redesigning the programme timetable. Nobody asked me to; I just got on with it. I know I'm pretty diligent and set high standards for myself. It's important to get the details and the small things right, otherwise the big things don't work.

"I've bought a caravan (called Mabel) to go in the bottom of my garden, and I'm going to do her up so I can have a study area. I can't wait."

One of the professors has been encouraging me to do a degree since I arrived here. I could sit at this job and do it perfectly well until I retire, but I want more. I'm only thirty-five and I've got a lot to give, so that's why deciding to do a degree makes sense. I know that it's going to be at least the next six years of my life. l've bought a caravan (called Mabel) to go in the bottom of my garden, and I'm going to do her up so I can have a study area. I can't wait.

One of the main reasons for driving myself to achieve as much as I can is that my mum was thirty-seven when she died and I suppose that instilled in me an awareness that it could happen to me at any time. I'm not necessarily going to get to eighty or ninety. It's real and it happens, so I suppose it makes you think, while I'm still around it's best to do as much as I can. Now l've got the boys, I also want to show them that they can achieve anything if they really want to.

I'm happy with my lot; I'm not dissatisfied or feeling that I have a void in my life, it's just that I want to make the most of it. I've been a school governor, I've completed all sorts of physical challenges like a half marathon and a duathlon, and now I'm taking on the degree. I have an appetite for life and I believe people should give things a go. Try jumping out of a plane, try doing a night course or a marathon. Too often I hear people say negative things, 'I don't have this, I don't have that, I can't do that, it's too hard.' I think it comes back to people I love not being here anymore and knowing that I need to make the most of my life. 


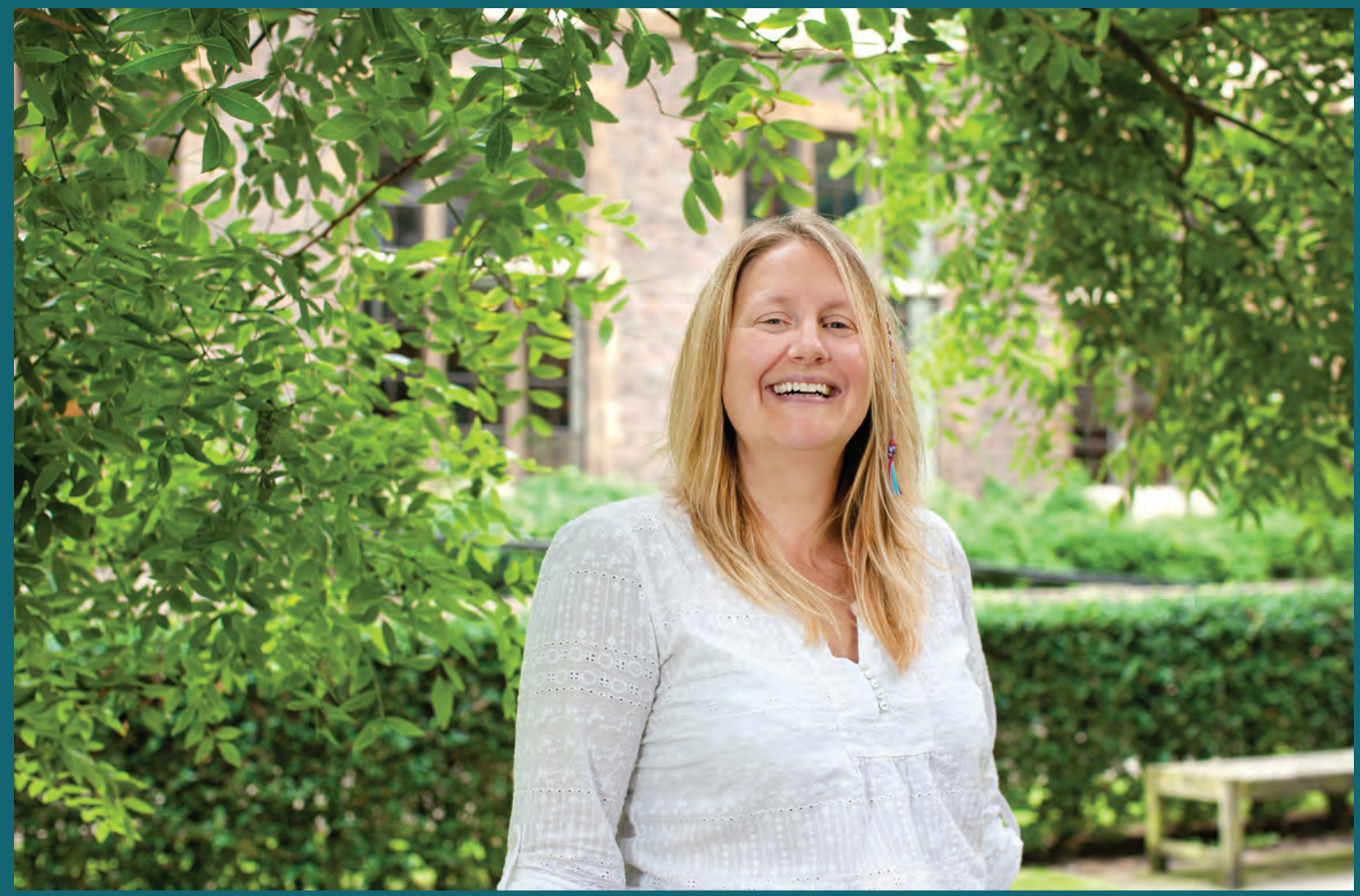

"I have an appetite for life and I believe people should give things a go." 


\section{Joya Chatterji}

Dr Joya Chatteri is a Reader in the History of Modern South Asia in the Faculty of History and a Fellow of Trinity College. Originally from Delhi, she is the editor of the journal Modern Asian Studies, one of the leading journals in the field.

My father was, in his own way, a feminist, and even as a little girl I remember him saying things like 'It's very important to have independence, marriage is not a career and you must be more than your appearance.'

My sense of what constitutes achievement relates to those early messages. I value freedom and independence, and can't bear being hemmed in by fixed ways of thinking. I think that my desire to form my own ideas has made me a bit of a contrarian.

Despite my upbringing and nature, when I first arrived in Cambridge from India I found it all very daunting. It initially threw me and, to an extent, shattered my confidence. I felt I had got in by mistake, that I'd tricked the system and that I was an imposter. I suspect that might be why some students experience me as a good teacher, because I know what it means to feel uncertain and can reassure them they're not alone. I try hard not to undermine them because I understand only too well what it's like to feel overawed.

"I realised that the trick is not to shout at the room, but to speak as if you're having a really interesting conversation with a few people."

How did I start to recover my confidence? At first I figured out that by writing I could still express my thoughts without needing to raise my hand and talk. Through this I realised that my ideas held up to scrutiny. Eventually I became a lecturer, which meant I absolutely had to get up and speak. With time and practice I developed my own style. I realised that the trick is not to shout at the room, but to speak as if you're having a really interesting conversation with a few people.

I remember vividly a dinner with colleagues that took place relatively early in my career. After the meal I went out for a cigarette and I can still recall my colleagues being shocked. They'd made assumptions about how this 'nice little Indian lady' would behave, thinking that I would be quite 'traditional'. I suppose that made me aware of how I could be perceived, and this influenced my decision not to make an issue of my ethnicity or gender in terms of how I managed my career in Britain. I wanted to be recognised as an individual, as a person, rather than as 'an Asian woman'.
For this reason I didn't want to make anything of the fact that I was a single mother. I never missed work to go to my child's school play (I simply rearranged my schedule quietly, without any fuss), because I didn't want it to be an issue and there's no question that it does affect how women are perceived. I never fought that battle, which to some extent I regret. I suppose I felt uncomfortable addressing issues that could appear to benefit me personally (I was the only young woman in my department, then, in that situation).

"I value those (men and women alike) who have the courage to go against the grain and disturb the flow."

When I think about people I particularly admire, I'm struck by the fact that those who immediately come to mind are women. I don't think that many of them necessarily made their gender a dominant point either, but they were strong, they were respected, they were articulate and they didn't hide. They all had very different styles, but in their own ways they sent the message that it is possible to be all of those things. I value those (men and women alike) who have the courage to go against the grain and disturb the flow. Taking the safe option is perhaps the approach that will get you through the next day, week, month or year, but at the end of your life it's probably not the choice you will value most.

"I suppose my personal definition of success lies in encouraging a certain kind of intellectual confidence in others."

I've had to do a fair bit of introspection lately and l've asked myself the question, 'In what way have I made a difference?' With writing scholarly books and articles you're often preaching to the converted, whereas with teaching you do feel more of a sense of having made a difference to some lives; just a few, which is good enough. I suppose my personal definition of success lies in encouraging a certain kind of intellectual confidence in others. 


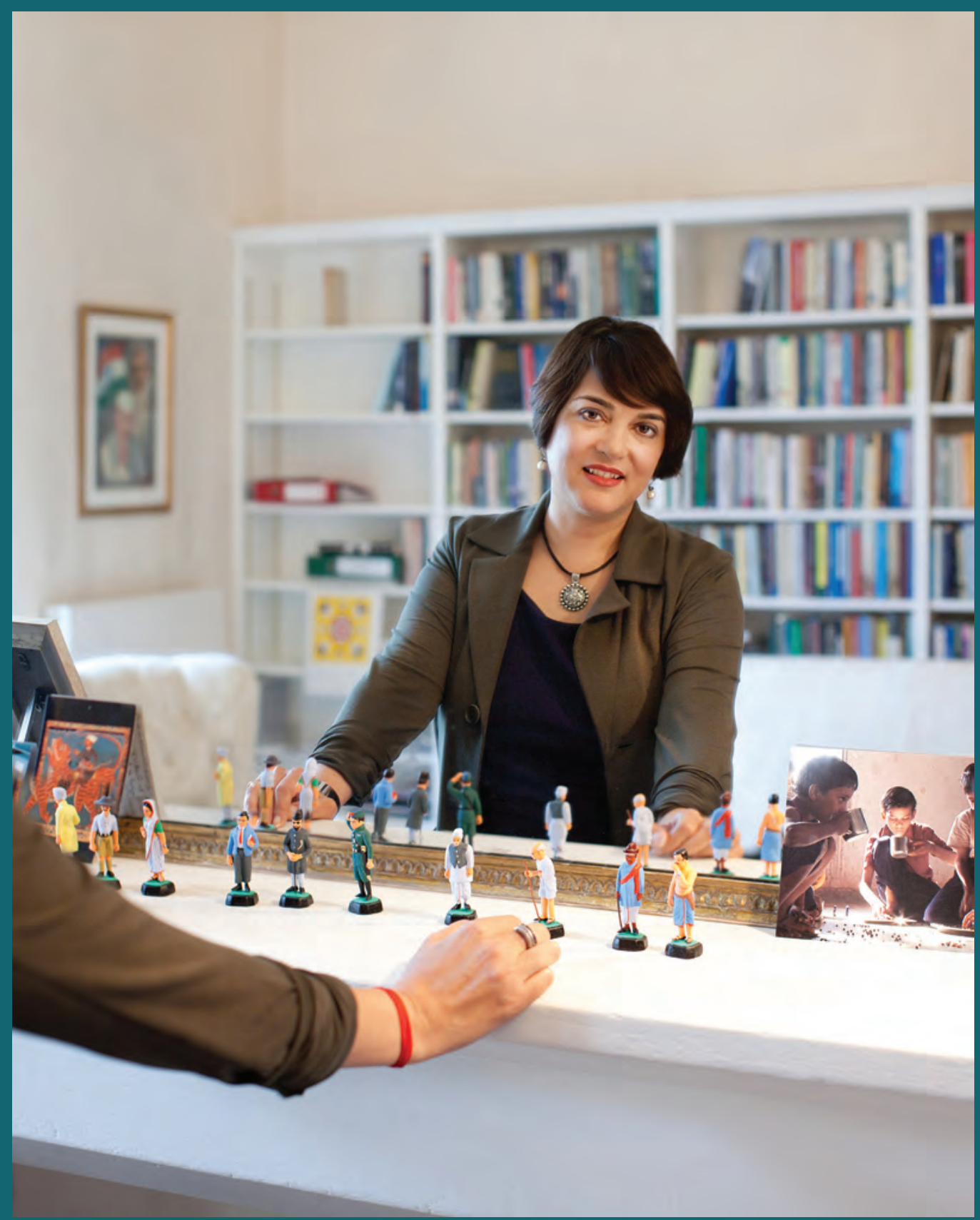

I'm very aware of how little control one has over life, and how little difference the effort of one individual makes in absolute terms. Being ill has meant that I understand better what it's like to be weak in a physical sense. I think it gives me more empathy with those in a position of relative weakness, which in turn affects both my research and my teaching. At the moment l'm working on migration, citizenship and the situation of minorities in different parts of the world. I became a historian because I was interested in telling stories that hadn't been told, and whilst I don't really care so much about whether the next book is a success, I do care strongly about the people whose lives I'm writing about.
When I think back, and ask the big questions about what all of this is about, there are moments that I treasure. I'm very proud of my students. But I am also very proud of having brought up a son who is utterly kind and gentle and respectful to women. I treasure my friendships. I'm also really proud of my garden, much more so than any of my books! So it doesn't hurt to have a focus outside the next part of your career or the next publication, and it's wise not to make your life too one-dimensional. 
My motto is 'enthusiastic serendipity'. There are lots of opportunities that come our way and the trick is to be sufficiently aware to see them.

Serendipity can put you in the right place at the right time, but you also need enthusiasm to take advantage of a situation. If you're constantly running yourself ragged and feeling very overwhelmed, the opportunities could knock you in the face and you still might not notice them. It's about putting yourself in the right frame of mind to be able to look, listen and be receptive. And sometimes that means taking risks.

A good example of this was when I joined the creative team at the Rambert Dance Company to work on a new piece in honour of Charles Darwin's 200th anniversary. It all came from a chance remark at a New Year's party, which led to me being introduced to Mark Baldwin, their Artistic Director, and we've been collaborating ever since. It's fascinating work that combines my twin loves of dance and science and it came about by pure happenstance; but I still had to be open to it. Similarly, I went out on a limb in doing an unusual lecture at the Royal Institution on mental time travel with my tango partner, Clive Wilkins, who is an artist and writer. Working together we were able to bring elements of dance, magic, art, writing and science into our presentation. In both instances I could have avoided the risk of doing something different but I didn't: after all, what's the worst that can happen? Divergence, creativity and innovation are all exciting places for me.

"My favourite tango moves are the ones where I feel I'm flying and that carries through to my intellectual life."

Movement is really what I'm all about. My favourite tango moves are the ones where I feel I'm flying and that carries through to my intellectual life. I've always been fascinated with birds, with how they move and how they perceive the world. I feel as if I am quite birdlike and I definitely have wings; just because you can't see them doesn't mean I haven't got them! Movement and birds are the two things that unite everything I do. I don't separate or compartmentalise my dance life from my academic life; I'm not a university professor one day and a tango dancer the next. It's about taking very disparate disciplines and interweaving them in a way that allows you to see things in new or unexpected ways.
I've always tried to think a bit differently and not follow a regular model. It got me into a lot of trouble when I was younger. As a postdoc I didn't dress conventionally and I remember going for junior research fellowship interviews in my high heels and little mini-skirt. At that stage of my career I felt that I wasn't taken seriously and was seen as a little blonde lass from Blackpool who looked more like a dancer than a scientist. It meant the some people dismissed me and it was only when I wore a more conventional outfit that I got a position.

Back then I found it quite hard to find female role models, although I think that's much easier now. When I was an undergraduate, there simply didn't seem to be that many female professors. I struggled with how to get the right balance between being a very girly girl because that's what I am - whilst also being seen as seriously committed to my work. When I observed most of the high-ranking women at the University, the way they looked and the way they came across just wasn't me. Looks aren't important in themselves, except as a manifestation of your personality and I wanted to be true to myself.

"I also got to do the splits on the red carpet at the Royal Society when I was awarded my FRS!"

I felt liberated when I became a Fellow of the Royal Society. I'm not any more sensible than I was twenty years ago, but now l've got a stamp of approval and with it comes a lot of freedom. I also got to do the splits on the red carpet at the Royal Society when I was awarded my FRS! It was an honour and it mattered enormously to me but it's dangerous to go swanning around thinking that I'm important and I don't mean any of this in an arrogant way. The real value of an FRS is it demonstrates that I meet the highest external standards and therefore people trust me when I want to try out something unconventional. It's a fast track to being able to explore more divergent ideas.

What's success? I want to be able to play. This sounds trivial but it isn't meant to be. It's a privilege and pleasure to be able to play with ideas and it's about freedom not status. If I am a role model in any way, I hope it's in showing that people can be successful by being themselves and there isn't just one way to do things. I don't like to be prescriptive and I certainly wouldn't want anyone to think that they need to dress like me or be like me. I want to encourage them to try and tailor-make their lives so that they spend their time doing the things they really enjoy. 


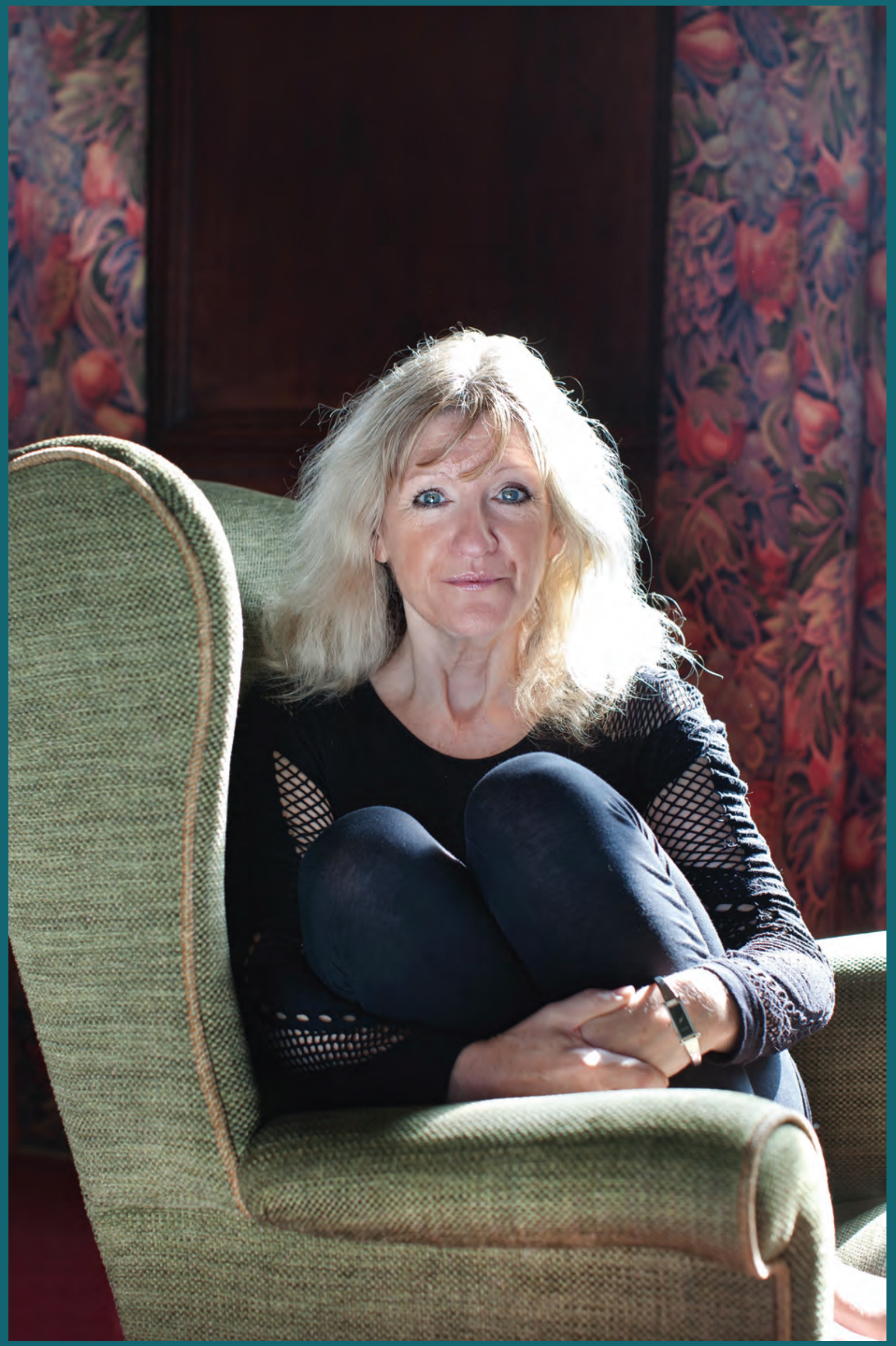




\section{Sheila Scarlett}

As well as being employed as Master's and Bursar's Assistant at Selwyn College, Sheila Scarlett is also Junior Esquire Bedell - an office dating back to the thirteenth century - one of the University's part-time ceremonial officers.

I completed my degree at Cambridge later in life than most and with the added diversion of being a single parent. It was at a time when my self-esteem was particularly low, and it showed me what I was capable of, indeed had been capable of for many years.

It proved that I was an intelligent human being in my own right and that people believed in me. The acknowledgement and approval of others was hugely encouraging and provided the sort of confirmation on which I think many of us thrive.

For my generation there was certainly less expectation that girls would pursue further study and, as nobody in my family had gone to university, there wasn't a precedent to help me challenge that attitude. I went to convent schools until I was sixteen, where politeness and good appearance counted for more than academic achievement. Although I had interviews for university at that age, I didn't get good enough grades and I convinced myself that I wasn't good enough. I dare say these days I would have been encouraged to go for clearing, but actually I think I got much more out of doing a degree as a mature student.

I was in my forties when I was encouraged to apply to Cambridge by a friend who is an academic. My initial response was, 'Don't be ridiculous. You must be joking,' but then I decided l'd give it a whirl. I didn't think for one minute that they'd offer me a place and was completely staggered when they did. Why did I get in? Because I wasn't stupid and I really wanted to do it. I was completely motivated and, despite having significant other demands on my time, I was willing to focus and make it work. I also had wonderfully supportive children. In fact my older daughter and I applied to university together, we did our UCAS forms together and we waited for our A Level results together. It was all very strange but rather lovely.

"As long as men can't give birth, I don't think that absolute equality is possible."

I am very pleased that her generation seems to have more of an expectation of progress than mine, but at the same time I do have more concerns for my daughters than for my son. They are all making great strides in their careers, but I worry that there is an expectation these days for girls to aspire to have it all. You see women trying to do the impossible and tearing themselves down the middle. Yes, women should have the same opportunities as men, and men should do their share at home. But expecting to have a career that takes them to the top as well as being the perfect mother can leave women feeling guilty on all fronts. Something has got to give, but honestly l'm not sure what the answer is. As long as men can't give birth, I don't think that absolute equality is possible.

I do feel discomfort when I think about myself in relation to success. I have a tendency to rate myself against women whom I see as having a profession - a career that includes managerial responsibility. Initially I studied languages and worked for a wine broker, which was exciting and great fun, but l'm not sure I saw myself as a professional woman and in some ways I still don't. I also wonder what else I could have been capable of doing. In particular I would love to have continued studying formally, but that hasn't stopped me following my interests in my free time.

"Ultimately, I have been able to take my own advice: 'Refuse to be blocked by those who don't rate you as good enough."

I remember one of the tutors at our Cambridge induction weekend telling us, 'You'll struggle at the start, but the brain will grow muscle and you'll be able to do things in three terms' time that you can't imagine doing now.' She was absolutely right: the more you listen, read and talk, the more you find you are capable of doing. I look back and think, how on earth did I do my degree, but actually I did and I know I could again. Subsequently it gave me the confidence to apply for the ceremonial post of Bedell at the University, which was something I would never previously have considered. It is a position that gives me a certain profile, and I look somewhat conspicuous with all the gear on, so perhaps that meant I came to people's attention when they considered nominations for this project.

Actually, it's okay to feel that you're not one of the successful people and to be hesitant or under-confident at times. I think most of us experience these sorts of feelings. But despite never really having been encouraged to be daring, I have still taken chances. I have handled the scary and the unknown, and when my personal circumstances changed I was able to make another future for myself. On that basis I suppose I can accept that some people might see me as successful, even if I don't find it easy to think about myself that way. Ultimately, I have been able to take my own advice: 'Refuse to be blocked by those who don't rate you as good enough.' 


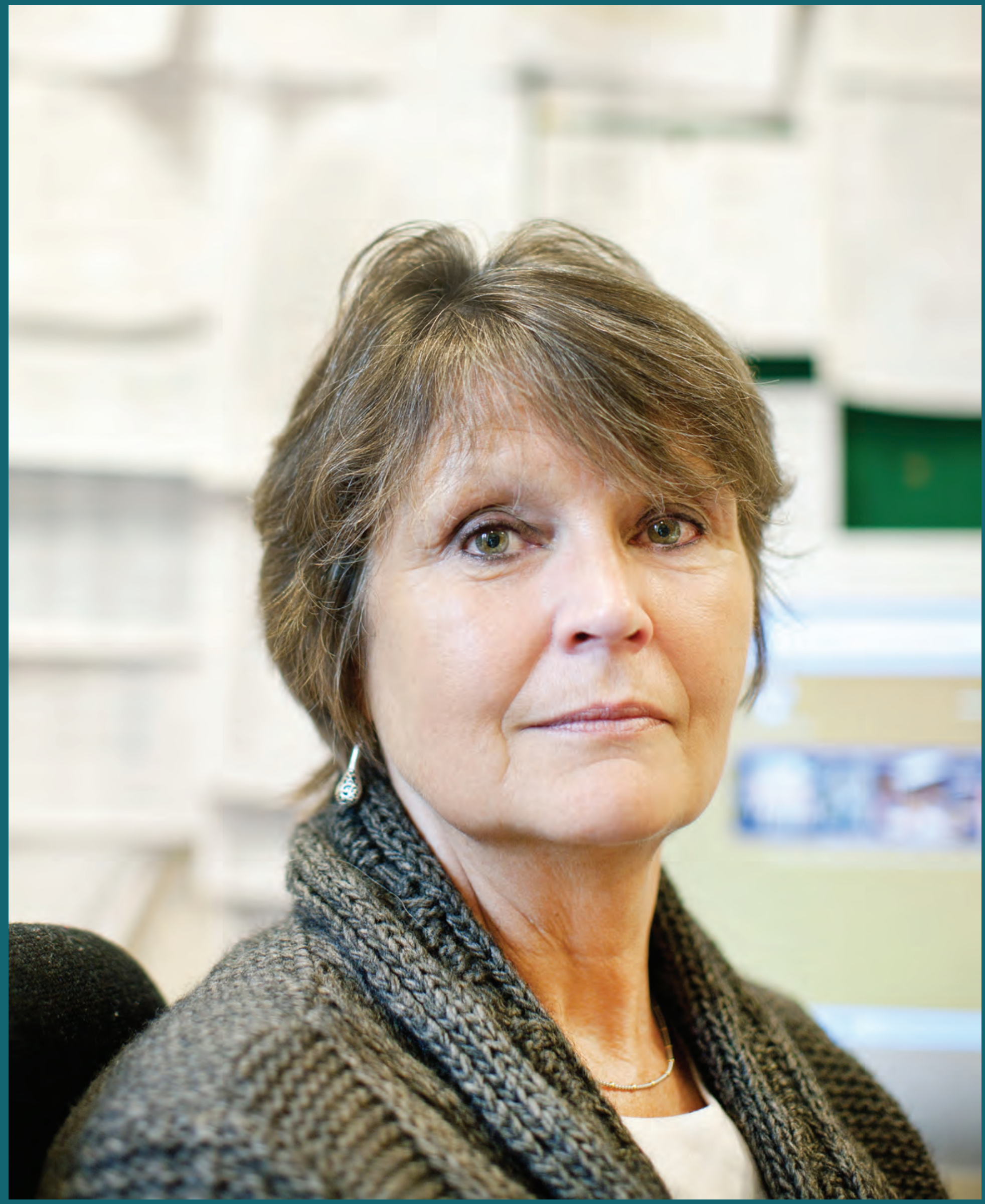




\section{The challenges experienced by women working at Cambridge}

Triumphing in the face of adversity and overcoming challenges can bring a real sense of achievement, as discussed in the previous chapter. But challenges are not always so neatly linked with a positive sense of accomplishment. There are some aspects of working life that are tough and test one's character in all sorts of different ways. This section explores those situations that the women of Cambridge found most notably taxing, and indicates some of the ways they were able to access the resilience to cope with them.

Though gender is highly relevant in many instances, in other areas the challenges described are by no means exclusive to women, or to Cambridge as an institution. They illustrate a more general pattern where individuals are likely to be under pressure in a modern working environment. We hope that, in our University context, a willingness to describe and face these challenges will underpin a determination to bring about change, whilst at the same time offering valuable insights for institutions and companies more broadly.

\section{The 'juggling act'}

"Probably the biggest challenge is the one we all face today: balancing all the balls we are juggling, professionally and personally."

Liba Taub

Almost everyone involved in the book talked about the necessity of juggling multiple competing demands, and doing so with varying degrees of proficiency. At times most balls remained in the air; sometimes compromises were made, and at other times balls were dropped.

The most obvious tension in this juggling act was experienced when trying to make sufficient time for both family and work. It would however, be too simplistic to frame 'family' as a challenge, given that it was also the source of the greatest pride and sense of achievement for many. For this reason, the choices, difficulties and positives associated with integrating work and family life will be considered in more detail in the next chapter, where the focus is on gender and its implications. For similar reasons, those challenges predominantly associated with gender - such as sexism or negative beliefs about the capabilities of women - will also be addressed in the upcoming chapter.

\section{High expectations and workload}

"The expectations here are so high - everything must be done to the highest standard because we are the best academic institution, and that adds to the pressure."

\section{Catherine Barnard}

Working at the University of Cambridge brings with it implicit and explicit expectations of excellence. Added to this, the women who participated in this book tended to have exacting standards for themselves, combined with an unwillingness to compromise the quality of their work, even if it meant doing punishing hours. As a result, we found that considerable commitment, sacrifice and weighty workloads were the norm, not the exception. The pressures associated with organisational and personal excellence sounded at times unrelenting. That said, the passion and enthusiasm expressed in comments made earlier in the book indicates a willingness to invest heavily in jobs that hold significant meaning.

"Inevitably there are always more competing demands than there is time to meet them."

Ruth Cameron

Sheer volume of work seemed to be exacerbated by women being asked to take on more committee, administrative and college duties than their male peers. Some of this relates to a positive awareness of the need for greater female participation in decision-making bodies and a desire for inclusion. Given the relative scarcity of senior women, this was seen to noticeably impact on them. Other aspects of allocating the administrative burden, however, require further scrutiny and cannot be accounted for by ambitions to achieve greater representation.

There was mention of a 'tsunami' of paperwork and a shortfall in the institutional administrative capacity available for women to draw on and provide, whatever their role. Several people talked about needing to develop a greater capacity to say 'no', whilst also acknowledging the significant systemic pressure to say 'yes'. Those who were more senior, longer in post or more aware of the broader political context found it easier, or safer, to be robust in declining certain tasks. That said, relying on women to say 'no' risks putting all the responsibility on them for managing the way in which projects, and particularly administrative tasks, are allocated. There is merit in an organisation being able to reflect critically on who gets asked to 
do what, so it can pick up on any potential unconscious bias and ensure that roles are fairly shared amongst colleagues. It is also vital that women who aspire to contribute to the bigger picture of organisational governance or policy can access such developmental opportunities regardless of their academic, administrative or academic-related roles.

The consequences of having very full work and home lives ranged from a lack of sleep and an inability to take part in networking through to not being able to make sufficient time for other important interests such as sport, volunteering, photography or gardening. A few people referenced the negative impact of heavy workloads on their health. There was a tendency for some women to simply work harder and longer, rather than addressing underlying issues relating to work allocation, managing boundaries or the need to identify priorities to focus on.

Those who seemed most at ease with the realities of this kind of work pressure expressed a pragmatism that allowed them to realise when 'good enough' was sufficient. There was a broad acceptance that, at times, something just has to give. These people were better able to let go of their own shortcomings, rather than holding on to guilt. Some sought out flexible working options to enable them to manage the juggling act, for example by pursuing part-time roles or adjusting their hours to enable them to pick up children from school before completing their work in the evenings. The women who coped with their workloads most effectively also seemed better equipped to ask for help, having invested some of their time and energy in relationships that could provide them with support when needed.

\section{The complex and demanding work environment of the University}

Cambridge is a complex environment, rich in tradition and with all the rules and hierarchies that you might expect from an institution over 800 years old. To a certain extent all organisations are complicated human social systems with unspoken norms, allocations of power and intricate group dynamics - and the University is no exception. But it could be argued that Cambridge is perhaps more opaque and resistant to change than other younger, smaller or simpler environments. For those attempting to navigate their careers at the University, this kind of context presents a range of challenges.

The way Cambridge is structured engenders competition, for example, between schools for resources, researchers for funding and individuals for progression. Having the ability to step back and read the dynamics of such an environment, in order to be able to plot a way through it and exercise influence, is no mean feat. Some of the women involved in the book had clearly spent time and energy understanding how the political system worked, so that they could choose how best to engage with it. Despite this, few had escaped unscathed or avoided conflict entirely, and there was repeated mention of how hard it can be to pursue a career in this sector. Resilience, deciding not to take things personally and a robust support network all helped in this regard.
"Eventually the winds of change started to blow in the right direction and change was accomplished. It took ten years, which I now think was relatively quick for Cambridge."

Debbie Lowther

Allied with resilience, people talked about needing to have the perseverance and persistence necessary to effect progress. Cambridge was described as a hard place in which to bring about change, so there was talk of the need to be patient enough to play the long game, to build long-term alliances and to generate consistent evidence to support your argument. All of this takes energy, especially in the face of demanding workloads and a desire for a home life, but opting out brings its own dangers. Organisations are not inherently 'fair', so there was seen to be real value in being able to anticipate where risks and opportunities may occur. For certain participants, it also sounded as if they believed it was part of their responsibility as leaders to develop political nous and to use their influence to benefit others.

"The hardest things I've had to deal with are when I think things are happening that aren't fair or well considered, or that will have a negative impact on my staff or the organisation I'm working for."

Nathalie Walker

Perhaps unsurprisingly for an elite academic institution, the way in which status works at Cambridge can also bring challenges. Some women talked about the difference in perceived value between academics and non-academics, whilst others mentioned being looked down on if they didn't have a degree, or lacked a degree from the 'right' place. Experience garnered outside the University, in another sector, at times could either be underrated or not fully understood.

"Working within complex human structures will always provide interpersonal challenges."

Carol Brayne

People talked about vastly differing experiences in the quality of leadership and management that they had come across, from the truly exceptional to very poor. There didn't seem to be a clear route to developing management capability amongst individuals who may be experts in their field but had little experience of leading people.

Participants described examples of less than effective management practice, such as a reluctance to challenge poor behaviour, or patchy efforts at communication. There was also talk of feeling excluded by cliques that seemed to be based around gender. That said, the natural bonding between those who share common backgrounds and interests should not automatically be criticisedindeed, many women talked about valuing this kind of connection themselves. What matters is that important decisions are not taken informally by a group of 'insiders' but are made as the result of rigorous processes and good management. 
"Under good leadership, openness and open discussion prevails. Not infrequently, however, aggressive and opaque practices prevail without check."

Simone Hochgreb

Many of the women involved in this enquiry held management or leadership responsibility themselves, and some were candid about feeling unprepared to inhabit this kind of role. They expressed a marked preference for working collaboratively, rather than competitively, and for concentrating on good communication. In many cases this had served them well, but there were still plenty of stories about working with difficult, resistant, uncommunicative or unmotivated colleagues and how time-consuming this could be.

When thinking about how to be successful at Cambridge, it seems that it is worth expending effort to try to comprehend the institution's complexity, as well as to take advantage of any opportunities to develop one's own leadership and management skills. To become politically astute is also not at odds with retaining one's integrity, and need not imply collusion or game-playing. To hope that simply being good at doing your job will be enough to get by is to risk ignoring the realities of what it means to work with others.

\section{Job insecurity and funding challenges}

"The assumption is that part-time workers are less committed than full-time workers and that we don't work at the same level as those who work full-time."

Liz Hide

Many of the women we spoke to experienced non-linear career paths that deviated from what might be considered the traditional model of employment more commonly associated with their male peers. There were examples of career breaks, maternity leaves, academia being pursued later in life, returning to work after significant amounts of time out, part-time working, moving between unestablished positions, losing funding for employment and having their careers affected by shifting locations with a partner.

"I experienced the difficult life of a non-tenured postdoctoral researcher. I spent almost two years fighting to secure my career and juggling short-term contracts financed by a variety of different funding streams."

Jane Goodal

The participants viewed this non-linear pattern with varying degrees of ease or discomfort, and acceptance or resentment. Some were unsettled by change, felt anxiety around a lack of job security or experienced being undervalued when returning to work. Others saw this work pattern as an inevitable part of being a woman in the workplace and sought to play the game as best they could. There was however, clear room for improvement in the way that a range of different employers accommodated this non-linear pattern. In recruiting for new posts there tended to be assessments that failed to take into account, for example, the impact of maternity leave on the number of articles published and an unwillingness to consider the value of roles taken on outside the workplace, such as being Chair of the School Governors.

"The challenge of returning to work after a long break is that you have no idea how to value your own skills and lack confidence in your own abilities."

Rachel Fogg

From an academic perspective, there was also the constant pressure to secure funding, along with the spectre of what could happen if they were unable to land grants. The implication of losing funding typically extended beyond the individual, and they felt increased pressure to look after the interests of their teams. There was also the confidence-sapping experience of receiving rejections for funding applications, and many people found it hard not to take this personally.

"Funding is the biggest challenge. At first the challenge was winning fellowships to secure my own career, and now I am faced with winning grant incomes to secure the future of my research team."

Rachel Oliver

\section{Failures, under-confidence and a sense of 'falling short'}

"I have often felt an outsider (in my science as well as in my gender), and imposter syndrome is never far away."

Athene Donald

The previous points made in this chapter have largely focused on challenges arising from the organisational environment. But each person interacts differently with their context and brings with them their own quirks, uncertainties and personal history. All of this affects the way they experience and respond to challenge.

The vast majority of the women involved in this book were clearly very focused on high performance and delivering work of the best possible quality. There are many upsides to setting such high personal standards, but we also heard about some of the potential downsides. Several of the women talked about having a negative or overly critical internal voice - one that found it hard to celebrate success and was always looking for flaws. There were times when the focus on quality seemed to go into overdrive, with the result that the bar was set unattainably high, which could for example lead to poor boundary-setting and working excessive hours.

"My weakness was not feeling able to ask questions - not wanting to show lack of knowledge or understanding. Developing the confidence to acknowledge this weakness and to ask questions became my biggest strength."

Lisa Jardine-Wright 
A number of the women we spoke to were also very honest about feeling doubt and under-confidence at different points in their careers. There was talk of 'imposter syndrome', which was characterised by a fear of being exposed as not being good enough. Achieving greater seniority or securing accolades reassured some, but for others it only heightened their worries about being 'found out'. Some women found that their confidence wobbled when they were surrounded by other high-performers at Cambridge, having been used to being top of their peer group elsewhere. For other women, particularly in support roles, the perceived (or actual) difference in status between academic and non-academic staff stimulated worries about being seen, or being treated, as inferior. Bouts of uncertainty could be brought on by a particular event, like failing to secure a grant or job, or not reaching the level of academic achievement expected. Women talked about receiving, and to an extent internalising, messages about not being able to achieve at the same level as a man, often despite evidence to the contrary.

"Whilst I think it is important to be self-aware, my internal voice can be quite critical."

Jessie Monck

One route to diminishing the anxiety, doubt and lack of confidence associated with imposter syndrome was by acknowledging how very commonplace it is, for both women and men. Others found it reassuring to hear other successful people being candid about their own fallibility. Again, tapping into supportive networks to discuss their concerns was often a way of getting a greater sense of perspective and perhaps new insight into what was fuelling their worries.

"I am not as academically confident as many of my colleagues (or, of course, as many of my colleagues appear to be)."

Rosanna Omitowoju

\section{Challenges beyond work}

Life beyond work brings profound challenges that encompass bereavement, health issues, caring for others and some of the difficulties associated with aging. Given the career focus of this book, participants shared less detail about these personal areas; nonetheless, it is important to remember that people will inevitably experience life events of the most testing kind. Such experiences are not ones that can be neatly compartmentalised, and they undermine any notion that work and life can ever be completely separated.

People also mentioned the effect of feeling multiple or layered differences alongside their gender, including factors like class, ethnicity, disability or sexual orientation. Being perceived to be different from a dominant norm in more than one way seemed to risk compounding feelings of isolation.
"Although my career looks very seamless and successful when summarised in a few short sentences, it most certainly had some low points."

Gillian Griffiths

In conclusion, there was not a single participant who sailed through their careers without experiencing a range of challenges, some of which were deeply unpleasant or unsettling. Yet it was often the most trying times that enabled people to develop a robust sense of self-confidence and an evidence-based belief in their own resilience. They might not have sought out such difficult situations, or have been able to connect them with a sense of achievement, but there was still something to be gained from coming out the other side. Withstanding challenge, learning from it, accepting a degree of fallibility and deepening their resilience were qualities that seemed to connect the women in the book, and as such can be linked with an understanding of what it means to be successful.

"Everyone has setbacks: it is how you cope with them that matters."

Athene Donald

\section{Comment}

Part of continuing to drive progress as an organisation consists of recognising where change is needed. The challenges identified by women at Cambridge give both direct and indirect indicators of where the institution still needs to evolve if it is going to offer women an improved experience and address some of the difficulties highlighted in this enquiry. Having already begun to ask questions of our own culture and practice, we take a degree of reassurance from the fact that there were few surprises and that the areas we have been concentrating on most recently as a University broadly relate to the issues highlighted by participants. That said, we are in no way complacent, and approaches to areas like flexible working, refining our promotion and recruitment processes and ensuring women are able to exercise leadership and influence will continue to attract our efforts. We are also very clear that these are not just 'women's issues'. The fact that the drive to progress gender equality in particular is governed by the Gender Equality Group and Gender Equality Champion will hopefully provide assurance that the issues raised by the women in this book are addressed by the University in which they work. 
Mary Beard is a Professor of Classics at the University of Cambridge and a Fellow of Newnham College. The author of numerous books and articles (including Pompeii: Life of a Roman Town, which won the Wolfson Prize for History), she is a Fellow of the British Academy and a regular contributor to both radio and television.

At school I remember being part of a small Oxbridge class taught by this deeply eccentric guy. He used to bribe us to learn poetry by heart; the going rate for 'The Love Song of J. Alfred Prufrock' was 50 pence and 10 quid was up for grabs for anyone who mastered 'The Wreck of the Deutschland'.

But bribery was also a joke and like all the best teachers he showed us how to learn and how to express an opinion. It was incredibly exciting to start to appreciate how extraordinarily open-ended intellectual enquiry could be.

Many years later it's either been my good or bad fortune to have ended up in academia and making television programmes on the Ancient World. That's inevitably raised my profile and I was recently a panellist on Question Time. After that appearance I started to receive the vilest Twitter and internet abuse. I could've chosen to ignore it but I decided not to. For centuries women have put up with this sort of thing in the hope that if you shut up it'll go away. It doesn't work. I'm also such an academic that if somebody says something I don't agree with, my autopilot response is to answer back.

"For centuries women have put up with this sort of thing in the hope that if you shut up it'll go away. It doesn't work."

There's a tremendous advantage to being quite resilient and fifty odd. Those Twitter comments were bonkers blasts of aggression and I wanted them to stop but I wasn't sitting there feeling personally attacked. I'd feel much more attacked if someone said, 'Look, 50 per cent of the footnotes in that article are completely wrong.'

It would be a lie to say that gender has held me back in my career; but it has sometimes been a case of feeling in a foreign country. As a graduate student the University seemed to be a man's place and for a long time my mates and I would say, 'How can we get around this?' We tried mimicking the men and the way they spoke, but I came to see that the pretence was always deeply unsatisfactory. You can't pretend to be a bloke, and the most important thing is to find a way to talk and write that feels to be YOU. The best thing for me was stopping wanting to do things 'properly' and feeling able to focus on questions such as, what do I want to say here? What do I want to show them? How do I want to change what they think?
It may be deeply old fashioned, but I used to like the idea that there wasn't much promotion in the University. Occasionally people were plucked out for advancement but it wasn't part of a career plan. It freed you up to value different things. There was greater collaboration, and success was something embedded in the community rather than the individual. It's a more egocentric environment now. I must be very careful not to be hypocritical though, because l've been successful within the terms that are laid down. If I'm in that race, I'll play the game. But if I look back I think it has set us apart more than it's brought us together.

"I find that the people who are most talented in helping me to rethink my ideas often don't measure up to the more usual marks of success."

I don't really know what it means to be successful. I've written a lot about Roman history and l've enjoyed doing that. But I do find myself wondering, of those of us writing now, who will be big in fifty years' time? We can't know. I think the measurement of success is deeply problematic. It is very nice to get a promotion; it's very nice to get a pay rise and that makes all kinds of things more pleasant. But you'd be mad if you thought that it was the be-all and end-all of success. I find that the people who are most talented in helping me to rethink my ideas often don't measure up to the more usual marks of success.

When you look at rewarding success the debate inevitably becomes deeply gendered. There's still a sense that women are the carers. If we are really serious about wanting to promote the careers of women there are ways we can do it. Like most men, I didn't want to have kids and put my career on hold; I wanted to keep on having both. Two people make children and I don't see why my career options should be worse or better. But childcare was cripplingly expensive, so I bought my choices at a very high price. When my male colleagues are getting a bit arsy as they look at some woman's $\mathrm{CV}$, I suggest to them that they ought to credit women with one book for each child. It's not quite what they have in mind! 


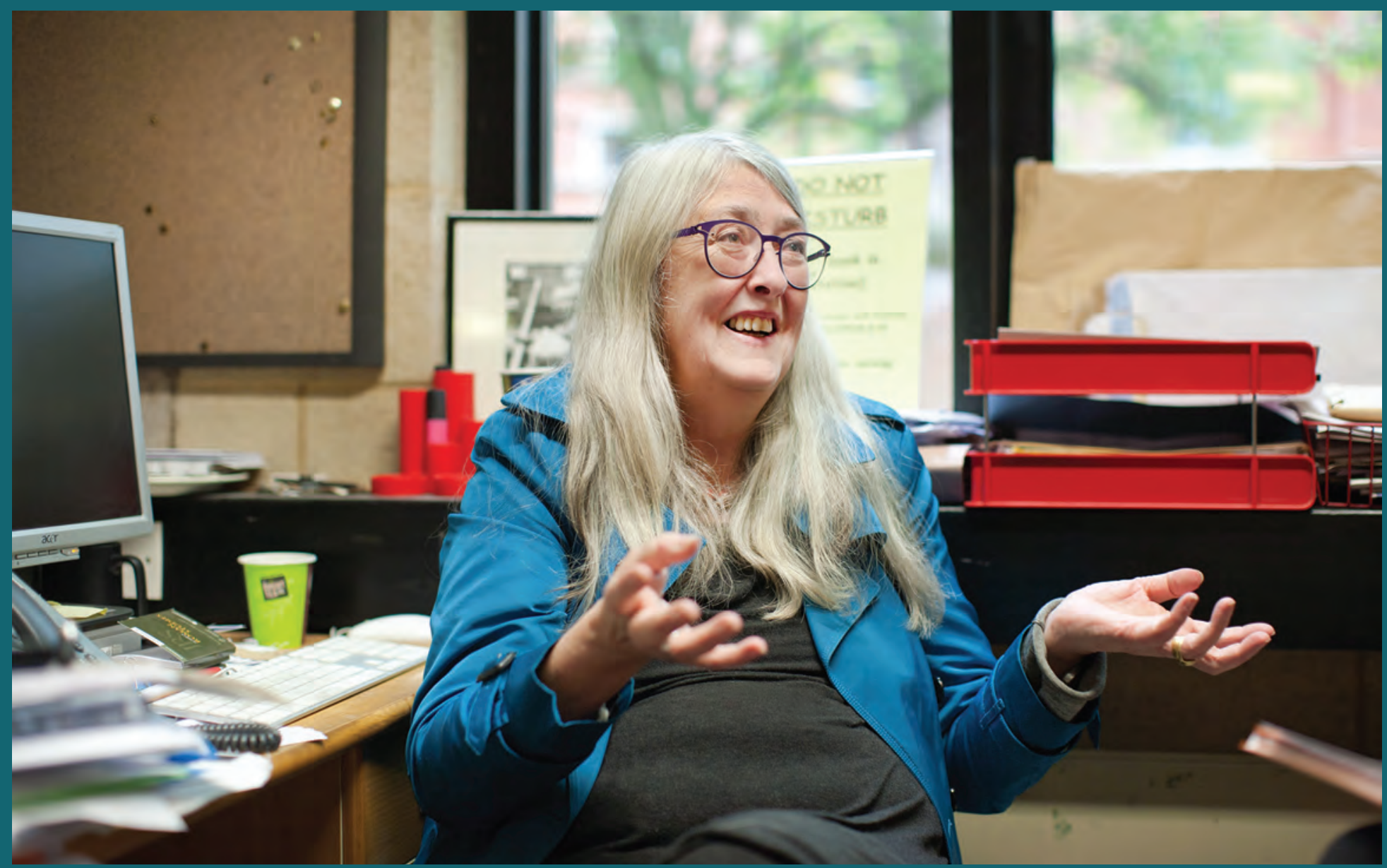

I don't think improving the situation is about going for simplistic answers like only working nine-to-five, not having talks outside those hours, or just setting up some job shares. I call these 'male quickfixes' and they're quite clunky. We've got to get around to really thinking about what an intellectual community is when it's a mixed one with kids.
Amidst all this, it's important to acknowledge progress even if we haven't got everything right yet. People often seem set on proving that Cambridge is a socially rigid environment, a dinosaur stuck in the nineteenth century. They're wrong: the University has changed dramatically in an incredibly short time. When I was an undergraduate in the seventies only 12 per cent of students were women, there was clear gender discrimination and we had to be cleverer than the men to get in. We're in a very different place now. 
Kusam Leal is the Deputy School Secretary in the School of Physical Sciences, which includes being Secretary of the Graduate School. She has held a number of roles at the University since moving there from the NHS, where she worked in both operational management and planning.

I joined the NHS straight after university because I wanted to do the kind of job where I could get to the end of the day and feel that l'd done some good.

You know those aspirations that you have when you're very young? I started out working in an old Victorian asylum - quite an eyeopener for a new graduate - and that was followed by a whole series of jobs in operational management, including a stint at Great Ormond Street Hospital.

By the end of my time there, the NHS felt as if it was in turmoil. There was constant change and I had to keep reapplying for my own job. Eventually, I saw a role advertised at the University and knew that the skills I had were transferable.

I often joke to my friends outside, 'I don't know why they let me in, because everybody here has got a PhD.' When I first arrived I kept waiting for somebody to tap me on the shoulder and say, 'What are you doing here?' It was almost as though I was worried that twenty years of experience in the NHS didn't really count for much. But actually what l've learnt is, don't underestimate your own skills and abilities. It doesn't matter where you start off and what you start with. It's about being a rounded person with some emotional intelligence. Cambridge needs people who have been outside in the real world and can bring all that depth of experience and skills. That's what I bring and I celebrate that now. I feel like I've earned my place here.

"When I first arrived I kept waiting for somebody to tap me on the shoulder and say, 'What are you doing here?'"

Being a member of an ethnic minority and a woman can also give me an extra dimension in terms of seeing how difficult it can be for others. When I was first looking for jobs I sent off lots of applications and didn't even get interviews. Then I stopped putting 'Kusam Leal' on my application forms and just put 'K. Leal'. I also tried not to give an indication of my gender if I could help it. Suddenly I started getting a bit of interest. I remember thinking, 'I can't believe this is happening.' Perhaps as a result, I'm very aware of making sure that I try to treat people equally. I make an effort to take people as I find them and not judge them because of their class or sexual orientation or anything like that.
Experience has taught me that there is no one model for the successful person. I definitely believe that you need lots of different types of people in a team. You need the loud people with lots of ideas who tend not to finish things. You also need the ones who can quietly get on with it and do all the background work. You need the ones who are questioning all the time and slightly cynical. I genuinely value difference in others. One of my closest friends is very conservative with a big 'C', whereas Tony Benn is one of my heroes, but she and I get on really well because we respect each other's views.

I believe that if you feel strongly about something, then be part of the change, don't just sit there moaning about it. At Cambridge I go out of my way to volunteer to sit on committees related to HR or Equality and Diversity. When I look back on my career I take pride in having been part of teams that helped to create positive change, for example making the business case for the Phoenix Eating Disorder unit in Cambridge. "I believe that if you feel strongly about something, then be part
of the change."

Over time, and with the help of some inspirational managers, I've come to realise that I don't have to be the loudest person in the room to be successful. I had role models who took time to invest in me, saw my potential and helped me along the way. I wouldn't say I started out being that ambitious but they encouraged me to set my sights higher and broaden my horizons. Do I see myself as a strong woman? I think so. When I'm really sitting thinking about it, I can acknowledge that I have achieved a lot and overcome some quite difficult situations. 


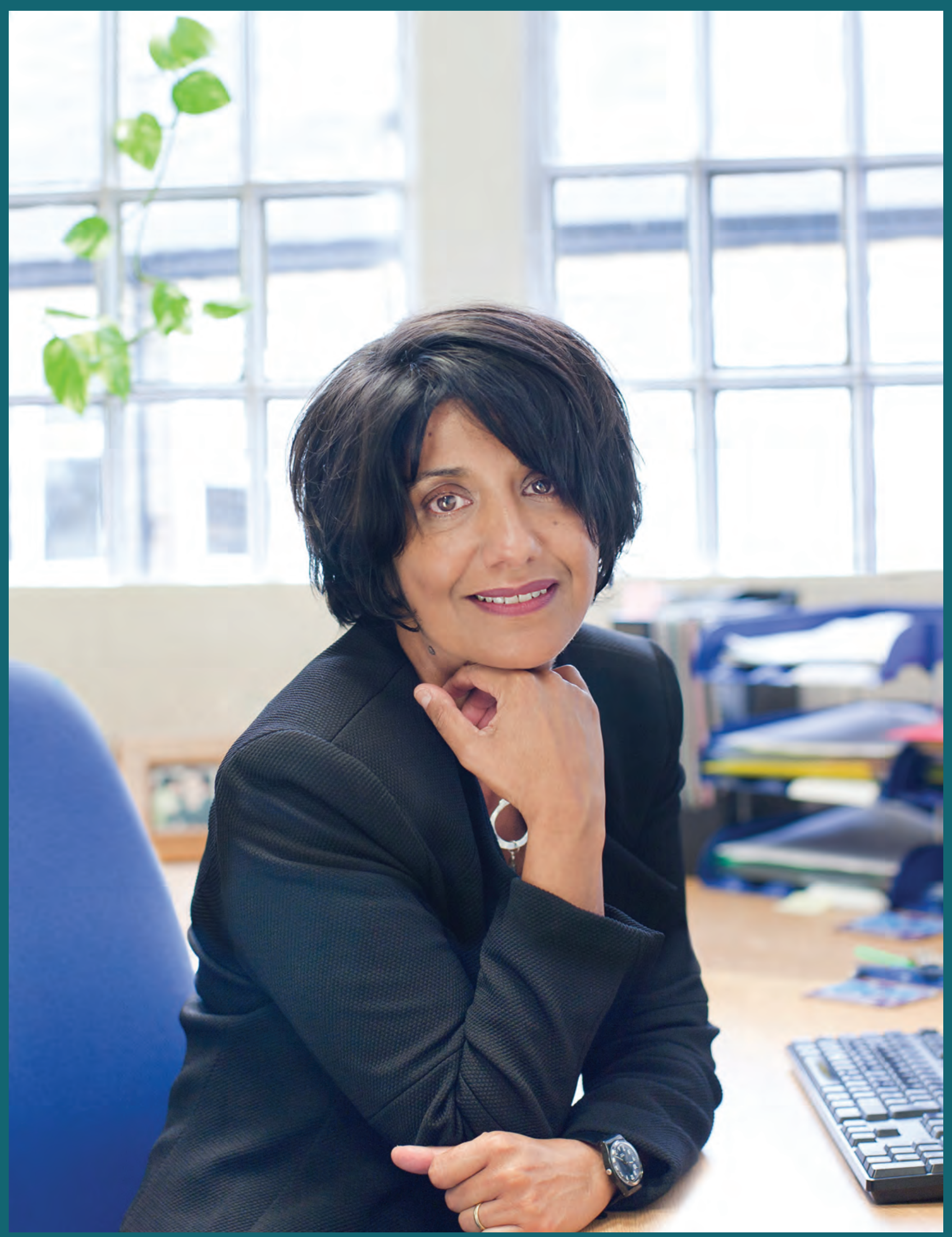




\section{Sandra Waterhouse}

Sandra Waterhouse is the Global Director of Operations for Cambridge University Press and a member of the Press Board since 2012. After starting work at the Press in 1978 as a trainee in the Accounts and Costing Department, she has since worked her way up through a number of senior roles.

These days it seems that you need a degree to do anything, so I'm quite pleased that I was able to do well without one in the first place. There's always been a part of me that likes to break the rules, stretch myself and take on a challenge.

I was a bit rebellious as a teenager: I would party hard and come home late after curfew. I think I was quite hard work for my parents. I remember the day I told my father I wasn't going to go to university; he was incredibly disappointed as I think he had dreams of me being a barrister. But back then there was nothing I really wanted to study and I was fed up being at school. Many years later I was put forward for a Cambridge MA and my dad was chuffed to pieces, but to be honest I think part of me felt that I didn't deserve it. The Chief Executive of Cambridge University Press said it wasn't really an honorary degree because l'd fully earned it, but I still don't completely buy that.

I'm quite uncomfortable with being seen as successful. I know it's a strange position to hold because if I step back and look at it, of course l've been successful. I've got a great career and I have a very positive home life. From the outside l'd probably be seen as successful because I've got responsibility for Global Operations and I'm one of only three women on the Press Board. But it feels a bit too easy if I'm really honest. I move in reasonably successful circles and when I think about the people I really rate, it's the ones who have built something from scratch and really grafted. I've had challenges, but perhaps I didn't see them as significant enough to allow myself to properly value my achievements. I know that's a bit nonsensical; intellectually I get that I am successful but emotionally I don't.

"When I think about the people I really rate, it's the ones who have built something from scratch and really grafted."

Looking back on my time at Cambridge University Press I don't think gender has been an issue for me at all. Being a woman in the print business in the 1980s had its moments but they didn't overly affect me. I do recall a meeting where a colleague said to me, 'I don't know why you're even talking, because you've got babies at home and that's where you should be.' My approach was not to lower myself to that level and just get on and do my job really, really well. You're going to get spiteful comments thrown at you at different points in your career and you need to move past them.
I can remember my mum saying to me, 'You really need to let go more, you don't have to be superwoman.' I'd listen to all of that and think it was nonsense, but at that point I was still attempting to live up to an impossible standard. I was trying to run a spotless house, bring up the children brilliantly and have a successful career. After my first marriage broke down in the early nineties, I didn't want anybody to say to me that I couldn't manage. Self-reliance was very important to me and for a long time it was a necessity as I was on my own.

"I don't think for me success can ever be just about the job. It's no good having a great job and then a lousy family life."

Being as independent and forceful as I am, I never thought that I would settle down again, but actually I have learnt that I like to have somebody to lean on. I think I was a bit deluded to believe I could do it all myself. My husband taught me to share the load and to achieve a better balance. I have a very active life, but it needs to be about more than work. I enjoy going to a party, or heading off to the spa with my girlfriends or setting myself a new physical challenge. It's also important to have some down time and a really good support structure. I used not to have that and without it life can be really, really miserable.

I don't think for me success can ever be just about the job. It's no good having a great job and then a lousy family life. I think you need to do the best you can and it's down to you to define what that means, it's no good somebody else doing it for you. You'll earn respect just from the fact that everybody knows you're giving all you can.

I was fifty-five in January, so I do wonder what the next few years will hold. Will I stay at work? Will I retire early? My husband and I both have a dream to live by the sea and sail. My daughter's married and my son has gone off travelling, so there is a bit of empty-nest syndrome, but I can't imagine that I'm going to put my feet up and start knitting any day soon. 
THIS IS

A PRINTING OFFICE

CROSSROADS OF CIVIIIZATION

REFUGE OF AII THE ARTS

AGAINST THE RAVAGES OF TIMI

ARMOURY OF FEARIESS TRUTH

MGAINST WHISPERING RUMOUR

INCFSANT TRUMPET OF TRADE

ROM THE PLC WORDS MYY AY AR

Nor TO MREH ON WWTS OF NoUND

vor to

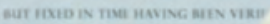

IRIFND YOU STAND ON SACR

\section{THIS IS A PRINTIN}


Dr Nicky Athanassopoulou spent twelve years in high technology companies before joining the IfM Education and Consultancy Services (IfM ECS) as an Industrial Fellow. She has held a number of roles in project management, new product development, technology and business development.

I am a curious person. I see curiosity as a driver for moving things forward and I think it's incredibly important to work things out for yourself instead of accepting existing norms.

I must get that from my dad who considered Plato's dialogues and Einstein's space-time concept perfectly normal topics for dinnertime conversation with his twelve-year-old daughter. Before long I was improvising electrolysis experiments on the kitchen floor and taking apart my first watch to figure out how it worked.

Being a good all-rounder at school I was not sure what to study until a new physics teacher turned up. His first lesson was on how super fluid Helium-3 can crawl unaided from its container. At that moment I knew that I should study physics. The wonder of the natural world seemed unimaginably beautiful to a teenager growing up in a small village in rural Peloponnese.

"I kept asking questions and reminded myself of Eleanor Roosevelt's words, 'No one can make you feel inferior without your consent."'

A few years later I came to Cambridge to do my doctorate. I didn't mind that most of the students in the lab were men, although I did wonder what had happened to all the women. During my undergraduate course in Greece there had been an almost equal balance of men and women. Cambridge was a steep learning curve. It was not only the science, but also the culture and the language. Most people were very helpful, especially my fellow students. As I had come here to learn, I was not afraid to say 'I do not know', even if this occasionally led to comments like 'women are not capable of studying physics' and 'women are not good at maths'. But they did not worry me unduly and they certainly did not reduce my confidence or my belief in my own abilities. I remember thinking that if I knew everything I wouldn't need to study, so I kept asking questions and reminded myself of Eleanor Roosevelt's words, 'No one can make you feel inferior without your consent.'

After completing my PhD I was keen to continue in physics while other students fled to the City. But I had been so focused on my doctorate that I hadn't spent much time understanding how the academic system really worked. Other people seemed to know how to get research grants, secure support from well-connected supervisors or get help in finding suitable posts. I don't think this was a gender issue, just a lack of the right support at the right time.
When my first postdoc finished and I was looking for a second, I realised that to stay in academia would mean moving countries and forgoing any personal life for some years. At that point I opted to move into industry instead.

Since then, I have learnt the importance of actively networking and having an informal network of advisors and mentors. This is particularly important for a woman working in a field like physics, which is still very male dominated in the UK. In academia, many aspects of selection, recruitment, retention and promotion need overhauling for the twenty-first century so we don't continue to disenfranchise half our human capital. We could, for example, be more imaginative about sourcing references from postdocs or students about how much someone motivates and supports them. We could run selection committees more objectively. We could stop expecting academic women to produce the same number of publications as men despite many having careers affected by maternity leave. The latter is a real issue in industry too. There are still negative attitudes about women taking maternity leave or becoming less flexible in their working hours after they return.

But ultimately, we need to start increasing the female student numbers in physics and related disciplines. Some girls are put off sciences from primary school here. My six-year-old daughter came back one day and said, 'Mum, maths is hard.' Where did that come from? It runs deep in society and that's sad. I'm not saying everyone needs to be a scientist, but good education should be focused on generating options for both boys and girls and not limiting them.

"People define success in different ways and it's good to know as early as possible what is important to you."

Generating options, being curious and continually pushing onwards are my criteria for success. This can be as simple as reading a challenging piece of work on a completely different discipline right through to travelling up the Amazon. It's about pushing boundaries, having an appetite to explore the world and yourself. It's about striving to be a better person and having meaningful, supportive relationships with other human beings.

But people define success in different ways and it's good to know as early as possible what is important to you. Then you make sure you don't compromise on that. Maybe ultimate success comes from the

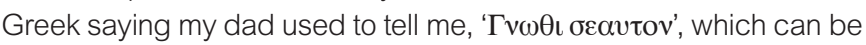
loosely translated as 'know thyself.' 


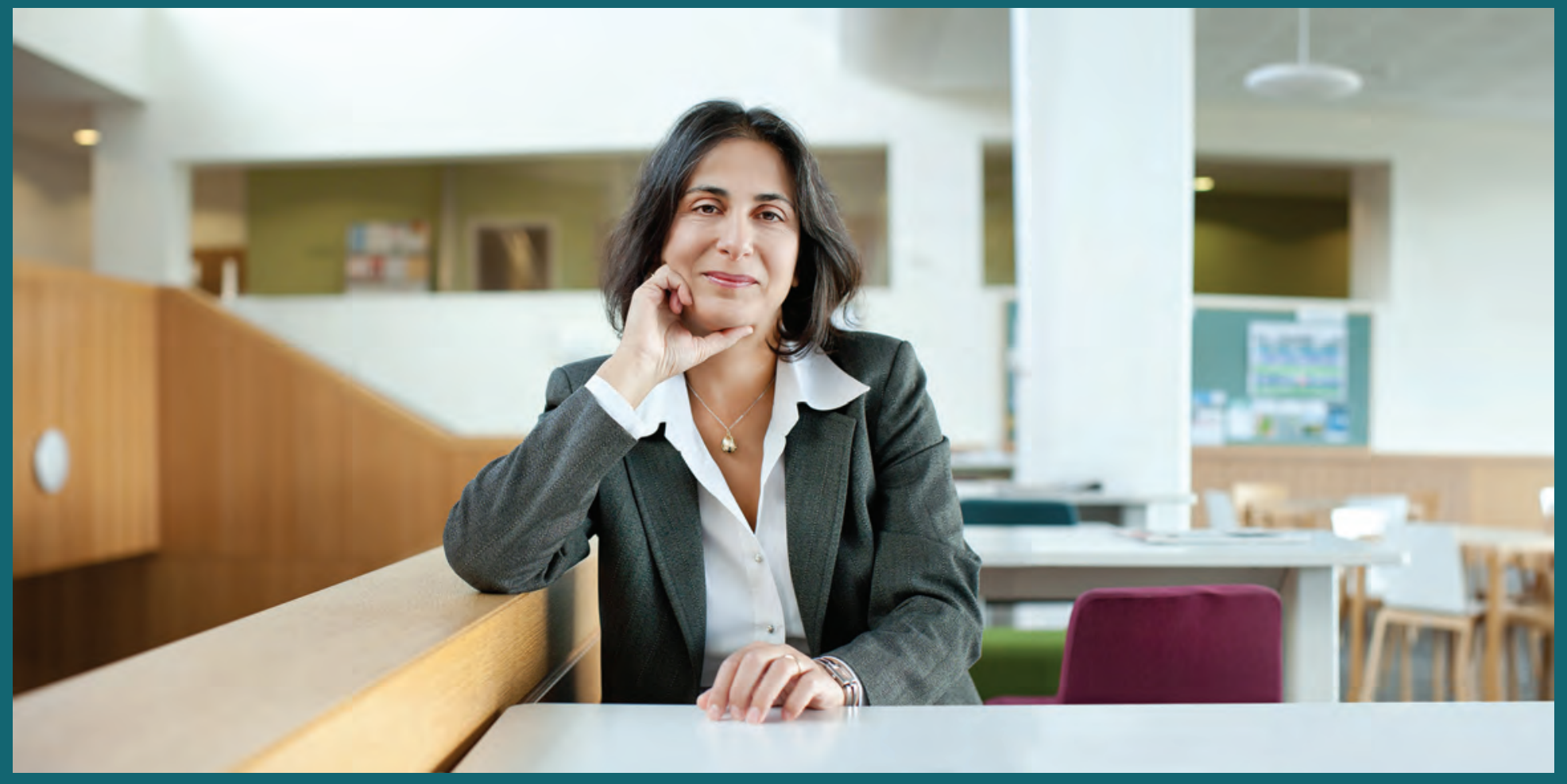

"I didn't mind that most of the students in the lab were men, although I did wonder what had happened to all the women." 


\section{Gender and its effect on}

\section{working life}

\section{Framing the debate about gender}

We asked women at Cambridge the question, 'How do you think your gender has affected your working life?' Based on the responses we received, the majority of the participants read this as an enquiry into whether their gender had been an issue or problem for them in the workplace. Whilst this chapter will endeavour accurately to represent the concerns expressed, it will also look to capture broader insights and observations about how best to realise the talent of women in the workplace.

"Academia, including Cambridge, needs to change to become more inclusive as soon as possible. Otherwise academic institutions will not only continue to squander talent but also become increasingly out of step with a society that is changing and modernising."

Sarah Teichmann

\section{The relevance spectrum}

There was significant variance in the extent to which women saw their gender as relevant to them as they pursued their careers. We have described this as a 'relevance spectrum', with the poles represented at one end by those who saw their gender as not at all relevant and the other end by those who felt it was always and inevitably relevant in every situation. There were many women who took up a place between these poles, seeing their gender as somewhat relevant some of the time. Others could be seen as moving along the spectrum, often stimulated by a change in life or job circumstances, or in response to aging. Most noticeable was the shift that took place when women became parents, which tended to move their gender from the background into sharp foreground focus. Across all points of the relevance spectrum there was a consistent desire to be rated based on one's competence and ability, not based on one's gender.
"Gender is in the grain of all we do: sometimes it makes one an irritant but it also allows you to contribute fresh experience."

Gillian Beer

"It would be a lie in my case to say that gender has held me back. But it has sometimes been a case of feeling in a foreign country."

Mary Beard

"I would say not at all, up until the point at which I got married and had children. Then it was fundamental."

Sam Lucy

"Gender is important, but it should not define you. On the other hand it is quite all right to behave like a woman in committees etc - after all, most men behave like men."

Alison Smith

"Until a few years ago I thought my gender was entirely irrelevant, but I suspect that may be because actually my youth was a bigger barrier than my gender."

Nathalie Walker

"I don't think of myself as 'a woman'. I think of myself as 'a person'."

Jennifer Clack

The fact that a book is being written that focuses on women at Cambridge indicates a pre-existing bias on the question of relevance. The raw data around the lack of women moving up and through organisations, inhabiting leadership positions and securing appropriate recognition for their work leads us to believe that gender needs to be looked at and cannot be totally irrelevant. Gender may not be the most important thing about a person or something they see as having influenced their own career trajectory. But it does not necessarily follow that gender is therefore irrelevant, or that it does not in some way affect how colleagues, or society more broadly, view women. There is no expectation that a reader should share this position - nor would all the women involved in this book. The comments and insights gathered here stand on their own merits and a reader can draw their own conclusions from them. 


\section{Upbringing and schooling}

People come to Cambridge having already been exposed to messages about their gender from their parents, schooling and wider society. This is of course true of both men and women. The narratives and quotations in this book express a real range in the gender messages by which people were affected. These run the full gamut from hugely positive and empowering, right the way through to extremely inhibiting and undermining.

"I have just begun to realise that a lot of gender inequality becomes embedded at an early stage at school. Therefore it is important that not only all staff, but also all our students are trained in gender equality and best practice as soon as they arrive in our care."

Val Gibson

Some people talked about having parents who created an expectation that girls and women could do anything they set their minds to. Several women made specific mention of their fathers being particularly keen to challenge stereotypes, and some were described as 'feminists' in their own right. In contrast, other parents were uninterested in their daughter's education because of their gender, disapproved if they took up an apparently less 'feminine' subject like engineering and discouraged them from returning to work after having children.

"Having the confidence to ignore prejudices has been crucial, as has a strong belief in my own abilities. I have to thank my solid upbringing for this."

Nicky Athanassopoulou

Beyond parents, early formative experiences at school were also mentioned as having an effect on how women viewed the possibilities or limitations of their gender. Some women talked about having had inspirational teachers - both male and female - who saw their potential and pushed them to achieve. Others had less happy experiences that prescribed far more rigidly what girls should and shouldn't do and presented a very restricted view of the careers that they were capable of pursuing.

"School careers advice was terrible. We were not encouraged to plan ahead and map out careers as our male fellow students were."

Rachel Fogg

\section{Gender assumptions, expectations and stereotypes}

Once women joined the workplace, their sense of what was acceptable and unacceptable for them to be and do began to be shaped by their working environment and interactions with colleagues.

"It is usually not acceptable for a woman to be seen to be angry, as she is regarded as hysterical and out of control, whereas a man can get away with it."

Deborah Howard

When the women described their workplace experiences, there seemed to be a discrepancy between the behaviours that a man could demonstrate without negative consequence - and sometimes even exploit - and those seen as acceptable for women. Outspokenness, assertion and even anger were ways of behaving that seemed to be judged differently when coming from a man. For women, there was the risk of being seen as frightening, aggressive, strident or disruptive when holding a reasoned but determined position.

"I have clearly caused some of my colleagues to feel that I am 'dangerous' in ways I have never understood, possibly because I am fairly outspoken and that isn't consistent with how women are stereotypically meant to behave."

Athene Donald

Women also talked about how their 'voice' was heard - or not - in the various organisations for which they had worked. There was reference to be being described as anything from shrill, stroppy and hysterical through to frivolous and chatty. There were also examples of feeling voiceless in meetings where they were often in a minority to start with: they didn't get space to speak, colleagues talked over them or a male peer was given credit for a point they had raised. An absence of voice also related to the lack of female representation at certain levels and on particular bodies.

"I miss female colleagues. Many men are now aware of the importance of good working relationships with female colleagues, but there is still the 'boys' club' when it comes to informal collaborations and banter."

Wendy Pullan

Attached to frustrations around voice were comments about feelings of isolation and fears of tokenism when women found themselves to be a solitary female presence, or in a small minority. This presents something of a challenge to organisations that have real positive intent to increase female representation but find themselves 'over-asking' the few women perceived to be suitable candidates for committees or other bodies. In this situation there is merit in querying the selection criteria used, challenging assumptions about the 
seniority level and background needed to sit on particular groups, as well as considering creative ways of spotting talented women at more junior levels and involving them at an earlier stage. All of this offers the possibility of casting a wider net to engage broader groups of women in larger numbers, especially in the decisionmaking processes of an organisation.

"Where I am in new situations with male colleagues, it has been presumed that I wouldn't be the President; you have to deal with situations where you might be the only woman in a key decision-making body, or just regularly getting talked over in committees."

Rosalyn Old

More broadly, there was irritation expressed at the reduced expectations and assumptions that the women had encountered during their working lives. Some talked about situations where it was automatically assumed they were the most junior person in a meeting, when the opposite was frequently true. Others talked about needing to fight against limiting beliefs relating to being both a parent and having a job - a problem we will discuss in more detail later. On the most basic level, women we spoke to expressed the desire for a starting point where as much would be expected from and of them as from a male peer.

"Some people are rather surprised by your achievements and tenacity, rather than expecting you to do well."

Abigail Fowden

Some women talked about having limiting traits that they saw as being associated with their gender - such as an innate conservatism, perfectionism, lack of self-confidence, risk aversion or an unwillingness to promote themselves or their achievements. It is important to note that a number of women rejected the idea of gender-based traits outright and saw these instead as personality-based.

"Probably its biggest effect is the high standards I set for myself (verging on perfectionism) and the tendency to wonder if I'm doing enough/could be better. This is a tendency that women/girls are more likely to exhibit."

Jessie Monck

It was noticeable how much context made a difference to the way women experienced the potential advantages, disadvantages or insignificance of their gender. There was talk of progressive departments, excellent leadership, visible sponsorship and support from those senior to them. All of these led to women feeling more able to bring their talent to the fore and be recognised for doing so. Being able to see a range of varied role models - including women - thriving in their discipline or area also provided a genuine basis on which to be positive about their prospects. Several women talked about feeling accepted and valued in one part of their working lives - perhaps in their team or research group - and far less so in others.

"I have rarely experienced prejudice. However, male academics do occasionally treat me like a secretary, and industrialists and overseas scientists can exhibit some surprisingly unreconstructed attitudes."

Rachel Oliver

Some participants commented positively about progress made around gender equality, legislation and the educational opportunities available for girls and women. Despite some grounds for optimism, there was little sense of complacency or a feeling that parity had been achieved. Several women talked about the energy it took to challenge, cope with or defy the limiting assumptions attached to their gender. This in itself offers a pressing reason for organisations to be passionately interested in inclusion, as there is a clear impact on performance.

"I often get frustrated with the time and effort it takes to overcome default assumptions. I probably could have done more with my life if I could have used all that time and effort for working, instead of justifying my existence."

Shima Barakat

\section{Bias, sexism and discrimination}

At their worst, gender assumptions manifest themselves as overt sexism or discrimination. Much of what we heard about was at the 'lower' level of unconscious bias, but this still affected the weight given to women's opinions, the opportunities open to them and beliefs about their capabilities. There were, however, specific examples of sexism, sexual harassment and explicit discrimination. These serve as a warning about the importance of robust organisational policies and procedures to identify and tackle sexism and discrimination when it occurs. Just as importantly, these examples point to the value of developing leaders and managers who won't tolerate such behaviours and who help to create an inclusive culture where it becomes increasingly unlikely that unreconstructed attitudes have any place.

"The academy is very male dominated and the more senior I have become, the more clearly I have understood how deeply gendered it is."

Sarah Franklin 


\section{The practical impact of gender assumptions in a work environment}

"I am well aware that serious talent is being wasted in Cambridge and elsewhere by systems that have allowed 50 per cent of the talent pool to occupy fewer than 15 per cent of the senior positions."

Theresa Marteau

The attitudes described in the paragraphs above were seen to play out in a range of practical ways. They had an effect on who was encouraged to go for promotions, who was invited to apply for jobs, who got asked to do administrative tasks and how important information was used and exchanged between members of what were still often seen to be 'boys' clubs'. Given that men still hold the majority of leadership positions in the majority of organisations, they exercise significant sway over the decisions and views that shape their workplaces. It is human nature to be less aware of the biases that don't personally affect us, or at least not negatively, so it requires specific effort to step back and notice where they may be present. All notions of merit are subjective, and organisations need to question how that subjectivity potentially affects who is seen as successful. A more inclusive definition of success starts to reshape workplaces by enabling them to identify and then reward a broader range of contributions from a more diverse group of individuals.

"As a lecturer and beyond, I have found heads of department will expect more teaching from me than from a man, and expect me to do more committee service and jobs like running courses."

Anon

These observations emphasise the importance of recognising that gender issues are organisational issues. Recruitment, promotion and performance are all leadership concerns and require leadership attention. The patterns described here are also by no means exclusive to Cambridge, which as an institution reflects the society it is part of. Cambridge cannot 'solve' wider gender issues, but it can become increasingly aware of them, take steps to address inequality within the University and also exercise its influence to stimulate debate beyond the University.

"In a system that relies on self-promotion, women will continue to hold back."

Abigail Brundin

\section{Ways that women responded to assumptions and stereotyping}

'Every other independent investigator in the department was a man and a lot of people didn't seem to realise that a woman could be her own boss. It was very frustrating, but I concentrated on doing the best work I could and eventually people caught on.'

Margaret Robinson

On an individual level, women described a range of responses to the blockers, assumptions and stereotyping they experienced. Many chose to try to counter negative assumptions by concentrating on producing the highest standards of work. This paid dividends in some circumstances, but was insufficient to secure appropriate recognition in others. Some women looked to put themselves in the best possible position for advancement by diversifying their skills and seeking out opportunities to use them. Others, but perhaps too few, talked about the value of securing support from mentors and sponsors to help them navigate their careers. Many made use of good friendships and networks to provide individual support in handling situations, but fewer to connect with other women experiencing similar concerns or to mobilise broader demands for improvement.

"There are sufficient women in the University for us to work together, make a difference and take on challenges. There is no need to feel alone: many women in the University have had similar experiences."

Abir Al-Tabbaa

Several women in leadership positions had the authority, seniority and political awareness to be able to shape their college, department or discipline. They seemed to feel a personal responsibility for making a difference by improving the circumstances and opportunities for other women. Given that there are relatively few senior women in total, there was some mention of isolation, suggesting the value of creating more natural opportunities for them to collectively exchange insights and amplify their influence.

"It has been important quietly and persistently to challenge language that excludes women and to look out for younger people who can be drawn into positions of influence."

Gillian Beer 


\section{The opportunities of gender}

"Perhaps it's been easier to remember who I am when the rest of the room is predominantly male. So - lucky break?"

Sarah Worthington

Although the women involved in the book talked about the assumptions and stereotyping that came with their gender, many also focused on the potential opportunities too. Some were very open about the fact that there being fewer women at their level, or in their discipline, meant that they were able to stand out in a positive way - even 'breaking up the tedium' of a previously all-male environment. Being conspicuous sometimes meant they were able to draw attention to their achievements, were noticed as a conference speaker and were invited to join a particular group or committee. When this was allied with self-confidence, women talked about being able to bring a fresh perspective to a situation, meeting or problem.

"I have been offered opportunities because someone 'wanted a woman' to join in, and that has given me chances I would not otherwise have got."

Athene Donald

The non-linear career paths pursued by many women we spoke to also presented the potential for gathering more diverse experiences that in turn could positively affect the insights and contributions they were able to bring. They also talked about the resilience and flexibility that came with forging a career that deviated from a traditional norm. Some women set their careers within the broader history of women's rights and talked about their good fortune in being able to access the workplace at all. They were able to appreciate how much had shifted for women during their lifetime, whilst also seeing that more needed to be done.

"I think being female has many advantages - I am more able to ask for support than many colleagues, have a good network of female colleagues I can share lunch and a grumble with, and am better at communicating than many around me."

Beverley Glover

Whilst some women were uncomfortable with the notion that there were such things as typically female attributes, others claimed a perceived advantage around competencies like communication, collaboration and building relationships. Whether linked to gender or not, these qualities clearly benefit organisations and are features of some of the most effective leaders.

\section{Family and parenthood}

Beyond the workplace and how women engaged with it, the most frequently mentioned impact of gender was in relation to family life. There were examples of all sorts of different family models, encompassing divorce, being single, parenting of babies, teenagers and adult children, blended families, caring for elderly parents or siblings, late-in-life marriages - and many more. These family situations were also affected by other conditions such as high or lower incomes, job security or coming from another part of the world. Whatever the particulars of their circumstances, the women involved in this book expressed a desire to nurture healthy family lives along with their careers, even though making this work was described as 'no picnic'.

"Childcare burdens still fall disproportionately on women and as a society we are not doing nearly enough to change this culture in either our private or public lives."

Nicola Padfield

Whilst it is important to acknowledge different family types, it is also true that the vast majority of comments made in this area related to the challenges and rewards of having both children and a career. The facts of childbearing, expectations about where the primary responsibility for childcare sits and the perceived viability of having a demanding job as well as being a mother - all had clear implications for women in their working lives.

"As a PhD student I was told quite definitively by a (male) Harvard professor that it was not possible to be a scientist and a mother."

Gillian Griffiths

The challenges of combining parenting with a job have been touched on in the previous chapter in relation to work volume and handling competing commitments. In addition, there was also specific mention of the sheer exhaustion of having very young children, the practical frustrations associated with breastfeeding, finding meeting places that allowed children and the eye-watering costs of childcare. Some women talked about the guilt associated with not being there for all the school meetings, plays or pick-ups and a sense that other women were somehow coping better than them - although we didn't hear any evidence to substantiate this belief.

"I have met some incredible women who have left academia, not because they were not passionate about it but because they felt it forced them to choose between a career and their children."

Genevieve Maul

Lots of women mentioned not being able to attend networking events or conferences that were outside childcare hours and/or involved travel. This led to concerns about the loss of 'social capital' 
and curtailed access to opportunities, which was also seen to lend an advantage to male peers. These worries were accentuated by the fact that having children often coincided with crucial career junctures and promotion points. It seemed that many of the women involved in the book had faced problems getting others to take them and their ambitions seriously as a professional when they had young children.

"Women with children often miss out on networking that occurs outside the hours of childcare."

Theresa Marteau

The overall picture however, was far from one of gloom, doom and despondency when it came to being a parent. For many this was a fundamental part of their identity and the source of some of their greatest happiness. People talked about the sense of perspective and groundedness that came with having children. They were refreshed by having to step away from the day job to focus instead on their family. This in turn could bring greater discipline and focus to their work. There was a sense of the feedback loop between work and home, which meant that being happy and fulfilled in one sphere made it more likely that they were happy and fulfilled in the other.

"A degree of compromise is necessary, but the children will survive and hopefully appreciate and respect you for your decision in the long term."

Fiona Gribble

So, is it easy to have children and a demanding job? Clearly not. Can having children bring extraordinary rewards and pleasures? Absolutely. But these are perhaps the wrong questions to focus on. If having children is non-negotiable for the majority of the women involved in the book, then it is more interesting to ask questions about how to make this work most effectively for individuals and their organisations. At an individual level there are choices to be made about which meetings and responsibilities to hold on to and which ones to let go of. Many women described making it work alongside a supportive partner who shared the responsibility of parenting with them. There is also a need to manage expectations and boundaries with colleagues where possible, as well as encouraging simple but significant changes like scheduling a crucial morning meeting fifteen minutes later to allow parents to do the school run.

"I have also accepted that my career trajectory is not a single gradient, but it has to include steps, when other priorities (eg children) become important."

Val Gibson

But the responsibility cannot all be the individual's. An organisation that wants to retain its women needs to think about making it as easy as possible to be both a parent and a professional. Men and women have children, parent and are involved in childcare - these factors are not exclusive to either gender. Over time, truly progressive work environments will enable both genders to fully access the kind of flexible working that encourages productive home and work lives.

"I feel that it is time to move beyond seeing childcare as a gender issue and consider instead how we support academics, both male and female, who value both time with their children and their careers."

\section{Gender equity and engaging the support of male colleagues}

"It is likely to be enlightened men that help women most in the next ten to twenty years because of the paucity of senior women in every major career path."

Sharon Peacock

The previous paragraphs further emphasise the importance of shifting the debate away from women's and mothers' issues towards discussions about gender equity and enabling parents of both genders to maintain their careers. It is clear that any progress in this area requires the active engagement and support of men if it is to get anywhere.

"Supportive colleagues make the impossible possible, and it can be surprising who that might turn out to be."

Corinne Roughley

Men are bosses, peers, friends, sponsors, mentors and junior colleagues. They are decision-makers and followers. Strong working relationships exist across the genders, and some of the most powerful advocates for inclusion are men. Women are also by no means universally supportive of other women. Men are therefore integral to almost all work systems and a vital part of the conversation about how to make them more inclusive.

"My husband's work has paid for me to enjoy the privilege of being able to stay at home with my children, and I would see him as at least as trapped in the stereotypical male gender role as I may seem to be in the female role."

Rachel Fogg

Much of the gender debate tends to focus on the differences between the sexes - in power, numbers, opportunities available, remuneration or approach. Differences do exist, but perhaps we need to think more about the common territory between colleagues committed to the wellbeing of their institutions, sharing a passion for their work and also a desire to have healthy family lives. 


\section{Jane Clarke}

Jane Clarke is the Professor of Molecular Biophysics and Senior Wellcome Trust Research Fellow in the Department of Chemistry. She began her career in science as a teacher in a comprehensive school. She later moved with her family to the USA, where she took a master's degree that kick-started her new career in research.

I don't like unfairness in a system. I think education, training and aspiration are things that everybody deserves. It's political and I'm a feminist through and through.

Feminism is about fairness and equality; it means that we should organise our society in such a way that it shouldn't matter what your gender is, it shouldn't matter what your marital status is, it shouldn't matter what your parentage is.

I'm very tough and self-reliant and have always drawn on the incredible example set by my mother. She was the first person in our family to have a degree - both my grandfathers were colliers. Even during the war and even though her own mum had died, my mother still managed to go to university in Cardiff. I admired her so much and I still do. It's my regret that she never saw me get my PhD; she'd have loved it.

"Being a woman means I am a role model, like it or not."

I didn't fit the pre-defined norm of an academic from the outset. I was a teacher before I did a part-time masters degree and fell for research. It was so exciting - the not knowing, problem solving and following your nose when you've got an idea. It's the best job in the world being a research scientist. But when I first approached the Biochemistry Department at Cambridge about continuing my research, they said 'You're forty years old, you've got two children, you're joking, go away.' Fortunately I had an introduction to Alan Fersht who was the world's leading protein chemist. He gave me a chance and a first foot on the ladder.

This is seen as a man's career. Being a woman means I am a role model, like it or not. If you give a bad lecture and they only have two lectures by women a year, then the message is, women are useless lecturers so we don't need more women. As Deputy Head of the department I try to use my influence to bring about a real cultural change, but it's hard and it can also be lonely with so few women in the department.
An academic career is very pressurised; you apply for grants and if you don't get them it can put your career under threat as well as other people's jobs on the line. I've also had to cope with significant challenges in my personal life. Having friends pays real dividends when you're under pressure. You need people who understand, people who you mentor and can mentor you in return. When you find friends that you can really talk to, treasure them.

"I've done it in such a way that I can hold my head up and say that I never trampled on anybody."

I judge people based on how they behave and what they achieve scientifically - not the trappings of importance, like the size of their office. You can be a successful scientist whilst recognising that you have young people in your care who deserve your support, your mentoring and proper training. These young people are not cannon fodder to be thrown in to do your research, regardless of their own needs. There can be too much of that in academia - it's highly competitive and it's tough sometimes.

I was delighted when I became a professor - my dad was thrilled to bits, my kids were delighted, my group were delighted. It was an acknowledgement of success and that's okay. But what matters most to me is my scientific opinion being held in respect by people whose own scientific judgement I value. I am one of the world leaders in my field and I'm tremendously proud of that. And I've done it in such a way that I can hold my head up and say that I never trampled on anybody. I've also done it starting late, in an unusual way, and I think that's something to be proud of. It shows that there's more than one way of having a successful scientific career, and you should never be told otherwise. I've done it with the love and support of my family, doing my full share of being a mother and a wife and a friend to my friends. I've got two kids and they're really nice people, they're great parents and I'm proud of them. This balance also means that now I'm facing retirement, I know that there are other things to life beyond my career. 


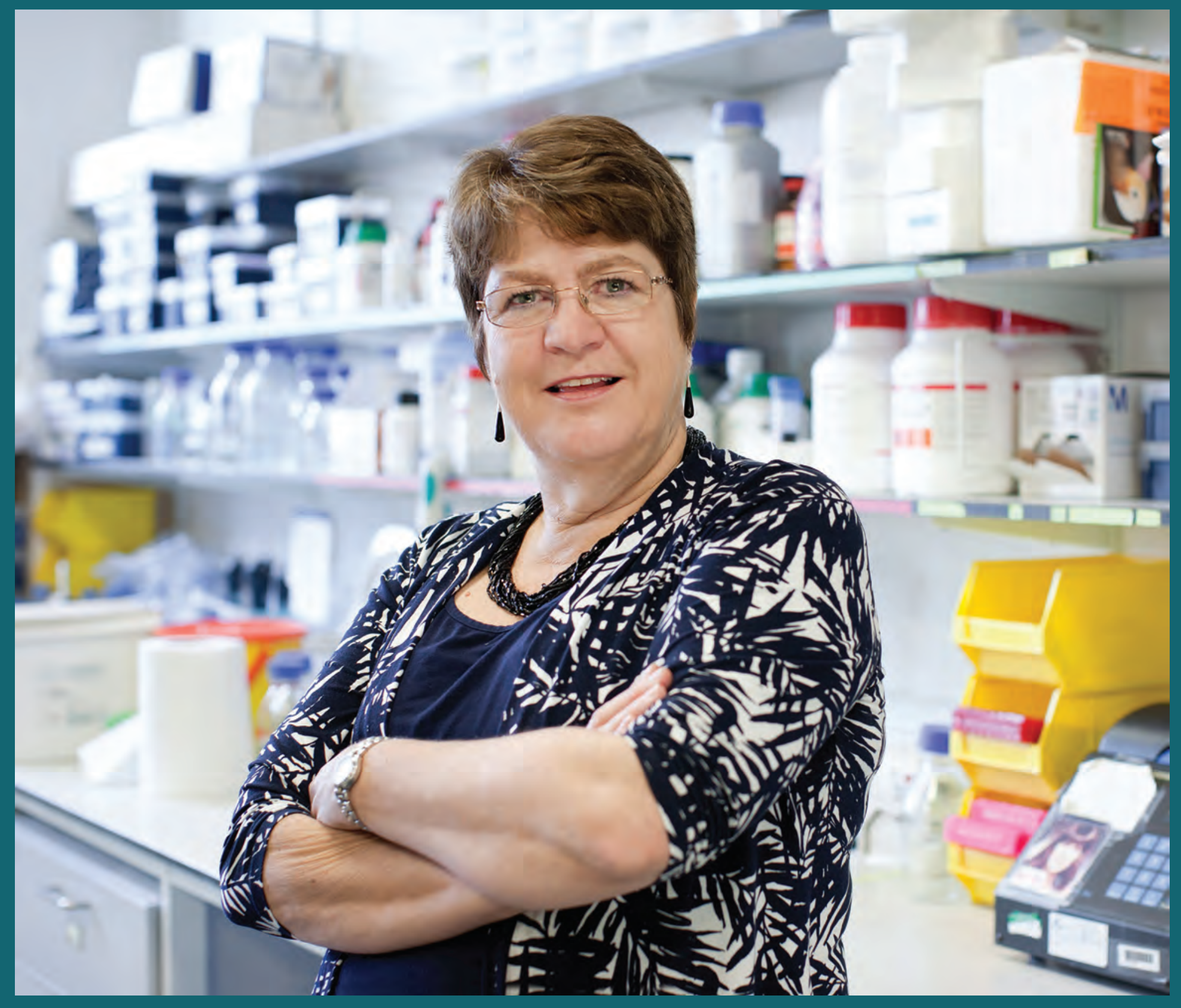

"When you find friends that you can really talk to, treasure them." 
Development Director and Registrar of the Roll at Newnham College, Penny Hubbard is an alumna of the College. She worked as a solicitor and took on a number of other challenges before starting her current role in 2007.

My upbringing set me up to be someone who is prepared to give most things a go. At home nobody ever shouted if you did not get an 'A', but it was a real problem if you had not tried your best.

My mother, who left school at sixteen, was an entrepreneur, so it is little wonder that we grew up wanting to take advantage of every opportunity that crossed our bows.

I was one of the first women at my City law firm to make partner, but I think my mother's influence was most evident in my having the confidence to know when to leave. Although it was a very hard choice to make, which took a long time in the planning, I learnt from her that once you have made a decision, there is no point looking back. Although I was very proud to have been made a partner in such a male environment, it became clear that the situation was unsustainable. I was a mother with two small children, and I wanted to see them. Initially I tried to cope by having a series of very good nannies, but that did not work as a long-term solution. There was no discrimination in the sense that I was treated no differently from the men, but I was expected to work like a man, which meant regularly doing fourteen-hour days and working weekends.

"I have been prepared to sacrifice wealth and prestige to achieve a balance that works for us as a unit."

My husband and I ultimately decided that it was not what we wanted. Although I was concerned that I was letting down the younger women coming up behind me, I felt I had to give precedence to my family. I have been prepared to sacrifice wealth and prestige to achieve a balance that works for us as a unit. My girls will always come first, and I am really proud of them. Along with my husband and my friends, they sit at the centre of what is important to me; my sense of success is linked to feeling happy with the choices I have made.

I aimed for a life with breadth whilst leaving room for relationships. I came to Newnham as a student and being here helped to establish those priorities early on. Jean Gooder, the most inspiring Director of Studies, encouraged us to do more than just the purely academic, and I involved myself in Footlights and CULES and made a number of very good girlfriends who I am still close to. I know I might be biased given that I am now the Development Director, but I believe Newnham is the most fantastic environment for students who value pastoral support and the space to develop great friendships.
Working here I have gone from being in a career where, as a commercial property lawyer, I was often the only woman round the table, to a situation where it is all women. The College Council at Newnham is extraordinarily collaborative. There is a lot of discussion and negotiation with very little banging of fists on the table. I think it is exciting for our students to witness at first hand women running a multimillion-pound business.

"The people I respect most are those who exhibit empathy, are not dictatorial, communicate well and make an effort to get to know you."

We think it very important to reach out to alumnae and to celebrate the different and varied paths they have taken. We are frequently the top college in terms of the percentage of alumnae contributing and that really matters to me because I am motivated by people reconnecting with Newnham, not just by the level of donations we receive. I think my gender has been an asset here because I understand the importance that women place on their donations doing social good. They are much more interested in their money supporting a student than they are in seeing their name up on a building. I've loved being able to do imaginative things like 'The Newnham Conversation', where we host an annual discussion between two alumnae, such as gold medallist Anna Watkins and broadcaster Clare Balding. We ran the first ever May Ball purely for alumnae held by a Cambridge College and have recently set up a group called 'The NewnhamRoll Mums'. We want to be as inclusive as possible and demonstrate that we are proud of all our alumnae, not just the ones with their names up in lights.

In thinking about success it is easy to admire super-driven, highprofile figures, but the people I respect most are those who exhibit empathy, are not dictatorial, communicate well and make an effort to get to know you. I have no time for rudeness and a lack of appreciation: it does not cost anything to say thank you. I think this is one of the special things about working with the Newnham alumnae who appreciate the efforts we take to involve them in our community. In going the extra mile it matters enormously to me to see that my work is making a difference - whether it is in securing a small donation to enable a student society to get off the ground or obtaining a grant of $£ 1,125,000$ to endow the Valerie Eliot Fellowship and secure the teaching of English at Newnham. 


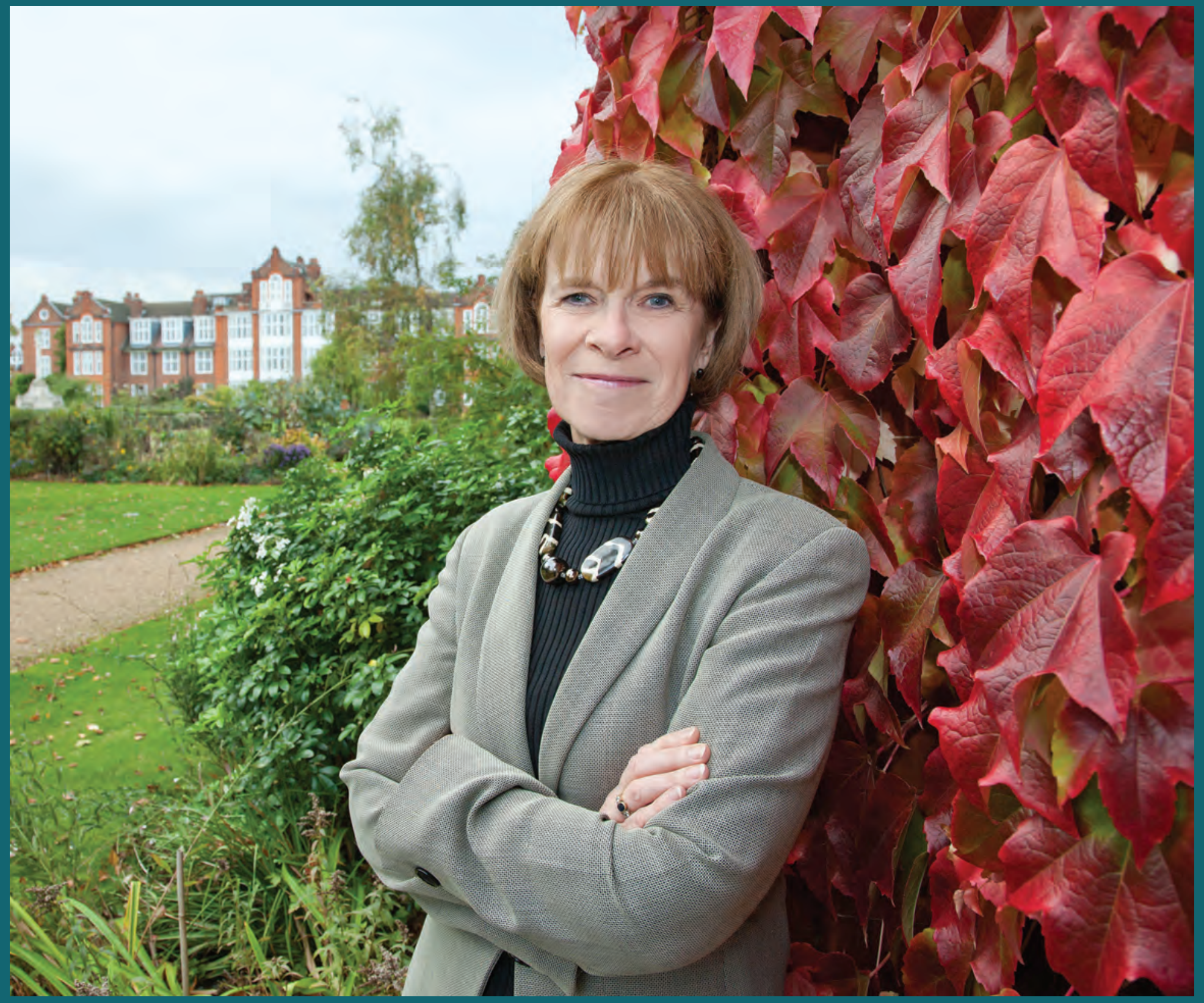

"I aimed for a life with breadth whilst leaving room for relationships." 


\section{Shery Huang}

Dr Shery Huang is a University Lecturer in Bioengineering in the Department of Engineering and Director of Studies in Physics at Homerton College. Her research is highly multi-disciplinary in nature, focusing on tissue engineering and biomaterial printing.

It's relatively rare for an early career researcher to have four PhD students and it's not common to get a lectureship before thirty. I feel that I have achieved this because I am very focused and extremely passionate about my research. I am also good at seeing opportunities and grabbing them.

I came over from China as an overseas student at the age of seventeen. After school in Loughborough, I moved to London and initially found it pretty isolating. I was quite a shy person, but I gradually gained my confidence through various experiences, such as undertaking voluntary work around London and performing on stage with the university contemporary dance company. During this time, I also discovered my passion for research and realised that I liked having the time and space to explore scientific problems. I guess you can choose whether to spend your time in college or in the lab, and for me it's all about having a passion for science. I have a lot of curiosity and I want to know why something happens rather than just accept that it does.

"I have a lot of curiosity and I want to know why something happens rather than just accept that it does."

After my undergraduate degree, I came to Cambridge for a PhD and by my third year I had decided I wanted to pursue an academic career. I applied for lots of fellowships but was not able to secure any of them. Through that experience I learnt I had to improve myself and be more focused on my work in order to be more prepared the next time around. This approach led me to obtain an Oppenheimer Fellowship jointly with a Homerton College Junior Research Fellowship. How did I cope with the initial knockbacks? I guess it's my personality. You just have to tell yourself that you believe you can do it, and you have to persevere. If I face a challenge, I may initially complain, but in the end I get on and do something about it. I guess I am resilient.
I currently hold a University Lectureship in Bioengineering. I lead a group of four PhD students, as well as a number of project students, and I have high expectations of their academic and research performance. I don't have a particularly formal management style, and I don't fix the times when they come into or leave the lab. I want to encourage them to take personal responsibility for how much they are going to get out of their PhD. I think an open working style leads to more creativity, so I guide them for about 20 per cent of the time, but for the other 80 per cent I like them to explore by themselves.

"If you believe in what you want to do, then you need to retain the commitment, focus and motivation to do it."

In terms of role models, I admire Professor Athene Donald and Professor Lisa Hall. They are both pioneers in their scientific fields. Previously there weren't many female scientists, but they were able to hold on and get to where they are today through hard work and outstanding research. Dr Kate Pretty, the previous Principal of Homerton College, is another role model of mine. Despite having held very prominent positions, Kate remains very down to earth, and she is very giving to the college and its students. Throughout her tenure she continued to conduct supervision and teaching in college. In my view, education is one of the ways you can really change people's minds and ideas. If you can educate a person, then they educate others, and this can have a great knock-on effect. Education really has the potential to make a significant positive change to society.

When I become more senior, I shall try to hold on to my core values. Even if the environment is competitive, I still want to focus on helping people. In some ways I'm quite idealistic. I know the world is imperfect, but I guess it's good to hold on to an ideal in order to improve it. If you believe in what you want to do, then you need to retain the commitment, focus and motivation to do it. I feel that in my role as a scientist and a lecturer, I can potentially make a difference to society through my research and the students I teach. This is what makes my job satisfying. 


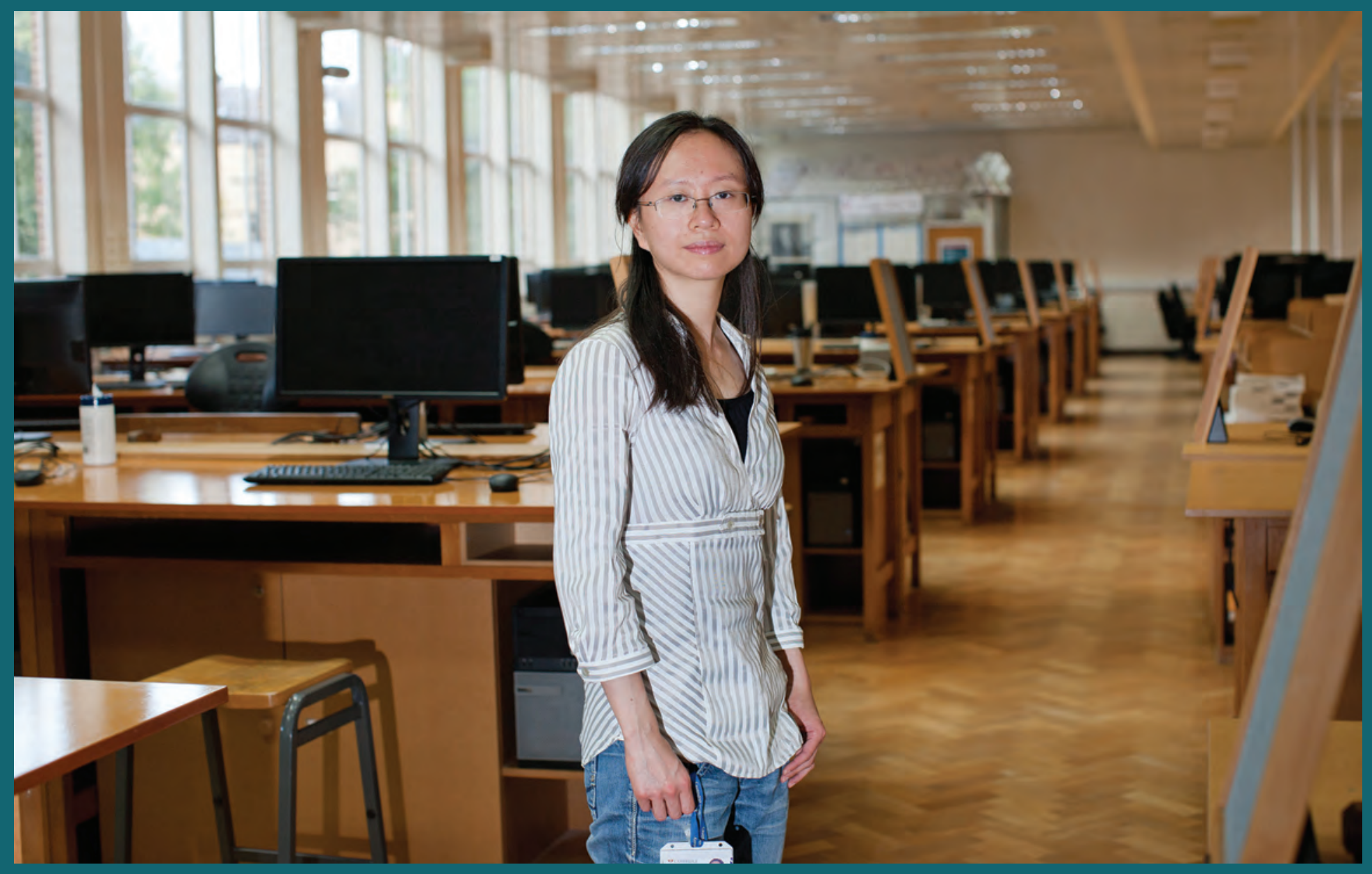

"When I become more senior, I shall try to hold on to my core values. " 
Sport has always been integral to my life and it's a core part of my identity. I love a challenge, but l'm probably more competitive with myself than with other people.

I want to see how far I can push myself. Winning is obviously an important part of sport, but you can't always be the best and you won't always win. If you rely on winning as your only goal then you're going to fail. Recently I did a twenty-four-hour race. I was never going to win, but that wasn't why I entered. I pushed myself to the absolute limit and overcame all the inner doubts, as well as a significant amount of pain, to reach my $100 \mathrm{~km}$ target.

I think success comes from having the right underlying process. If you look at the new Sports Centre, it's been a huge team effort. There's a natural tension between the architects, the users and the builders, so you have to engage everyone to make it work. There's also the operational team to consider; if you have a beautiful building but the staff aren't motivated, you've failed.

Success is a collective endeavour and is based on getting the right mix of people in a team. The Sports Centre staff is made up of really different characters with very varied skills and experiences, but that's what makes it work. To take a sporting analogy, if you have a team full of strikers, you will score lots of goals, but you'll also let plenty in. And if you have an excess of defenders then no one is ever going to score, so it's about getting the balance right. I genuinely value everyone's contribution to the organisation and try to make sure people know how important they are.

"Success is a collective endeavour and is based on getting the right mix of people in a team."

I would feel a bit embarrassed at being described as successful. I am just one of many contributors to a strong and effective team. I am certainly not interested in seeking individual glory. I like to work hard, support and motivate others and feel like I have made a contribution. I've come across a lot of people who talk a very good game but are so busy talking that they haven't really done anything. I want to ask, do you know what your team is doing? Do you know who your staff members are? What have you personally done? I don't want to be the person who can't answer those questions.
The sporting world is full of banter, but it is important to identify when the line has been crossed. Over time I have definitely become more confident in challenging sexist remarks. A witty retort, direct confrontation or a quiet word in someone's ear at a later time are amongst the strategies I've employed. I should like to see more emphasis nationally on how positive sport can be for women. There are far too many girls dropping out of sport in their teens and never coming back. Lifestyle and other interests, of course, play their part but so too do attitudes towards sportswomen and the quality of sporting experiences. If we can focus on delivering excellent sporting sessions for children that emphasise fun, teamwork, inclusiveness and a sense of belonging, we can perhaps challenge outdated attitudes in the process.

"If organisations follow a traditional target- and results-driven approach year-on-year, it can lead to a very narrow definition of success."

When I first arrived at Cambridge I was struck by how much information there was on men's sport and how little was available in relation to women's sport. I'm now working towards a PhD on the topic and hope that this will start to address the imbalance. In 2015, the Women's Boat Race will move to the Tideway and take place on the same day and the same course and in front of the same worldwide television audience as its male counterpart. I think this reflects a slow-burning cultural shift that has seen women's achievements within the University gaining the recognition they deserve.

I don't believe in quotas or positive discrimination. I should like to get a senior post not because I am a woman but because I am the best candidate. It's more about challenging the notion of how we define success in the workplace. Senior management teams and boards need to reflect the diversity of stakeholders and customers regardless of whether the organisation is a university or a FTSE 100 company. If organisations follow a traditional target- and resultsdriven approach year-on-year, it can lead to a very narrow definition of success. Instead, we need to go right back to asking what an organisation is trying to achieve and the kind of people it needs to do it. You then ground your ideas about success on something more relevant and meaningful. 


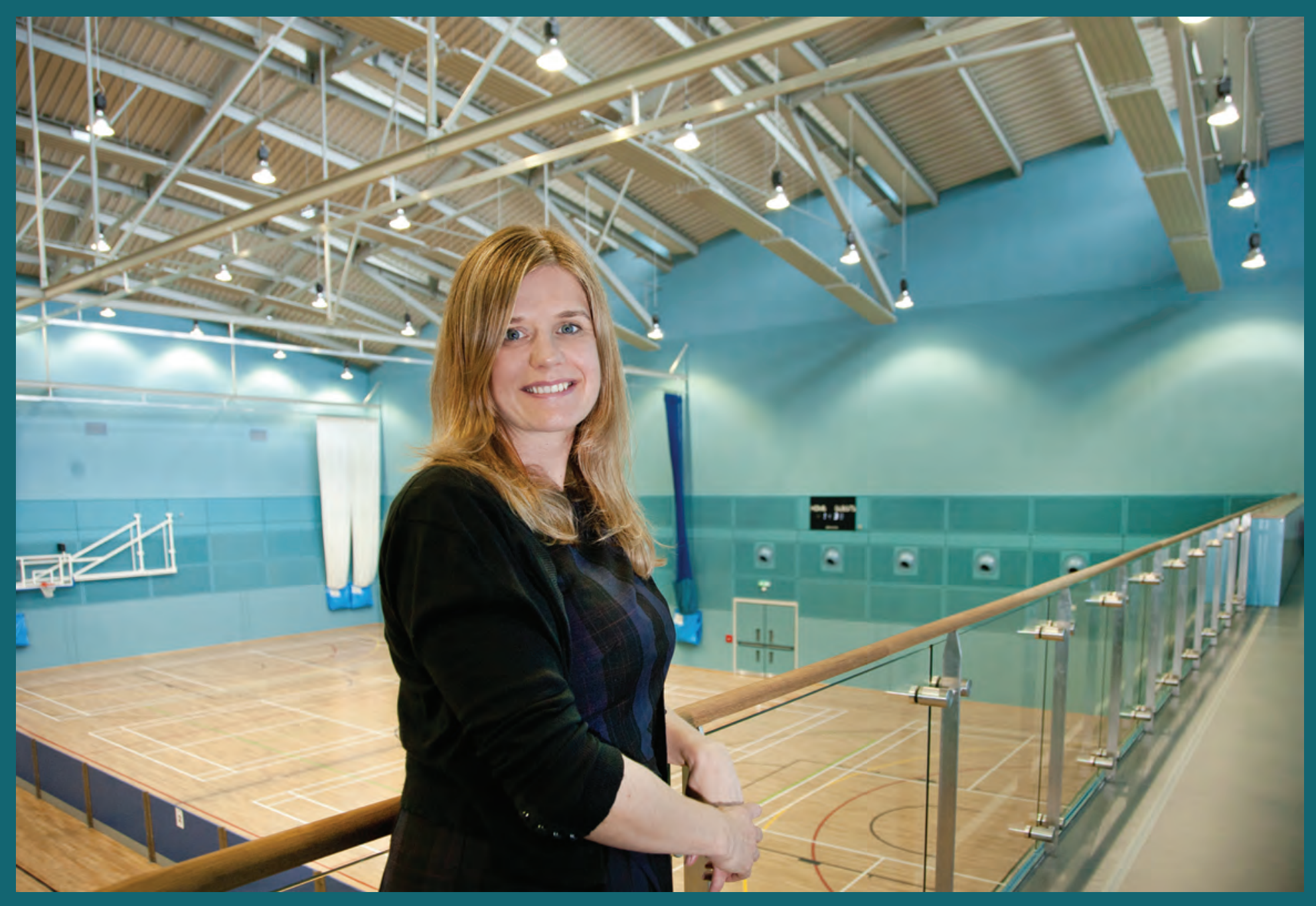

"If you rely on winning as your only goal then you're going to fail." 


\section{Admired qualities and role models}

\section{The term 'role model'}

Being seen as a 'role model' is not a universally appealing prospect. For some it suggests an expectation of perfection, the risk of being put on a precarious pedestal or the possibility of being seen as arrogant. This may explain the reticence expressed by a number of the participants when asked why others might view them as successful. In contrast, they were relaxed and eloquent when invited to talk about the women they saw as admirable or inspiring. As a result, we decided to blend these responses together, so that we could paint a more comprehensive picture of what it means to be a successful female role model.

\section{The inevitability of being seen as a role model}

"Being a woman means I am a role model - like it or not."

Jane Clarke

If there are fewer of you in the workplace, it is an uncomfortable fact that you will be more conspicuous. For women, this heightened visibility tends to increase with seniority, as their numbers diminish. It is therefore somewhat inevitable that people will be watching and making value judgements about how a woman does her job, like it or not. A younger colleague, for example, is likely to be observing her example to pick up clues about how things work and what it takes to get on.

It is also important to note that someone need not be senior to be a role model - in fact it is imperative that role models exist at all levels of an organisation to positively affect its culture. An operational manager, or group leader, is likely to have greater day-to-day impact on those around them than the most senior people in the institution.

To an extent we are all role models, irrespective of intent, on the basis that we exercise influence over others through our behaviour. The women involved in this book are role-modelling types of success just by who they are and how they approach their working lives. Becoming aware of, and accepting, this reality presents an opportunity to become more intentional with the effect we have on others. In essence, the choice is not about whether someone wishes to be a role model or not, but rather about what kind of role model they want to be.
And of course it's not just women who influence other women. Most people tend to work with composite role models, learning from a wide range of individuals that they see as admirable in some way. Although the focus of this chapter is on the qualities of successful female role models, it is important to note that many of the women involved in the book described men as having been some of their most formative and positive influences. A couple of participants were also very clear that they didn't feel that the gender of their role models was relevant to them in any way.

"I have to say that most of my role models have been men!"

Fiona Karet

\section{The qualities associated with successful female role models}

The summary of role-model qualities with illustrative quotes seen on the following page is based on the attributes that the women in the book valued most either in themselves or in the people that they admired. It therefore signposts those qualities likely to be appreciated by colleagues, whilst also signalling the behaviours most clearly linked with the definition of success that is emerging from this book. These qualities, presented in no particular order of priority, are not however intended to form a shopping list, which requires every item to be ticked off before a person can be judged to be successful. Instead, it can help individuals and organisations think about the qualities they value most highly and how they can create the conditions to make them commonplace. Inevitably - and reassuringly - there are also significant overlaps with trends and themes you have already seen emerging in previous chapters. 


\section{Role-model quality}

\section{Integrity}

Demonstrates self-awareness with insight into their own values, sticks to principles, consistent, kind and courteous.

Track record of honesty and fair treatment of others.

Does the right thing even when it's not popular.

\section{Relationship-focused}

Strong interpersonal skills, empathetic, with the ability to communicate well.

Good connectors and collaborators, able to engage others, often using humour and enthusiasm.

Generous in supporting and developing people.

Prioritises relationships and makes time for them.

\section{Authority and leadership}

Influential change-maker, able to challenge the status quo as well as to be diplomatic.

Authoritative and responsible, with capacity to inspire respect from colleagues - both male and female.

Politically astute, calm under pressure and willing to make tough calls when needed.

\section{Inclusive}

Proactive, visible advocate for more inclusive workplaces.

Exercises influence and demonstrates commitment to gender equality.

Puts time into supporting women and encouraging their development.

Invested in progressing broader diversity matters beyond gender.

\section{Illustrative quotes}

"I certainly don't play power games, but this hasn't prevented me from doing well in my field."

Margaret Robinson

"Be authentic, summon support, find like-minded others, do what you believe in, trust your instincts, take up offers of intellectual and other support/friendship, never compromise your basic values or identity."

Alison Liebling

"My students like me because no question is too stupid to ask, and I support the notion that there is no shame in getting things wrong."

Rebecca Simmons

"She always cared about more than just the professional me."

Nathalie Walker

"( $\mathrm{I}$ am) ready to listen to various sides of the argument, but also to make firm decisions. I try not to 'pull rank' but to take responsibility where it falls to me."

Judith Lieu

"An inspiring leader who commands respect in a male environment without either losing, or playing upon, her femininity."

Ruchi Sinnatamby

"I am particularly proud of being a role model not only for women, but also for mature students."

Patricia Fara

"Gender issues matter a lot to me, and l've wanted to play a role in related work in the University."

Emma Wilson 


\section{Role-model quality}

\section{Pioneering}

Pushes the boundaries and makes new ground, a 'first' of some kind.

Inspirational in showing the way and proving what's possible especially (but not exclusively) for women.

Demonstrates different routes to becoming successful and from a range of backgrounds.

Does things differently, able to take risks.

\section{Accessible and fallible}

Demonstrates range of human strengths and weaknesses, open about imperfections, willing to learn and grow.

A realistic and accessible role model for others, 'ordinarily extraordinary'.

Influential and helps to set the organisational tone, irrespective of seniority.

\section{High-quality work and attitude}

Known for producing top work that has significant impact on their area - whether locally focused or with global reach.

Determined work ethic, highly competent with ability to prioritise.

Enthusiasm for their subject; has the imagination and creativity to see things differently and solve problems.

\section{Rounded}

Manages to effectively integrate personal and professional aspects of life.

Able to accept when 'good enough' is sufficient to make it work, ensures they make time for family and friends.

Has outside interests, which may include physical, intellectual, community and creative pursuits.

\section{Illustrative quotes}

"I still find myself in places where one can be forgiven for thinking women have yet to be invented. Pointing this out - with grace and humour, but more importantly attempting to remedy it - is just one small example of the many interventions that senior academic women can make in working towards a 50:50 society."

Theresa Marteau

"I've very often been the only woman on committees etc. Chairmen vary enormously in how they regard me. In some cases I was clearly a nuisance. It often feels that I need to be twice as good to make the same impact as the next bloke."

Claire Barlow

"Often it is women of a similar age to myself who inspire me, and help me to feel that the inevitable corners I cut on both fronts (work and home) are understandable and justified." Rosanna Omitowoju

"I want to show my children that anything is possible if you work hard enough for it."

Suzie Stoodley

"I find her success in world-class science is an inspiration. The fact that she has done this without acquiring masculine traits and a ruthless attitude is even more impressive."

Jane Goodall

"I do not simply accept the status quo: I often try to improve systems, restructure the department etc."

Sarah Smith

"I admire them for being professional about their work, whether they are researchers, computer officers, academic staff or administrators and technicians. I admire them for their commitment to finding a good work-life balance so that they can approach their work with energy, determination and enjoyment, but also find time for the things that motivate them outside their work, whether that be music, travel, sport or family."

Rachel Fogg

"Some of my best ideas come to me in the middle of Jazzercise or karate! Being around my children helps me put a better perspective on life - so a disastrous day at work where nothing has worked is quickly forgotten about. This keeps me fresh for the next day!"

Jennifer Hirst 


\section{Role-model quality}

\section{Confident and authentic}

True to themselves, who they are and what they stand for, strong sense of self, at ease with and able to co-exist alongside disparate others.

Clear sense of gender as part of who they are.

Has own voice rather than imitating others.

\section{Resilient}

Tenacious, persistent and can withstand pressure.

Capacity to work with challenging situations and people.

Courage to take a stand and put head above the parapet for important issues.

Able to handle failures and recover from knockbacks.

\section{The 'add-on principle'}

In reviewing the qualities captured in the table above, and considering what it means in practice to be a role model, we were struck by what we have called the 'add-on principle'. This describes the cumulative expectation and repeated use of 'and' that came with seeing someone as admirable. For example, some women were described as academically or professionally brilliant and full of integrity and skilled at making time for their family. This suggests a richness and roundedness in what women valued and saw as successful. They seemed less inclined to view someone as impressive if that person displayed just one of these qualities in abundance, but failed to exhibit any others. Given that we only spoke to women for this book, we are not in a position to say whether men would require a similar breadth of attributes, or whether they would be more comfortable viewing someone as successful based on the strong demonstration of a single aspect. It would be interesting to see if other research could shed a light on any differences between the genders in this regard.

The darker side to the 'add-on principle' is that it suggests someone needs to attain an extraordinarily high standard before being viewed as truly successful. It was also noticeable that participants seemed to be more exacting in applying these criteria to themselves than to others. This streak of perfectionism holds the potential to drive high performance, but when overplayed also risks unhelpful distortions in self-assessment.

\section{Illustrative quotes}

"Women who have been able to be themselves (apparently) and keep their end up politely."

Claire Barlow

"She listens intently, and has such an ability to assimilate and process information, and then to make up her own mind and stick to it."

Alice Benton

"Her bravery in tackling such extreme and offensive sexism on behalf of all women in the public eye."

Liz Hide

"Knowing my brief, listening carefully, seeking collaboration, harvesting support and having resilience and courage to do the difficult things when necessary."

Carol Black

\section{The value of role models}

There is something fundamentally generous about a person accepting that they are a role model. In effect, they are seeing that their influence can extend beyond themselves and their own careers to impact on others. But role modelling is as much an exercise in organisational commitment as it is a matter of individual effort. If role models have the potential to signpost the way to a more inclusive future culture, whilst also having a positive impact on the current one, then how can organisations take best advantage of this? They need to think hard about who they typically see as role models, why and whether they are sending the right messages by the way they hold up particular people as success stories. Role models who are given profile and visibility are great indicators of who an organisation values most - and this can provide a kind of institutional audit of the range and diversity of individuals who are viewed as successful. If this range is too narrow, focuses just on the most senior, concentrates on one group over another or indeed lacks sufficient women, then there is room for progress and an insight into where that needs to take place. Ultimately, role models of the kind found in this book can inspire, embody and accelerate change - so any organisation would do well to find them and give them a platform. 
Professor of French Literature and the Visual Arts, Emma Wilson has been a member of the Department since 1993, including four years as Head of Department. She has been a Fellow of Corpus Christi since 1995, and since 2011 she has also been Course Director of the MPhil in Screen Media and Cultures. Emma has research interests in film, gender and sexuality.

For a while I wanted to be an actress before selfconsciousness hit in my teens. Then I discovered that I could be an academic.

I think perhaps because I've always had a strong relationship with my mother, perhaps because I was at an all-girls' school, perhaps simply through my interests, my love of women writers like Colette, and my sexuality: these were all things that made me feel that women could be as successful as men.

I was also lucky in terms of my generation and because I grew up in a family that very much recognised the women's movement and feminism. At home there was always a sense of the importance of women's achievement. My mother collected books by Virginia Woolf, Jean Rhys, Katherine Mansfield and many others. This affected what I could aspire to be as a woman, as well as the research questions that continue to interest me now.

Getting a place to study at Cambridge really marked a transition for me. It enabled me to flourish. When I came to look round Newnham I fell in love with the buildings, the atmosphere, the gardens and the sense of all these incredibly intelligent young women studying in this space. l'd always loved the poetry of Sylvia Plath, and the opportunity to study at the same college where she had studied meant a huge amount to me. I think that Cambridge carries that sense of wonderment when you're a first-year student.

"Success has come through a passion for my subject and a real sense that what I'm doing is what l'd want to be doing, in both work time and leisure time."

Since then I suppose success has come through a passion for my subject and a real sense that what l'm doing is what l'd want to be doing, in both work time and leisure time. I've had the opportunity to write on modern French literature, French art and world cinema. These things engage me totally.

Doing well in a degree or being promoted only really means something to me because I love the subject. I think seniority and academic recognition matter in terms of the freedom and possibility that come with them, though. I feel empowered to pursue the research topics that interest me most. And I feel that I can play a role within the University, say in relation to gender or graduate studies. Recognition makes a difference not just because it is an asset to me but because of what I can do with it.

How do I feel about being seen as a role model? I find it a joy! I'm certainly not a flawless role model. But if some younger women think, 'I can be an academic and I don't have to fit the mould and I can do more creative work or I can make these choices' because they see me, then I'm absolutely thrilled. It's always been incredibly important to me to be taught by very gifted women academics, to read their work and to see the ways women are changing academia. I'm in a department which has a good gender balance and where there have been several female professors of French before me. That helps considerably.

"It's always been incredibly important to me to be taught by very gifted women academics, to read their work and to see the ways women are changing academia."

I love the opportunity of supervising people and finding ways of enthusing them. I love the sense of possibility that comes from hearing someone's ideas and responding to them. Academia can be a competitive, driven environment, and everyone experiences doubts that can hold them back. At those points it can really help to have someone encouraging you to hold your nerve and believing in you. I was extraordinarily inspired and helped to move forwards by wonderful teachers - women and men - when I was a student, and I think there's a sense in which to be successful is to be able to help others to move forwards. Playing a role in enabling other people's progression gives something to me - there's a reciprocity to it.

I was the first in my family to go to university, and perhaps because of this, equality, diversity and visibility in the broadest sense matter to me. When I experienced inhibition it was in relation to class rather than gender, so I see gender as working within rather than separately from a whole spectrum of different identity positions. It's also important to recognise the diverse ways people are living in the University. I don't have children, I choose to live alone and I have an alternative sort of lifestyle. It matters to me that Cambridge in the main values people regardless of their gender or any other aspects of diversity. It's an enlightened and open-minded workplace and somewhere where I feel valued and I hope other people like me can feel valued too. 


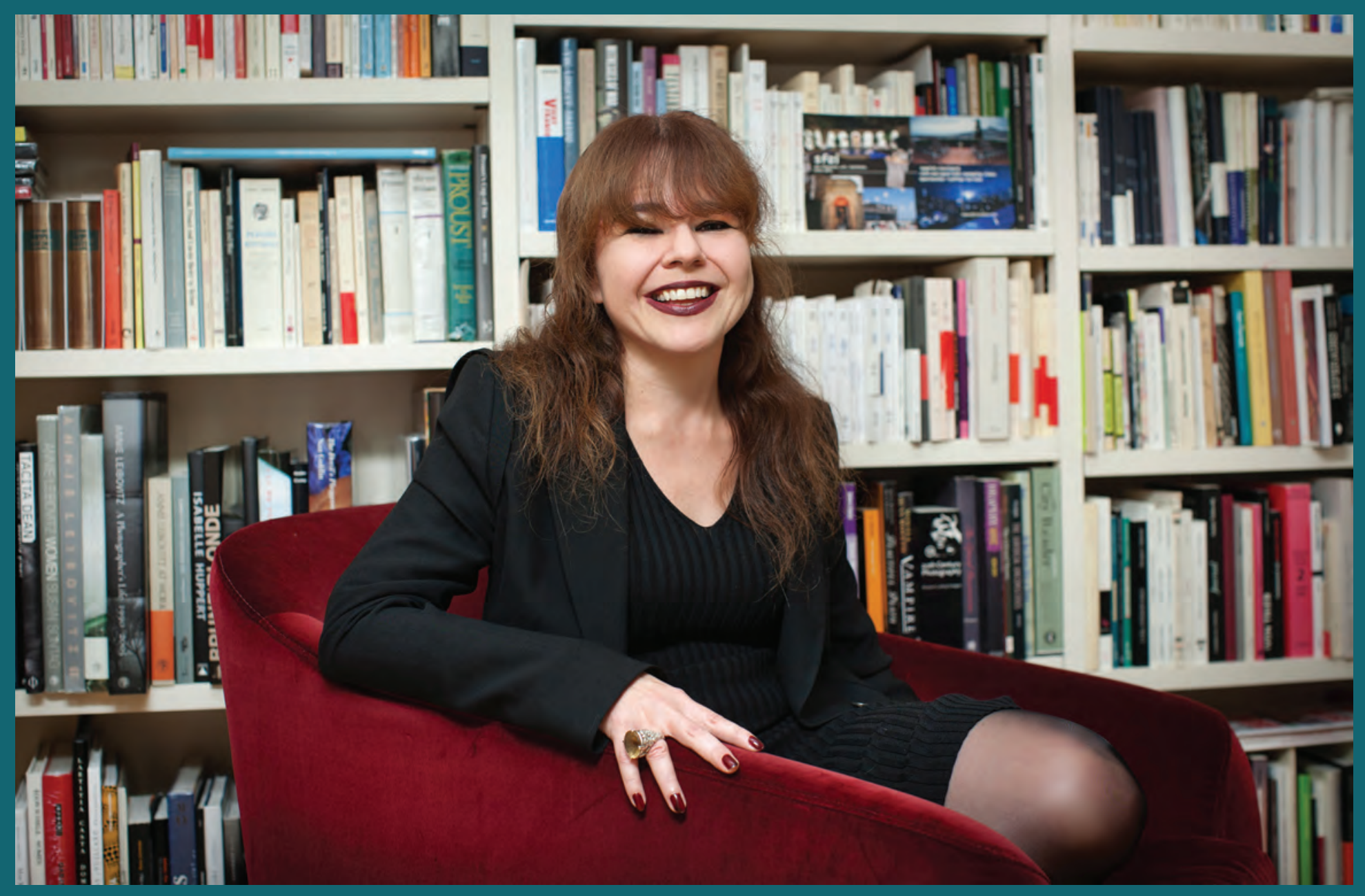

"I was the first in my family to go to university, and perhaps because of this, equality, diversity and visibility in the broadest sense matter to me." 
Joanna Cheffins

A graduate of the University and Joint Head of the Legal

Services Office, Jo practised law in the UK and Canada

before establishing the University's first ever in-house

legal service with job-share partner Helen Jackson.

I very much agree with the notion that 'success' has a million definitions.

When I first started out in law, I saw success as becoming a partner in a large law firm. Since then I have come to understand that relatively small deviations from Plan A can lead to opportunities that bring with them fulfilment in all sorts of different forms. My rather contorted career path has led me to a job that I find hugely stimulating and rewarding but would never have envisaged when I set out. Sharing that job with Helen has meant that balancing work and family life, although challenging at times, is actually possible.

Having qualified as a solicitor in England, I married a Canadian academic at a point in our lives when his career was more settled than mine. It was clear that if one of us was going to move, it was going to be me. At first I found it hard to settle in Canada, rather resenting having to requalify as a lawyer there and having to start my career all over again. But it didn't take long, once l'd cleared that hurdle, to start to enjoy myself. I was working in a completely different legal environment but it was a chance to look at things afresh and try something new. It was a very good lesson in understanding that change can bring opportunities that ought to be grasped.

As a result, I was much more open to the prospect of taking up an administrative role at the University when we returned to England. Shortly afterwards I became the head of the University's first in-house group of lawyers. I first met Helen when she came in as my maternity cover. As l'd hoped, Helen was interested in carrying on when I returned. Our boss suggested we share the job so we gave it a go. That was over ten years ago. Since then, the Legal Services Office has gone from strength to strength. We have a great team of really committed lawyers, handling a huge variety of legal issues on behalf of the University - everything from licensing the television rights to research on meerkats to assisting with a $£ 350$ million public bond issue.

Our job share works well for lots of reasons. Whilst we each have different skills, we both have a fairly pragmatic attitude to the job. We try to concentrate on how best to resolve a situation, rather than just giving pure legal advice. In terms of the added value to the University, I think we give a more complete answer to a problem by thinking through how the other one might approach it. We communicate well and put a lot of effort into coming across as

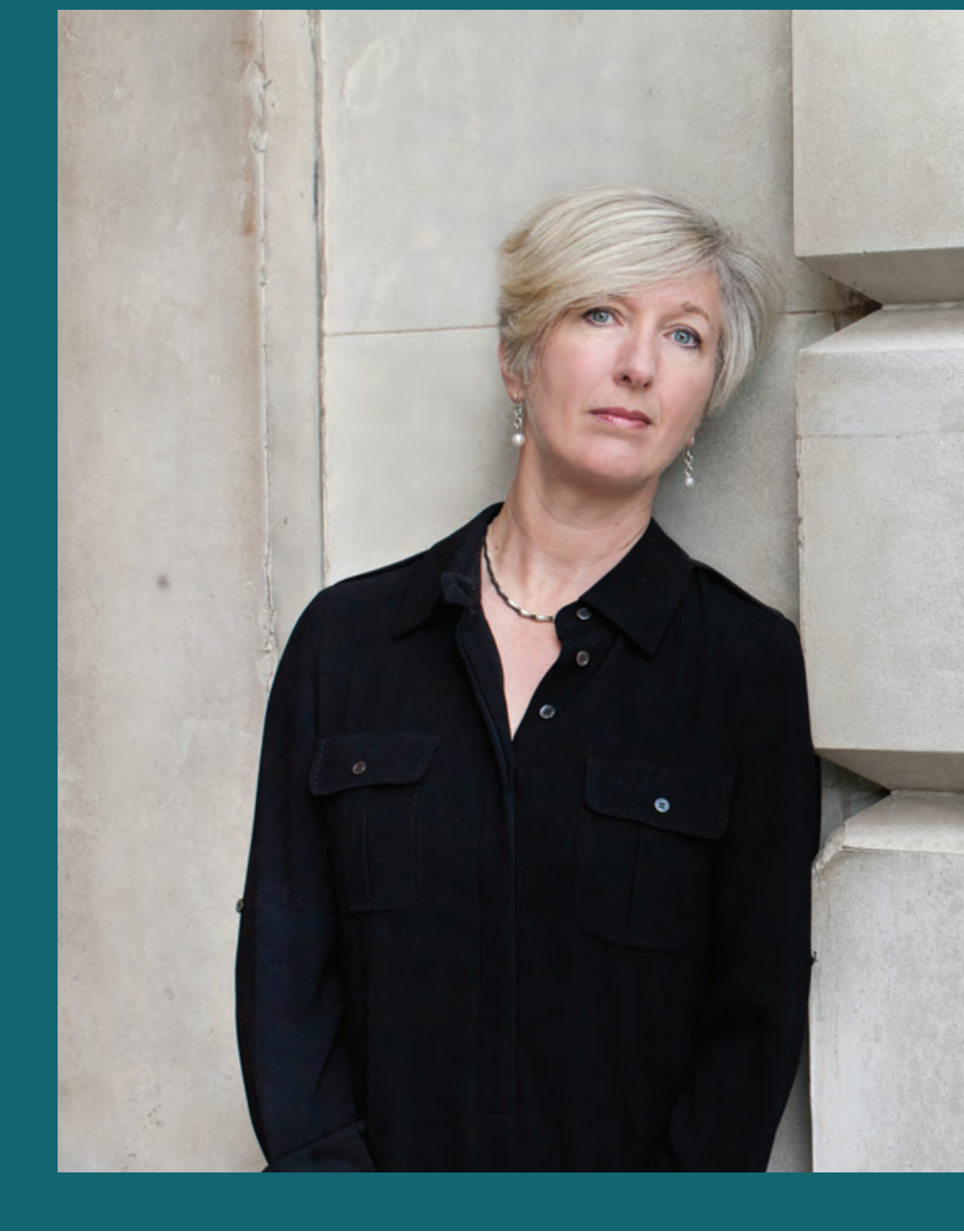

seamless. On top of that we have a lot of fun together. For me, it's essential to work with people you respect, trust and enjoy being with.

"In this environment it's very easy to measure women's success by what label they have on them."

My first reaction to being nominated for this project was great amusement, and then I was really pleased. In this environment it's very easy to measure women's success by what label they have on them. Does she have a PhD? Is she a professor? The University is rightly famous for the outstanding quality of its academics but an effective administration to support them is essential, so I was really pleased to see that acknowledged. We all add value to the organisation in our own way.

If I were trying to sell the advantages of my current position to an earlier self, l'd say that our job-share arrangement has allowed me to carry out a very fulfilling senior role whilst being far more involved with my family than if I were trying to go it alone. I would probably tell my twenty-five-year-old self not to be afraid to make changes that don't obviously fit with your preconceived ideas of success; those changes can bring their own opportunities if you let them. And women shouldn't feel that they haven't succeeded if they are aiming for a life that has a bit of everything in it. 


\section{Helen Jackson}

A Cambridge graduate, Helen has job-shared as Joint Head of the University's Legal Services Office for over ten years. Her experience as a solicitor includes work in the City and with a multinational electronics company.

After a brief career break, I took another risk covering Jo's role as Head of Legal Services. I loved it but found it too big a commitment at that stage. I knew that when Jo came back, the options were job sharing or nothing for me. I'd only met Jo twice but she persuaded me that it would be fine, and could even be fun, which fortunately turned out to be true!

Job sharing, if it works and your employer is open to it, can offer a (more than) full-time solution for a role, with the not-inconsiderable bonus of the breadth of skills and experience that two people bring. There's a lot to commend it. In our role, what's most important to me is not just providing an effective legal service but also that you see tangible improvements in the institution. And it's not just about the keynote things that people notice, it's about the small things that over time make a bigger cultural difference.

"Job sharing, if it works and your employer is open to it, can offer a (more than) full-time solution for a role"

I was brought up in Belfast, which is a wonderful place in many ways. However, the Troubles started when I was eight, and by eighteen I was absolutely ready to experience life somewhere else. Coming to Cambridge to study law presented an ideal opportunity to broaden my horizons.

That led to training as a solicitor in London, after which I hoped to join a nice middle-ranking firm suitable for a girl from Northern Ireland who'd scraped into Cambridge. My husband pushed me to set my sights higher. His attitude was, why not apply for the best possible jobs and see what happens? I very uncertainly approached a top City firm which was then quite small and full of very sparky people, and was astonished to be offered a job.

The nineties saw me returning to Cambridge, commuting to my job in the City - I was doing well but acutely conscious that I could see no way of combining that role with the sort of family life I wanted. The recession meant no law firms were recruiting; I took a risk and accepted the only job going, as an in-house lawyer in an electronics company. It was an enjoyable but extraordinarily male environment at that time; I really did find that the best way to get my point across sometimes was to prime a male colleague to repeat it five minutes later. But the main thing for me was to get my point across. Over nine years there I came to love the strategic involvement of being in-house.

In terms of 'what does success look like', for me, the primary objective was to bring up my children. I wanted to be around to offer them a stable and loving home where they could grow into the remarkable individuals I now know them to be. A successful career that compromised that would not have represented success for me. The last decade has been hard work on all fronts, with a workstation in the kitchen and many late nights over my email. At the time I felt I was just about 'getting away with it', but actually I look at my children who are, I hope, happy, kind and competent members of society, and at the regard with which our legal team is held, the fact that Jo and I are upright, still the best of friends and still married to the same husbands, and feel we have achieved more than we could ever have expected.

To my twenty-five-year-old self I would say that I have never adhered to any career plan I ever attempted to make, I followed my nose and worked very hard to do the best job I could on all fronts. The real surprise is that, at fifty-two, not only am I doing a job which I find really satisfying, but I still feel there is plenty of career to be had, and everything to play for! 


\begin{abstract}
Dr Rebecca Simmons is a Senior Investigator Scientist and Deputy Group Leader at the Medical Research Council Epidemiology Unit. Inspired after a summer working on a Native American reservation, she completed a $\mathrm{PhD}$ in diabetes prevention at Cambridge and has continued her career here.
\end{abstract}

On one level I understand that I'm a successful woman, but I've not fully grown into my success yet. I don't totally embrace it and I can see that I'm definitely a work in progress. But it's not something l'm beating myself up about; it's simply where l'm at right now.

I'm really proud of my working-class background. It defined where I started and still defines me to some extent. My father is an electrical engineer in a factory, and my mum worked at a playgroup. She then went to university in her mid thirties to train as a teacher and was the first person in our family to get a degree. She's incredibly approachable, but she's also got an inner steel and a work ethic that I really admire.

I think my parents are astonished on a daily basis that I work at the University of Cambridge, and to be honest they don't have much of a clue about my job. When they heard that my college fellowship came with ten free meals a week their comment was, 'Never leave, Rebecca, free food and all that cheap white wine too.' Well they haven't tasted the wine! They would be nervous about me risking any of that security. I'm also earning more than they earn, and that makes me feel deeply uncomfortable. I'm still struggling a bit with embracing how far l've come.

Cambridge can be a very inspiring place to be a woman. I'm in an all-women's college, so I see lots of examples of successful women at the top of their game. But in the medical field most of the senior people are men. It can be quite a macho alpha-male culture, so I try to be the opposite of that with my own team by being open and approachable. My staff and students know that it's okay to get things wrong and to ask stupid questions. I'm also aware that the numbers of senior women drop when they have families, limiting the role models we have around us, and I think things could be done to make it easier. I've worked in Denmark and they've got a much better system with parental leave and childcare.

"Cambridge can be a very inspiring place to be a woman."
On a personal level I'm clear that I don't want kids and I don't want to get married. My life is busy and I'm having way too much fun to sacrifice my spare time. I know that sounds really casual but actually it isn't; it's a clear choice. I think women who manage kids and have a career are amazing, but I know it's not for me.

I don't claim to have everything all sorted, but l'm pretty stable and people tend to come to me for help. It can be a tough world, so if you can make anyone's life just a little bit easier, that to me is a successful way of being. I'm very close to people who have had to deal with mental illness and depression. They know they can always come to me and I'm never going to turn around and say 'No', or 'I'm too tired'. It's very important to me that I have a job which means I can still be available for those I care about.

"I think women who manage kids and have a career are amazing, but I know it's not for me."

At the moment I'm a Deputy Group Leader in the MRC Epidemiology Unit. I love science because it gives me the opportunity to play with numbers and words and try to help improve human health at the same time. But, I have the appetite to take on more over time. I'm not interested in earning lots of money and ultimately l'd like to run a small charity, an NGO, or perhaps go into university administration. I'm efficient; I don't procrastinate; I delegate and know when to say no, so I think a complex organisational role would come naturally to me. I've learnt to concentrate on finding a niche where my skills can really shine. I know that I'm not someone who comes up with the big original questions about science, and I'm comfortable with that limitation. I recognise that I have other strengths, particularly in team working, and I play to those.

I tend not to worry too much about what people think about me, and I'm very comfortable with my own company. I do think you've got to be at ease with yourself before you can be in a meaningful relationship or help others. I guess in some ways I'm quite alternative. I don't wear a badge declaring my differences to the world, but I think it's important to try not to make judgements about people who don't fit a traditional mould. I just want people to be happy with who they are, and I try to live by that standard myself. I'm not gratuitously non-conformist but I do value difference and diversity. 


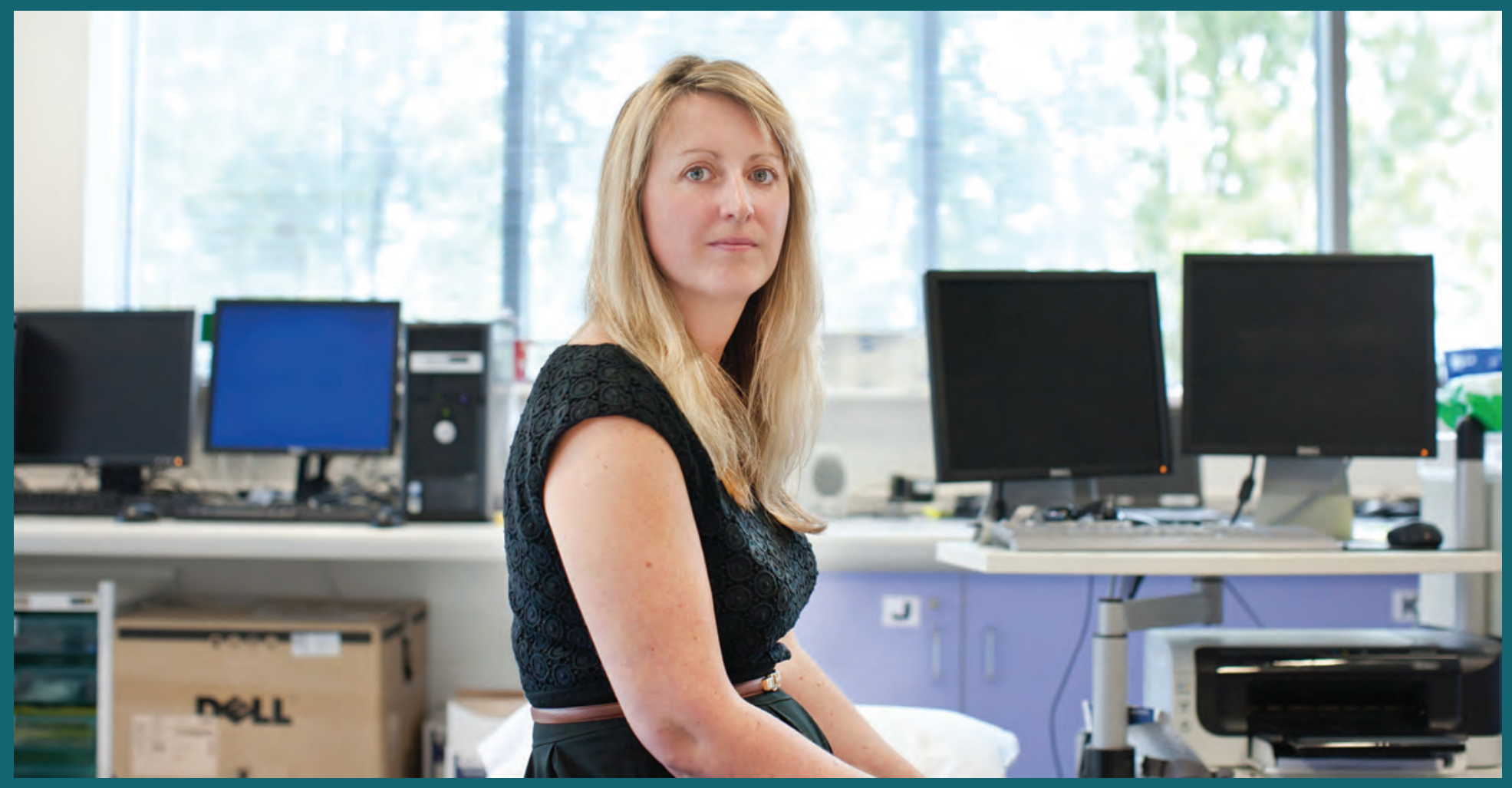

"I don't wear a badge declaring my differences to the world, but I think it's important to try not to make judgements about people who don't fit a traditional mould." 
Dr Kate Pretty CBE was Principal of Homerton and Chair of the Faculty of Human, Social and Political Science until her retirement in September 2013. As one of the University's five Pro-Vice-Chancellors she formerly held special responsibilities for outreach, lifelong learning and international strategy.

From an early age I was accustomed to taking responsibility and was pretty opinionated. My parents were left wing, politically engaged and curious about all aspects of the world. As a child, that sent me a message that you could question the status quo and be interested in almost anything.

I got hooked on archaeology when I was eleven and have never moved away from it. In the West Midlands there was a junior field group led by teenagers, which meant that we were able to get knee deep in running our own excavations whilst still at school. There was this great sense of camaraderie, alongside the immediacy and thrill of discovery.

It's impossible to run an excavation on your own, so archaeology is, by its very nature, a joint enterprise. The bigger the excavation, the more you're learning about what it means to lead or be part of a team. It's a great training ground, and I would guess that a disproportionate number of people with my background end up with senior roles in academia. Archaeology lends itself to a collaborative style of leadership, so I don't have a need to be out in front telling people what to do, or getting all the glory for a project. I take a lot of pleasure in others' achievements and the success of the project as a whole. Personally, the trappings of success have never bothered me, but I don't know whether this has any link to my gender or whether it's just how I'm wired.

I have been surprised to find that I am a natural risk taker. I think I'm somebody who says, 'Why not, sure, let's see whether we could do it', rather than, 'Oh, I don't know about that.' I was instrumental in Homerton becoming the newest college at the University, which meant taking risks to secure the right funding and the right people to make it happen.

"My usual strategy is to approach obstacles like water going round rocks, rather than forging straight ahead."

I also have an instinct for joining things or people up where it makes sense, for example in bringing all the museums together under one governance system. It took me seven years, but it was worth it and it subsequently contributed to the Arts Council giving Cambridge a multimillion-pound grant. Similarly, I have taken great pleasure in extending the University into the community and in setting up the national Young Archaeologists' Club.
Cambridge is a complex institution to try to move, partly because of the interrelationship between the colleges and the University. After forty years of experience, I tend to know which buttons to push, but my understanding of the system came over a long, long period. My usual strategy is to approach obstacles like water going round rocks, rather than forging straight ahead. It's very difficult indeed to get both quick and consensual change, so you need to be able to take a long view. You also have to know when to stick to your guns despite opposition and indeed ridicule.

"There are also a number of people who, for various reasons, make themselves indispensable number twos and never become number one."

It can be hard to be successful here, as it's a very demanding environment. As an academic you have to manage your research, your teaching, your college and your domestic life. As a Chair of a School, I was often in open competition for money and resources with the other Schools, and that brings with it inevitable power struggles. There will be people who falter and never quite get back on track, then there are those who never get out from under the shadow cast by a leading light. There are also a number of people who, for various reasons, make themselves indispensable number twos and never become number one.

You have to understand the game, how power works and how decisions are made. I was impatient with colleagues of my generation who said, 'I can't be bothered with all that decisionmaking and I don't want to spend time on committees.' To me that was opting out of Cambridge's democratic process, and if you don't vote you don't use your voice. There is a constant resentment of 'them', but it would help if people felt they had more influence and took more responsibility.

"I think we need to learn not to belittle or undersell ourselves and start talking about what we can do rather than what we can't." 


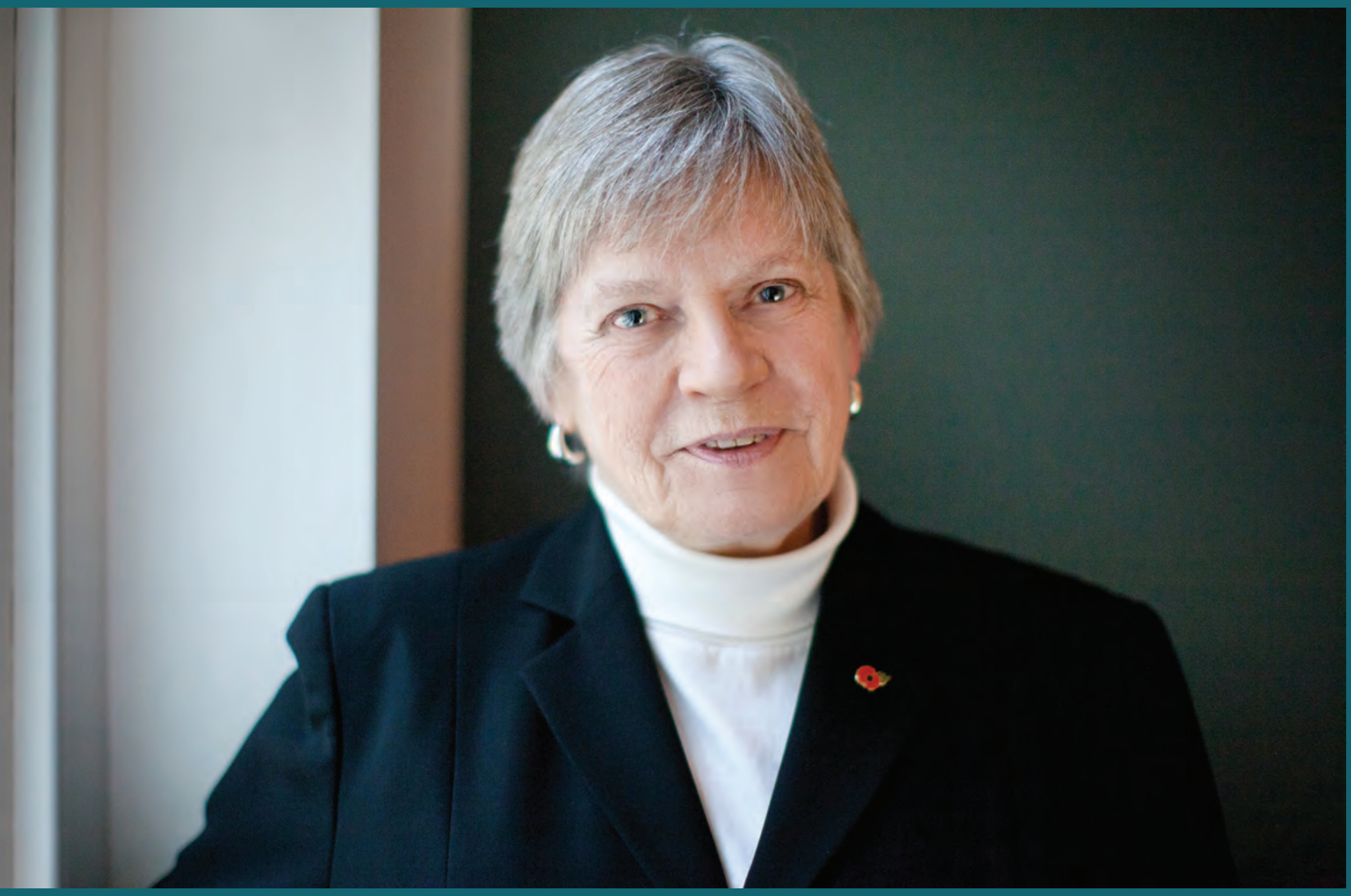

We've had lots of conversations at Homerton about how women can best find their voices and exercise influence. I think we need to learn not to belittle or undersell ourselves and start talking about what we can do rather than what we can't. We also need to secure influential sponsors, sit on committees and take advantage of initiatives like Springboard to develop as leaders. Finding one's own style is intensely personal and time-consuming but nonetheless vital.
Like many people, I don't find it easy to talk about my achievements, but I do know I'm a good chairman and facilitator. I'm good at bringing consensus, getting projects moving, appointing the right people and having a clear view of where something needs to go. I also have the patience to take time when it's needed. I'm good at bringing on colleagues because I think it's important to help to get the next generation moving. Now I'm retired from the University, I am increasingly tempted to apply my skills and experience in other spheres. It would be a bit of a waste not to. 


\section{Advice, insights and learning from experience}

The aim of this chapter is to highlight the advice, insights and learning from experience that women at Cambridge identified as most important. A digest of this sort runs the risk of generalisation, especially when working with such a diverse group of women. But despite the individual nature of each person's contribution, there was no missing the patterns that came through. These ten headlines reflect a strong degree of common understanding about the nature of meaningful success and how to go about achieving it.

The hope is that these insights provide a framework for individuals, or groups, to critically reflect on their own careers. The ten themes are listed below and then explored in more detail throughout the rest of the chapter.

\section{Authenticity and the value of defining success on your own terms}

\section{Shaping your career and taking opportunities}

The importance of challenging barriers and limiting beliefs

Resilience, risk-taking and coping with failure

Continuous learning and the benefit of feedback

Why integrity is vital

The importance of investing in relationships

Having a family and a career

Maintaining a life beyond work

The need for pragmatism

\section{Authenticity and the value of defining success on your own terms}

"Everyone's experience is unique and everyone's style has to be their own."

Isobel Humphrey

Women at Cambridge talked about the vital importance of knowing what you stand for, the values that drive you and the work you are passionate about. This understanding then allows you to align your behaviour and choices with what really matters to you, as well as generate a definition of success that holds meaning. A focus on authenticity helps you to ask deeper questions about the legacy you want to leave and what you want to be known for.

"Life is a balancing act. You need to figure out what is important to you and work everything else around it."

\section{Jennifer Hirst}

More people mentioned this piece of advice than any other, but a cynic may be tempted to dismiss it given the overuse of the term 'authentic' in the media and self-help books. Based on what we heard from participants, this would be a mistake. They made the point that an individual cannot view themselves as successful without understanding the values that underpin such a judgement. They can't realise their talents without knowing what they are. They can't be passionate about their work without having identified and then committed to doing something that excites them. They can't rigorously defend space and time for family and friends without fully appreciating the importance of this. Although authenticity was clearly valued by participants, they also indicated that it was not an easy state to maintain, sometimes leaving them feeling exposed, or subject to criticism. Having the support of family, friends and trusted colleagues can make all the difference in giving you the confidence to pursue an authentic approach to your working life.

"You are unlikely to do your best work if it is chosen for expediency, rather than from passion."

Ann Louise Kinmonth

The women involved in the book seemed to ask questions about authenticity that pushed them to discover their own way of doing things and operated against them imitating others to get by. Workplaces need difference - of opinion, talent, perspective, gender and expertise - and authenticity is the route to realising the value of that difference.

"I have found it important to work out what I am trying to achieve and to aim with quiet determination to make it happen. It is very important not to get lost in the process and lose sight of the goal."

Gillian Griffiths 


\section{Shaping your career and taking opportunities}

"Don't wait to be asked - do what you believe in with a passion and determination, and don't let indifference get in the way."

Polly Courtice

This point could best be summarised as 'instigate, don't wait'. There was a warning against passivity and hoping that someone will just notice the good work you are doing. The women at Cambridge were keen to encourage well-judged risk-taking and an appetite for seeking out, and grabbing, opportunities. There was an underlying recognition that career paths don't follow a pre-ordained route, and require an ability to respond to inevitable changes in circumstance. Whilst some people relied on structured planning and goal-setting, others were comfortable with a more emergent approach, but in both instances there was recognition of the need to take personal responsibility for shaping one's career.

"If you need a new challenge in your life, don't be afraid to change the direction of your career."

Annabel Smith

Finally, there was an encouragement to tell people about yourself and your achievements. This is not an uncomplicated piece of advice given some of the distaste participants expressed about self-aggrandising behaviour. Whilst reward systems may need to evolve, so that the loudest voices don't get a disproportionate amount of attention, there still remains personal responsibility for speaking up. There is value - even necessity - in finding a way of talking positively about oneself, one's team and one's achievements in order to avoid the risk of being overlooked.

"Being self-propelled and interacting with the people around you is more important than waiting for sage advice, since no one will know what is better for you than yourself."

Sharon Peacock

\section{The importance of challenging barriers and limiting beliefs}

"When someone says 'it is impossible to do that', do not believe them but simply prove them wrong."

Helen Mason

Related to the point above is the encouragement not to let your own limiting beliefs, or those of others, stand in the way of the working life you want. Attitudes about what women are capable of, the viability of having a family as well as a career and the effectiveness of women as leaders can all be subject to negative bias.

"Believe in yourself and what you can achieve. Because a man says 'you'll never manage to do that' doesn't make it true."

Helena Earl
It was recognised that parents, school and work environments combine to send messages that either limit aspirations or encourage them. Most people had experienced a blend of both positive and negative reinforcement, so saw the need for developing ways of filtering out and challenging those beliefs that have the potential to sabotage one's career. Simply put, this insight was about not letting others tell you what you can and can't do, but instead developing the capacity to define this for yourself.

"Follow your passion, whatever it may be. Don't listen to the doom merchants and don't give in to pressure to conform to someone else's idea of what you should or should not do/be."

Ottoline Leyser

\section{Resilience, risk-taking and coping with failure}

"Take risks, small ones to start with. Don't be afraid of failure, otherwise you will not achieve anything."

Rachel Fogg

One of the few things that can be guaranteed is that everyone will experience failures in their career - and the women involved in the book were candid about this reality. They underlined the importance of developing the kind of resilience that enabled someone to tolerate setbacks, learn from rejections and be able to move on without wasting too much energy on regret. They also talked about increasing the capacity to be able to handle a negative situation constructively, so that you can plot a way around it or come up with a 'plan B'.

"The best advice I've had in Cambridge was 'hold your nerve'."

Emma Wilson

Whilst it is important to take steps to shape your own career where you can, it was also seen as sensible to be able to acknowledge that, at times, things may be beyond your control, or you may simply make a mistake. In these situations, it is less about what has happened and more about how you handle it.

"If things become too difficult then you need to look at a different strategy, so you need to be open to new ideas."

Jane Goodall

Without the capacity to cope with failure, you won't be in a position to take the kind of risks that could accelerate your career, give you access to the people or opportunities that you might find most stimulating or even help you to maintain your integrity in the face of opposition.

"Try to look forward, rather than back with regret. This is especially important for women, whose careers may have pauses and interruptions."

Carol Black 


\section{Continuous learning and the benefit of feedback}

"Be observant of others around you - watch what people do well, be a magpie learner."

Jessie Monck

Given Cambridge's reputation as a leading academic institution, it is little wonder that the value, and thrill, of learning was very evident. This advice was a reminder to others to savour the learning they experienced, irrespective of the normal daily frustrations associated with doing any job. There was also an encouragement to learn from other people and be inspired by their approach, for example in the way they worked with a team or navigated a tricky situation.

"Accept that you will make mistakes and do not dwell on them; instead, regard them as part of a learning curve."

Sarah Smith

Women at Cambridge talked about the importance of actively seeking out feedback, even if it wasn't always easy to hear. We all have blind spots, talents we may have overlooked or flaws we are unaware of, so it was seen as important to have access to regular, honest feedback. This feedback also needed to come from diverse sources, not just natural allies, and was particularly essential as one became more senior.

"I have valued collaborative work more than anything and the pleasure of learning from others with different skills."

Gillian Murphy

\section{Why integrity is vital}

"Being respected is more important than being popular."

Karen Pearce

Having a well-earned reputation for integrity was viewed as the cornerstone of achieving success with substance and meaning. Whilst many of the women talked about making well-judged compromises in many areas, it was seen as vital not to compromise one's integrity. Integrity manifested itself in everything from the routine behaviours of treating people with decency, irrespective of status, through to knowing when to fight battles of principle or swim against the tide of popular opinion. Integrity meant acting in accordance with one's own values but not in a way that was naive. Many of the women could be seen to be guided by a blend of political awareness and integrity when making their decisions.

"Compromise and diplomacy are important in leadership roles, but never at the expense of integrity. Stand up for your convictions."

Alexandra Walsham
Having integrity wasn't about doing the right thing merely to get on, but doing the right thing based on conviction. That said, integrity did seem to be associated with those women who had achieved significant influence and seniority, so it might be seen to have had some impact on their success. One might assume that the behaviours associated with integrity, such as giving credit where it's due and treating others with courtesy, could also engender loyalty and support.

"Never be rude to people. Appreciate their input and say thank you (frequently) to all those that help you, from the cleaner to the Head of Department."

Abigail Fowden

\section{The importance of investing in relationships}

"The greatest satisfaction comes from interactions - so develop your own mentoring skills, celebrate your team's successes."

Beverley Glover

Women at Cambridge were emphatic that one of the most important ingredients for a successful working life is having a breadth and depth of positive relationships. The interpersonal way in which they conducted their careers is one of the clearest trends in the whole book.

"It is worth taking the extra time to go that bit further to help someone out when they need it. Generosity is its own reward. I would not be where I am if it were not for the people who have given their time, advice and help when I needed it."

Philippa Steele

Despite the reality of heavy workloads, people chose to set aside precious time and energy to nurture important friendships and valuable relationships with colleagues, team members, mentors, sponsors, students and postdocs. There was a clear sense of the mutual benefit that could come from such engagement. People talked about being able to turn to their networks for support and advice, but also about seeing them as a source of fun, ideas, energy, inspiration and collaboration.

"Creating a network of trustworthy colleagues who can also act as mentors brings relief from the relentless competition."

Simone Hochgreb

Many people emphasised the simple pleasure they got from being generous with their own insights, knowledge, labour or skill. Helping others, teaching them or contributing in some way to their progress was integral to being able to view themselves as successful. 


\section{Having a family and a career}

"You don't have to chose between having children and a career - you can have both."

Linda King

Family life means different things to different people, but the comments made about this point specifically related to having children whilst also pursuing a career. Many of the women we spoke to strongly rejected the idea that you could have either a successful career or children but not both. Some flat out refused to accept the premise that this was even a choice, given that being a parent and having a career were both fundamental to their identity.

Having children and a career took many different forms, including part-time work, maternity leave, job sharing, working unusual hours and taking significant career breaks. There wasn't one recipe that suited everyone, but there was a shared belief that it was possible.

"You have to try to enjoy and be good at what you are doing right at the moment, ie enjoy being at the park with the kids, not be stressed that you didn't finish a piece of work."

Rosanna Omitowoju

No one was blasé about how easy this was, and people talked about the need to make compromises, as well as the reality of having periods where they missed out on networking, conferences or travel. Many described the effort and thought that had gone into putting in place the necessary support systems for this situation to be viable. They talked about seeking help when needed and, if possible, finding a partner who was as committed to making this work as they were.

"You CAN do research and have a family. If you decide to go down this route, make sure you have understanding and support in place from your partner/family/childcare etc."

Val Gibson

\section{Maintaining a life beyond work}

"It is important to maintain friendships, interests etc, that take one out of the academic bubble and remind one that there is a larger world out there."

Megan Vaughan

Cambridge can be a very intense and sometimes insular working environment. The women we spoke to were clearly very invested in their jobs but not synonymous with them. They advised making an effort to spend time on other people and other interests beyond Cambridge. This tended not to be about taking up a relaxing hobby but more to do with paying attention to other important parts of one's personality or passions. One person talked about being as proud of their garden as their publications, another described needing to maintain her creativity through photography, whilst a third was an avid traveller. Having this kind of hinterland meant that they could bring a greater sense of perspective to the question of what it meant to be successful.

"Life really is too short. All that matters is being happy and healthy and looking after yourself. You are then in a better position to help others."

Rebecca Simmons

Some women - although interestingly not the majority - also talked about how imperative it was to take care of one's wellbeing. The basics of sleep, exercise and eating well were mentioned, as was maintaining the boundaries necessary to do so.

\section{The need for pragmatism}

"I try to concentrate on what I feel is most important and not to worry too much about things like how my house looks."

Margaret Robinson

This relatively understated but nonetheless powerful insight came up time and time again. It makes the point that unrelenting perfectionism and an inability to know when to compromise have the potential to derail a successful, long-term career. Instead, there was a wise reminder about the importance of knowing when to give yourself a break, to let things go and to accept 'good enough'.

"Like many others, I never have enough time to do things 'properly'. I have learnt to accept that sometimes 'good enough' will do."

Alice Benton

Realism and developing a healthy sense of perspective also helped to differentiate between a major priority and a distraction. It helped to identify which battles to fight, when to say no and when to prepare for playing the long game. Pragmatism was not seen as the enemy of high performance, but rather as a way of concentrating energy on the things that matter most. It also allows for the development of a more constructive and less punitive internal dialogue that recognises human fallibility. Those women with the most experience were particularly emphatic about this piece of advice, maybe as a result of understanding the attritional nature of a long career. Given the high standards exhibited by so many of the participants in the book, this point seemed to be as much a note to themselves as it was a piece of advice to others.

"Remember it's a marathon, not a sprint."

Ann Louise Kinmonth 


\section{Ann Louise Kinmonth}

\section{Fellow and Director of Clinical Studies at St John's College, Ann Louise's research interests include the prevention and management of diabetes and heart disease.}

It felt as if I had to fight to exist as a thinking person. My family life was middle-England and, although I was fortunate in many ways, the education of the women in my family wasn't taken as seriously as that of the men.

While my brother was offered a good education, I was sent to an inferior boarding school. Since then I have always had to push against the notion that men do the serious things and that somehow women are just playing at what they do.

I have often found myself to be the only woman at a table of grey suits and had to learn how to deal with that. Even when I was on the Council of the Academy of Medical Sciences, I remember consciously deepening my voice, in hopes of being better heard. When a man was credited for a comment I had made I wasn't too bothered. I was most interested in getting my point of view incorporated. The purpose of being there was to be part of making something good happen, so actually I was pleased enough.

"It's not about separating women out and doing something different, it's about bringing them in."

My experience of Cambridge is that people are very serious about their work, and if they see that you are too, and that you have something to offer intellectually, you are welcome. In that way it's gender neutral. At the same time we need more bright women coming through and at my college we have been listening to students through an admissions working party which I chair. We heard that these women don't really want special measures, just to be visible along with everybody else. They want to see more senior women walking around the college; images of women up on the walls; for it to be commonplace to hear women speaking in a variety of arenas. It's not about separating women out and doing something different, it's about bringing them in.

My own visibility largely comes from what I have been able to achieve with my work and particular perspective. I am a specialist in Generalism. Throughout my career I have worked as either a Hospital Doctor or a General Practitioner and my academic work is grounded in this broad experience. Specifically, I have addressed research questions about preventive medicine, contributed to developing academic primary care and enabled the career path of young clinical academics in ways that were not available to my generation. This work matters to me and I have a strong legacy commitment. It's good to see how young academics that started out with me, from epidemiology to the social and behavioural sciences, are now running the show. I had no biological children, and in some ways I regard them as my 'academic children'. It is good to see my lines of work taken forward by others and the findings making a difference. I had to learn how to hand over to others and it became easier when I stood down from my chair; part of success is letting go.

I believe that success and failure are so close that perhaps one should not be too excited by either attribution. If I think about my achievements, I suppose what I value most is when I've managed things on my own terms, when I've not compromised my integrity and when l've brought original ideas effectively to the table. Success is perhaps a life well lived, and so when you act you must act absolutely wholeheartedly. If you're wrong it will soon become clear and you can change direction, but it's no good fiddling about at the margins. You are unlikely to do your best work if it is chosen for expediency rather than from passion. As my riding teacher used to say, throw your heart over the jump and the pony won't refuse.

No academic career is a walk in the park and I have had to deal with mine while managing the depression that began when I was a teenager. I have handled this with a mixture of grim determination and a realisation that different moods fit different parts of the research cycle. I declared this illness before I was appointed to my first chair in Southampton and my record of achievement won through. This is part of who I am and my resilience, such as it is, comes from working with that reality.

"I believe that success and failure are so close that perhaps one should not be too excited by either attribution."

There's seldom a moment when I'm not thinking that life is short. I am very interested in and curious about the world. We are lucky to be alive and we should use the time that we have well. When I talk about retirement with my husband we discuss the things we want to do before he or I die. I married relatively late in life and it suits me; with John came five stepchildren and five step-grandchildren. I carefully avoided being the wicked stepmother and being part of this family is an important part of my success. 


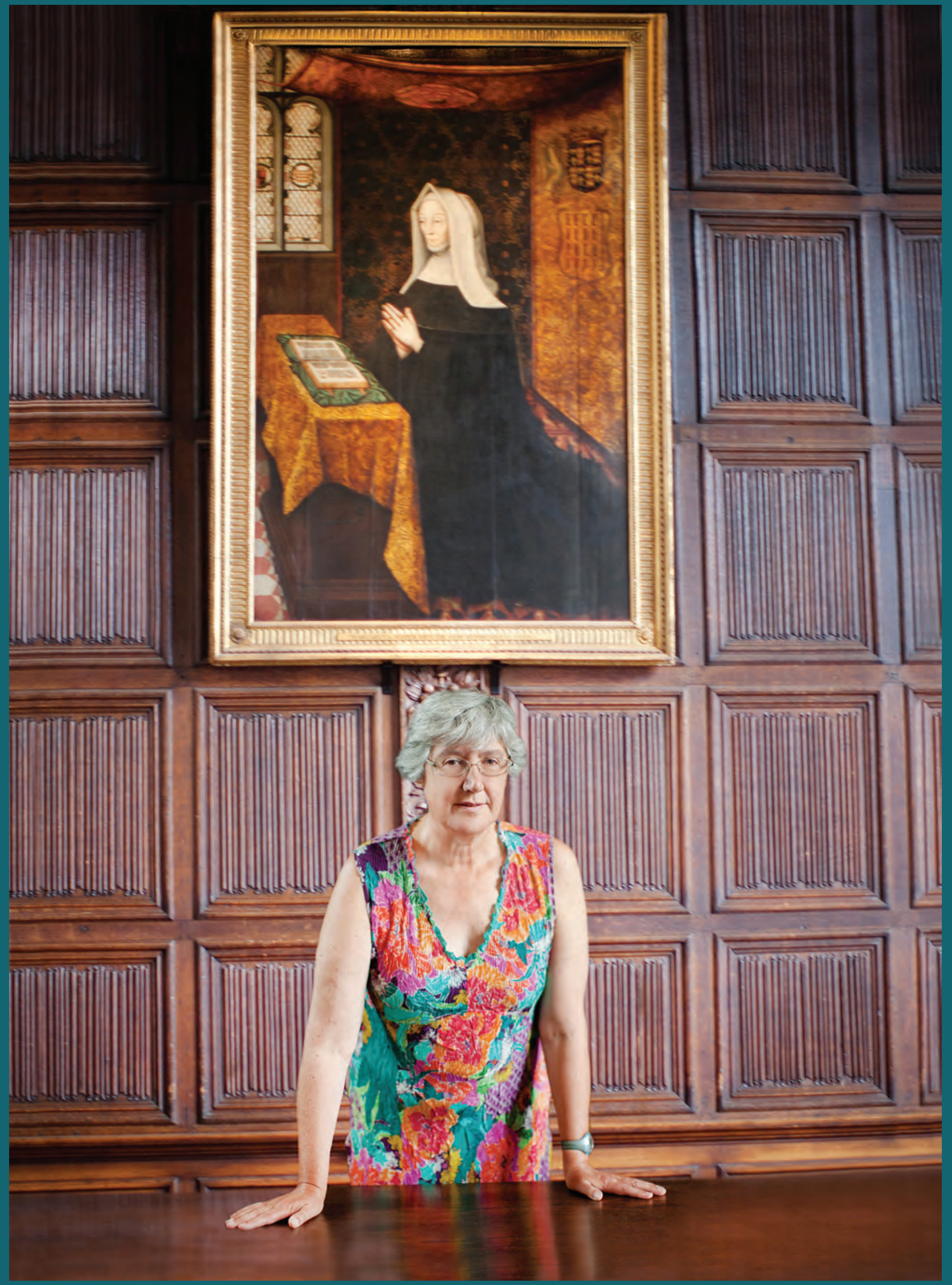


A degree in Modern and Medieval Languages has led Rachel Fogg into a varied career as well as time spent raising a family. Rachel is the Divisional Administrator for the Information Engineering Division, Department of Engineering and PA to the Head of Division.

I was absolutely certain that I wasn't going to be a stay-athome mother; I was going to be a modern woman and go back to work.

Then financial reality hit and I realised that my salary might just about cover childcare for one child, but not three. I decided that if anybody was going to make a mess of bringing up my children, it might as well be me! It meant I had to radically change my mind about what I thought I was going to do.

Success is about working in a way that fulfils the potential you have. I'm a linguist with a degree from Cambridge, and I could have had a career somewhere like the civil service. But I've looked to fulfil my potential in other ways.

"Success is about working in a way that fulfils the potential you have."

It's not necessarily about getting to the top of the tree; it's about using your gifts and aptitudes as best you can in various different environments. For example, I live in a small community and found my place in it by working out how best I could contribute. I became Chair of the School Governors, still run a Brownie group and am part of the choir. I don't want to come across as too pious; I get involved in things that might be seen as worthy, but I do them because they are thoroughly enjoyable and I love being part of something.

Sooner or later in many working partnerships, one of you will have to compromise what you do in order to allow the other to progress professionally. When the children were small my husband had a series of demanding jobs, which meant he had to travel a lot. That can be difficult for both sides of the partnership. For the person left at home with three small children, there's a tonne of stuff to do and you feel under pressure. The flipside was that he missed lots of opportunities to engage with the children when they were younger. It would have been wonderful if we could have been a bit more flexible about how we shared those things.

This would have been more possible if people recognised that efficiency doesn't have to mean working long hours. From a management point of view, it shouldn't matter if people need to work flexibly as long as the work gets done and nobody else is inconvenienced. Changing this sort of perception would have significant implications for women with children, not least because in my experience they're often the ones who make most efficient use of their time. At home they're always doing six things at once, so they just bring that attitude into the workplace.

Anybody who's spent a long time out of the paid workforce, whether male or female, finds it very difficult to come back. I can remember being petrified about returning to work. l'd run my home, been heavily involved in the local school and had a strong sense of my contribution to the village. But you worry it doesn't mean a thing when it comes to what will be valued in the workplace. There is no benchmark to tell you whether you will be more or less skilled than someone else. I ended up taking myself off to get some computer skills and built my confidence through a series of temporary roles that eased me back into the workplace.

I genuinely love coming to work here every day. Engineering is a fascinating place with people working on everything from wind tunnels and jet engines to medical imaging techniques. I get most satisfaction from my working relationships. The academics, postdocs, PhD students and administration team are my people and I care about them. I try to help out with whatever they need at the time and 'yes' tends to be my default response to most requests. I also tend to remember if someone is about to have a baby, submit their thesis or have just got engaged. For me it's about dealing with them as individuals and remembering all the things they have going on in their lives.

"For me it's about dealing with them as individuals and remembering all the things they have going on in their lives."

Although I'm very happy doing what I do, it still has to be said that I am not without ambition. I won't be sitting here forever and l'd quite like to run a small department at some point. In many ways if you're not moving forward you're actually falling back.

I'm astounded to have been nominated to take part in a book that looks at successful women in the University. Typically when people think about success, they think of individuals who've reached the top in their chosen profession, who are very wealthy, or who have some other amazing attribute. But there do need to be ways of recognising people who are good role models of their type. In status terms I'm fairly low in the pecking order, but I must project what other people feel are positive qualities. The French have an expression, 'sentir bien dans sa peau', which means 'to feel good in your own skin'. Maybe that's what makes other people think I'm successful, because I patently enjoy what I do. 


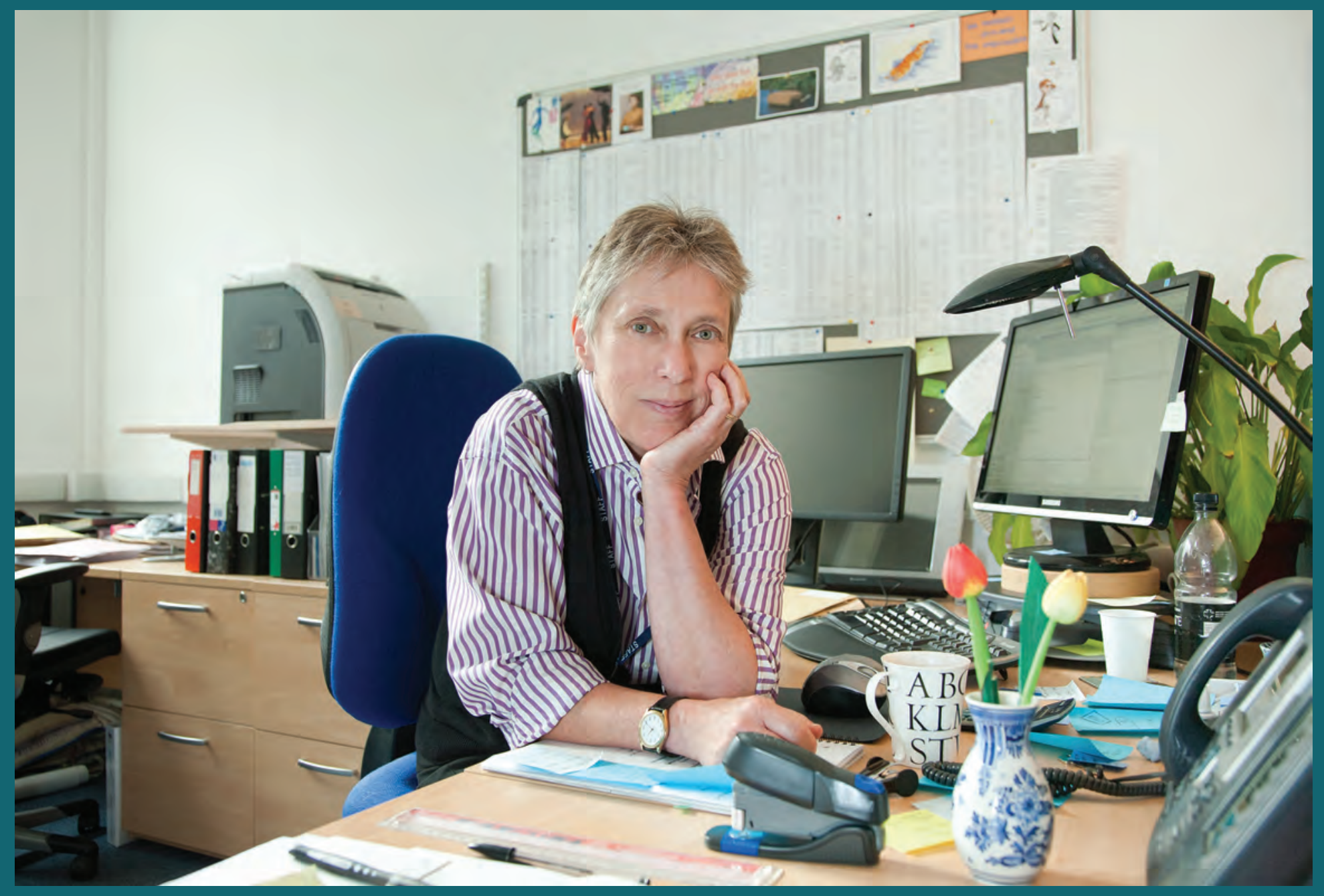

"It's not necessarily about getting to the top of the tree; it's about using your gifts and aptitudes as best you can in various different environments." 
Dr Philippa Steele is a British Academy Postdoctoral Fellow, Affiliated Lecturer in the Faculty of Classics and a Fellow of Magdalene College. She published two books in 2013, an edited volume entitled Syllabic Writing on Cyprus and its Context and a monograph, A Linguistic History of Ancient Cyprus.

As a Classicist, ancient notions of success resonate with me: fame-related words such as Greek kleos and Latin fama are based on verbs of hearing and speaking, and therefore reflect the notion of whether you are spoken about by others.

For me that has to mean more than accumulating noteworthy achievements; it's also about people speaking well of you and describing you as a decent person.

The person who still has the most influence on me is definitely my mother. She was a teacher and helped to inspire my love of history. At the same time she instilled the importance of being generous: with your time, your ideas and your willingness to encourage others. Interacting with people is such an important part of life, and if you don't see it as integral to your own success story, then I think you're missing out.

"Interacting with people is such an important part of life, and if you don't see it as integral to your own success story, then I think you're missing out."

As a Director of Studies it really matters to me that I have a positive impact on the students I'm responsible for. I was a student not so long ago, which makes me very aware of the pressure they're under. They might struggle to learn a language or write an essay, and part of my job is to provide practical support. But I also try to remind them about what they're good at and how hopeless it is to judge themselves by others' standards. They are all very different from one another and have varied ideas about what they want to gain from being at Cambridge, which means that there can't possibly be a universal standard for success.

Most students are at a formative age, where they're learning to be adults, experimenting with how they want to express themselves and deciding what kind of people they want to be. If they're taught by people who appreciate their individuality, it can give them a powerful sense of being accepted. It's the kind of experience that will really matter later on in their lives. I had a wonderful Latin teacher at school who still comes up to Cambridge and takes me out for dinner. He never lets me pay; his view is that people did that for him, and he would rather I passed on that generosity. I want to take the trouble to be there for my students, and to fight their corner when they need me to do so.
"I want to take the trouble to be there for my students, and to fight their corner when they need me to do so."

It's vital to have role models and people who are viewed as successful throughout every level of an organisation. When you come to Cambridge, you meet all sorts of people, and it's not only the famous professor who is going to have an influence on you. In fact, they might be a much more distant figure than the people you have dealings with every day, your fellow students, your tutor or administrators in the faculty. Everyone needs to play their part and the success of the whole system is more important than who is at its pinnacle.

"It's vital to have role models and people who are viewed as successful throughout every level of an organisation."

If being an academic has taught me anything, it's that the work you put in doesn't automatically lead to a tangible outcome, like a great article or lecture. Achievements are worth celebrating but so too is the hard work that may (or sometimes may not) bring them about. The journey itself has intrinsic value; working hard, trying your best and putting the effort in all count for something.

At the same time I still see myself as very career-driven and I love the thrill of being published. The Roman poet Horace said that he could never completely die because he would be remembered through his writing, so there is that sense of a life beyond. I remember the first time I saw my name in print and it was just the most wonderful feeling: it's a physical manifestation of all the hard work you've put in, usually over years. It's a tangible achievement and one that I will be measured by as an academic.

"Achievements are worth celebrating but so too is the hard work that may (or sometimes may not) bring them about." 


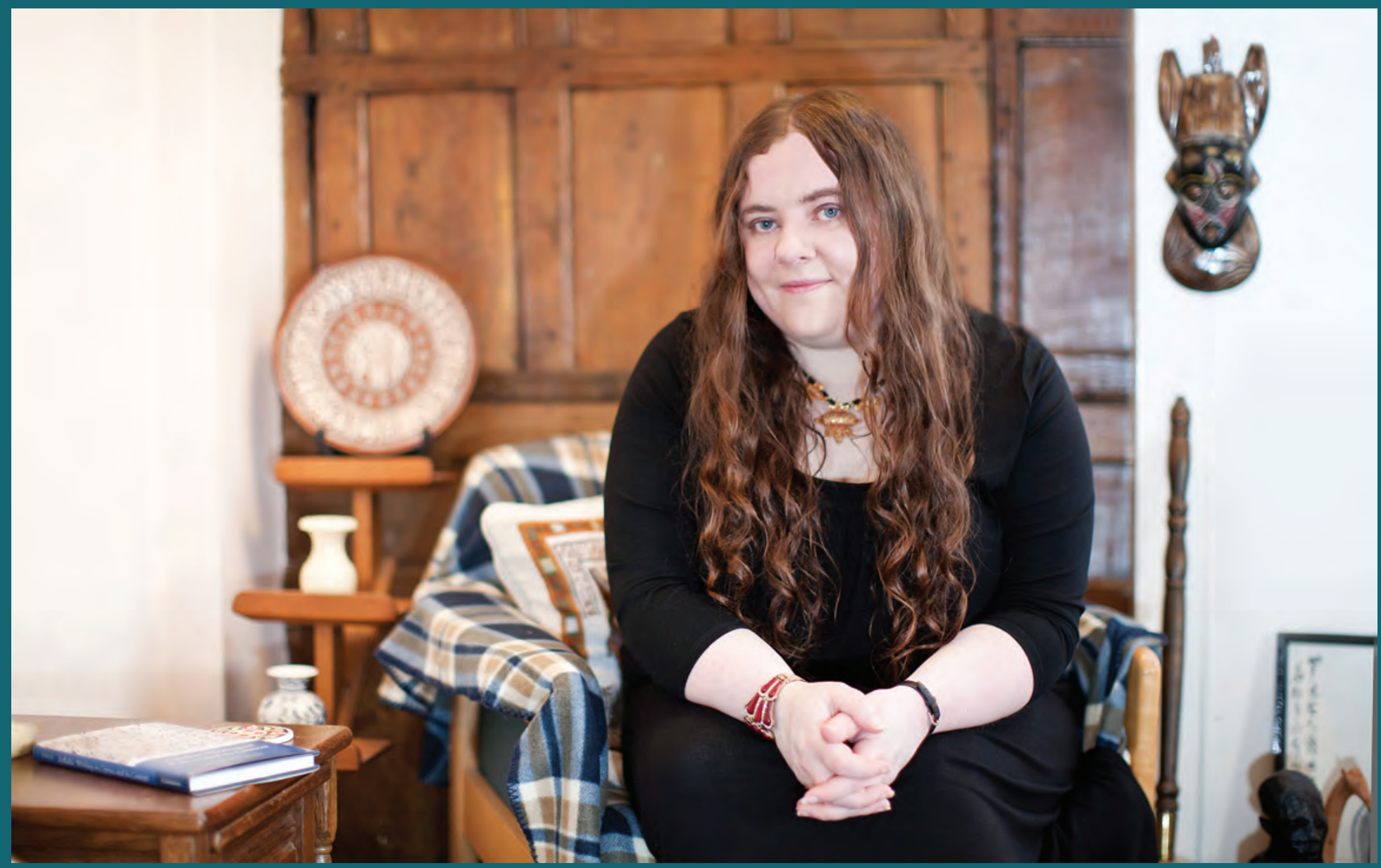

I've never felt that being a woman has had an effect on my career opportunities or likelihood of being published. Similarly, when I take on committee roles or collegiate responsibilities, I don't put that down to my gender: I just do them because I enjoy them. I suppose I might be described as being quite motherly with my students, but then again I know some male Directors of Studies who behave in a very similar way. In the Classics Faculty people are more interested in your value as a colleague than your gender, and there is a sense that everyone is on an equal footing. The same is true of the warm community at Magdalene College.
When you're at a relatively early stage in your career you aren't really thinking about what you've already achieved; you're more focused on what you're going to achieve in the future. But I am clear about the questions I need to be able to answer as I progress. What kind of a person am I? Do I work hard? Have I, through my endeavours and interactions with other people, done the right thing? I hope that would make me a better example for other women. 
Dame Barbara Stocking DBE was elected as President of Murray Edwards College and commenced her role in July 2013. She was previously the Chief Executive of Oxfam GB, which she led for nearly twelve years.

I don't buy the idea that you can be nice or competent but not both - not in the slightest.

I'm only competent because I am reasonably nice! I can still be firm and make the tough calls, but I just don't see the need to shout or be unpleasant. If you really believe in your people then engaging with them is essential - actually I can't see how I would get things done in any other way. The people I view as successful are those who can really deliver whilst maintaining their integrity.

As a teenager I already knew I wanted to get into international development. My parents were deeply embedded in their community and were always providing small kindnesses for others. They instilled in me a belief in community service and doing something of purpose. Added to this was a growing awareness of inequality. I saw how many resources our local private school had when compared with my state school. I don't remember being angry about it, I just thought, 'I don't believe these boys are any brighter than the people in my school, but they are getting more opportunities.'

"The people I view as successful are those who can really deliver whilst maintaining their integrity."

My subsequent career has focused on delivering for organisations that I can get passionate about. That's been the case at the King's Fund, the NHS, Oxfam and now in my role at Murray Edwards. When you are running organisations like these, you need to be able to manage other passionate people who tend not to be keen on being told what to do. To make it work, you have to genuinely believe in what you're trying to achieve; if there is even a piece of tissue paper between me and what l'm saying, then it would get spotted.

As a leader, you need to concentrate on getting the values and culture right, then you have to let go and trust your people to make the right decisions. In my experience they will repay your faith by bringing more imagination and insight than you could possibly bring alone. When I was working for Oxfam, I would turn up in the most remote places, and it was absolutely stunning to see how the staff there would be behaving absolutely according to our values. They would be treating poor people with respect and working with them as equals.
I was very proud to have been part of Oxfam, but after twelve years I knew I was ready to leave. The role at Murray Edwards was appealing, not only because I have a personal appreciation of what it means to be a student here, but also because there is a clear job to be done. It's not a well-heeled college, and I know I can help with the fundraising and organisation needed for us to realise our ambitions for women's development.

Our purpose as a college is to do the best by our students and provide nothing less than the academic excellence that is expected at Cambridge. But I also believe we offer more opportunities for young women. As a student, I remember being overwhelmed by these young men who had mostly come from public schools, where they had received much better teaching and were pretty confident about it. New Hall (as it was then) sent a message to state-school girls like me that they believed we could do just as well as our peers. That positive ethos and level of support enabled me to thrive, and I think it is still relevant now. When I asked our current JCR President, 'Would you try to be JCR President in a mixed college?' she said, 'No, I would never think that the young men would vote for me.'

When I left this college, I fully expected it would become mixed by now, but my own life and career experience tell me that its single-sex environment is still needed. Whilst I haven't encountered much outright discrimination, there has been plenty of stereotyping. For a while I didn't notice it, but then you realise that people are questioning whether you are tough enough to handle a challenging role. In interviews I have encountered men who have no idea what I've done, or how l've done it, so they don't respect it. Whilst women need the confidence to grab what's offered, I think men also have to start appreciating how women operate. A lot of men of my age and seniority are not used to working with women, and certainly not as equals. Many of them just don't quite know how to do it.

"Whilst women need the confidence to grab what's offered, I think men also have to start appreciating how women operate." 


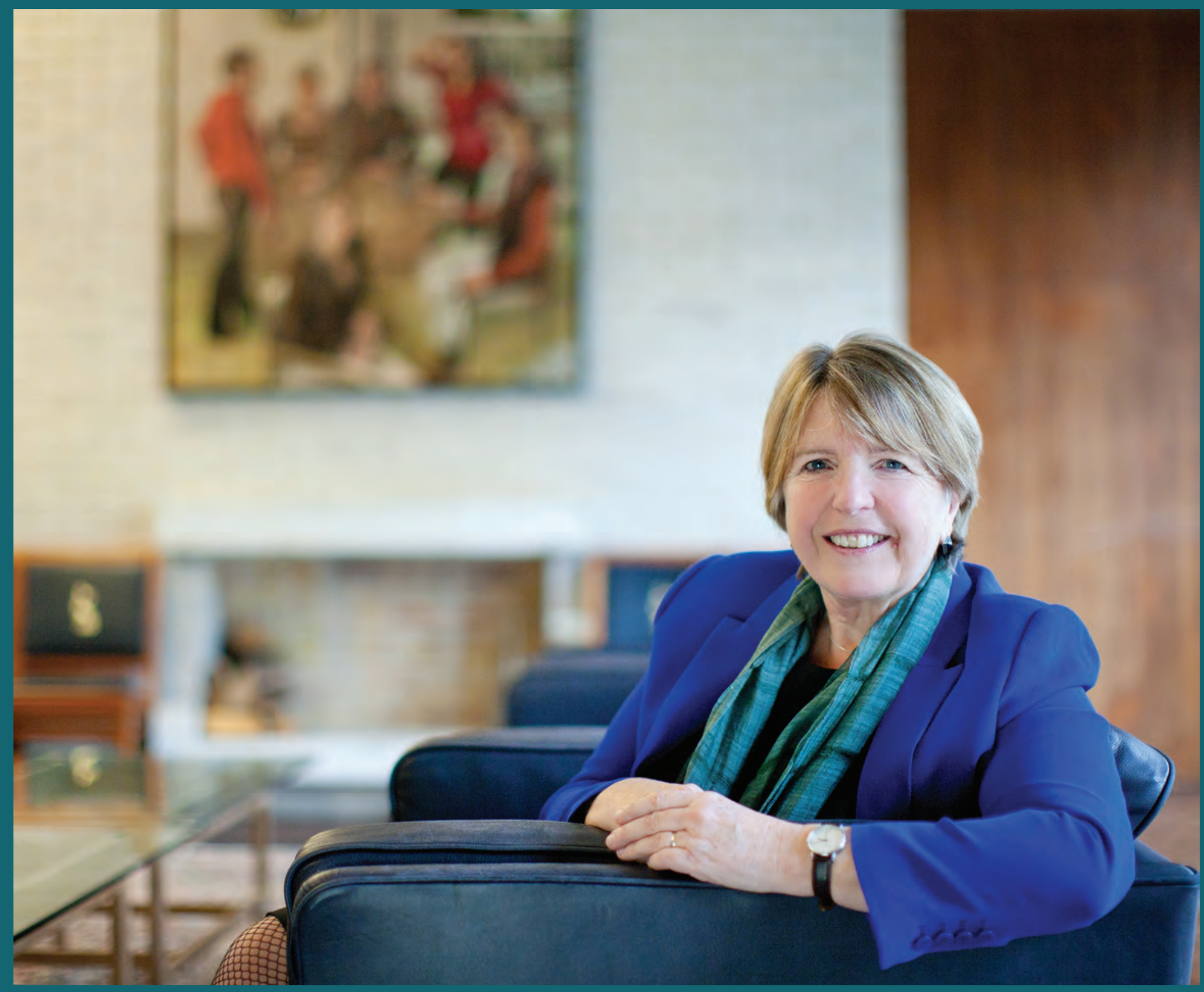

Nobody's career goes in one straight line. I have had some really tough times and if I ask myself, 'Have I ever been hurt by all this?' the answer is yes, but not so deeply that I didn't recover self-confidence. There have been times when I have felt that I wasn't understood, noticed or enabled to do the things that I knew I could do. I have got to points where I thought, 'It's never going to happen for me.' When I've hit those barriers, I have drawn on the support of my colleagues and in particular my husband. He has been prepared to listen to me, and believes in women so strongly that he gets as irritated as I do when men put me down. My career has been very hard in parts but very, very enjoyable in others, and there's more to come.

"Nobody's career goes in one straight line." 


\section{Conclusion}

The women who have participated in this book show the breadth of ways in which excellence can be demonstrated. Their stories and insights offer a tantalising glimpse of what could be possible if many more women were able to participate fully in the workplace. Each and every one was nominated by their peers as a successful individual who made an important positive difference to their working environment. Sometimes this contribution was matched by formal recognition and sometimes not. Amplifying the visibility, seniority and sheer numbers of women who are viewed as successful puts them in a position to contribute their considerable abilities to the University.

In some quarters there remains a pervasive myth that to be inclusive is to accept mediocrity. This does not stand up to scrutiny: real inclusion means insisting on excellence. It is about refusing to accept patchy recruitment processes that fail to reach out to the best talent available; it demands that leaders get the very best out of most, not just some of their people, and it drives high performance by creating highly efficient and effective working environments. If we settle for a status quo that only allows for a few to be truly successful, then the loss is everyone's: individual, organisational and societal.

Inclusive workplaces that develop a sophisticated understanding of what it means to be successful are not just good for women. Gender equity is about creating situations for men and women to thrive, do their very best work and align it with the other things that matter most to them, including their families. There is a need to reframe the debate so that it moves away from talking about 'women's issues', which require women to be fixed or perhaps to 'lean in' and fix themselves. A modern workplace that enables its people to have healthy, high-performing working lives is relevant to everyone and should be a core leadership concern.

Making the many and varied practical steps necessary to move towards becoming a more inclusive workplace is not a simple matter. There are no quick fixes. But progress becomes inevitable when individual will is brought to bear. Organisations change when the individuals within them choose to exercise their influence and leadership to insist on improvement. Progress happens when enough people, in enough parts of an organisation, agree on what is and what is not okay. It happens when people start to have rigorous, provocative and ambitious conversations about the best ways of working together.
This book is just one part of the demanding conversation that Cambridge is having about how to become more inclusive and therefore able to realise the talents of the women and men in its community. It is both a snapshot in time and a bold enquiry into how the University can expect more of itself. The narratives and themes in the book provide a signpost towards the territory that needs to be explored further and the questions that need to be addressed.

But Cambridge exists as part of a wider society and a wider intellectual environment. Media, education and even sport all set up expectations and gender norms for both men and women. As such, the organisational and individual questions identified as worthy of further debate at Cambridge are likely to prove of value beyond the University.

\section{Questions for the organisation to continue to explore}

\section{To what extent are we genuinely committed to becoming more inclusive?}

Unless there is room to ask searching questions about motivation, to express dissent and to interrogate the values that would drive any progress, then that progress will stall. This question stimulates a bold review of how things are currently and how we would like them to be.

Leadership is necessary at all levels, especially in an environment as diffuse and complex as Cambridge, so leaders need to know why and how they intend to lead in this area. They will inevitably encounter cynicism, vested interests and even sabotage, so they have to have a robust understanding of the values that are driving them to commit their time and energy towards encouraging greater inclusion.

If you don't know why you are doing something, sooner or later you run out of momentum, so it's worth spending time on coming up with responses to questions like, 'Do I buy the case that greater inclusion of women will add to, not dilute, excellence? Really? Who doesn't buy it, and how can I address their challenges?' 


\section{How can we define, measure and reward success more effectively?}

A traditional understanding of success is based almost exclusively on outcomes, such as grants awarded, papers published, reports completed, prizes won, metrics achieved, money saved or departmental systems redesigned. They concentrate on 'what' was done, not 'how' it was achieved. A positive outcome may well be the product of an effective process, but this is not always the case. For example, a strong research paper may be published to acclaim, but could be based on the work of a badly led and unhappy group, some of whom then choose to leave research for good.

Of course, any organisation needs high-quality outcomes and must reward the people who achieve them. But at the same time it needs to become deeply interested in recognising those who are good at the 'how' of achieving such outcomes and valuing and bringing out the best of them is part of what 'success' for an organisation must mean.

A more sophisticated and meaningful definition of success would enable an organisation to pick up on and promote people who are excellent at getting the best out of others. It would reward those who demonstrate strong interpersonal skills, set up and run wellbalanced, effective teams and prioritise the development of the people for whom they are responsible. It would capture and acknowledge the investment and time that goes into committee work, which strengthens a department or the institution as a whole. There is a tendency to view such qualities as 'nice to have' when actually they are an essential part of an effective organisation, as well as some of the core competencies of the best leaders.

\section{How can we reframe the debate away from 'women's issues' to talk about effective, modern workplaces?}

Both men and women can choose to become parents; both genders have caring responsibilities, important relationships and friendships, as well as an appetite to be more than just their work. There is the potential to focus on a shared agenda, but more often than not it gets positioned as a women's agenda.

If men and women become equally invested in creating more effective workplaces, then there is the potential to tap into much more energy, imagination and engagement. It is human nature to be interested in the things that are likely to benefit you personally, so men cannot remain on the margins of this work if it is ever to gain traction. As things stand, men also continue to dominate leadership positions, so it is quite simply essential to have both genders actively participating in decision-making.

\section{What policies, procedures, training, metrics and systems can we improve in order to accelerate progress?}

This may not be the most glamorous of points, but it is vital to look at the specifics of how an organisation is plumbed and where the particular blockages and opportunities lie. This is about identifying the levers that can be pushed and pulled to make sure that ambitions for inclusion become a tangible day-to-day reality.

For example, having clear guidelines about how appointments are publicised, unconscious-bias training for interviewers and a requirement to account for any shortlist that has only one gender represented on it would all help to change how women are recruited into and promoted through an organisation. Setting up robust metrics to run alongside this would capture progress and identify areas to focus on. Similarly, there could be reviews of policies around parental/caring leave, to try to understand how they could be applied to encourage a fairer working environment.

\section{How can we encourage the emergence of more diverse, visible role models?}

A simple answer to this question is that if you start addressing the four areas identified above, then you are going to begin to see the inevitable emergence of more diverse, visible role models. In the meantime, there is no room for complacency.

Role models send a message about what it is possible to achieve, just as the women in this book set an example of the different ways in which you can be successful. Role models prove what's possible for those who may share their gender, ethnicity, educational or social background, culture or subject-interest. Giving a platform for such stories is vital, especially when the numbers are currently stacked against particular groups. Panel events, interviews, committee representation, allocation of projects and public-speaking engagements all offer opportunities to vary the faces seen to be associated with success.

\section{Questions for the individual to continue to explore}

An organisation is made up of the people in it. To talk about the organisation and its people as being separate is perhaps strange but also necessary to emphasise that the responsibility for change is both collective and individual. An organisation may evolve its policies, structure or recruitment practices, but it is down to the individual to take advantage of the opportunities on offer. The stories in this book are from women, so the questions below are framed for a female audience - but they are also applicable to men who are interested in thinking about how they want to conduct their careers and the impact they want to have. 


\section{What do I really want from my working life?}

Many of the women in the book emphasised the importance of self-reflection and knowing what really mattered to them and why. They talked about pursuing their interests and passions wherever possible, as well as knowing when to compromise and when to hold the line. So this question is really about defining the success that has meaning and value to the individual themselves.

All of the women we spoke to faced a raft of choices, big and small, on a daily basis. They had to choose between competing demands on their time, which jobs to pursue, the relationships to invest in and even which battles to fight. Navigating these choices becomes easier when you have a deeper sense of what you want from your working life. This can change over time and in relation to circumstance, so it is helpful to develop a habit of pausing to step back and critically reflect on where you are headed.

\section{What effect does my gender have on my career?}

Whilst the book is an amalgam of highly individual voices, there are also shared patterns about what it means to be a woman in the workplace. Many of the participants talked about the impact of being a parent, how it feels to be the only woman around the table, the degree of responsibility felt towards supporting other women and what it takes to move upwards in an organisation. Despite this commonality, there was also some evidence of isolation and a sense of the pressure, or expectation, that can come with being one of relatively few women in a workplace.

Being a woman is not irrelevant to one's career - and that is not good or bad, it's just a reality. Society is such that perceptions around gender will affect us whether we like it or not. Thinking about what this means and what we want to do with it presents us with the opportunity to shape circumstances in our favour, rather than be ambushed by them. For those men reading this point, the same question applies: what effect does your gender have on your career? Addressing this question can help to make you more aware of how others treat you, the opportunities or obstacles that come with your gender, as well as of the biases that affect us all.

\section{How can I engage with the system most effectively?}

Careers don't just happen to us: they happen because of us, and it is entirely possible to be politically astute whilst also retaining one's integrity. It is vital to understand how decisions are made, the idiosyncrasies of who holds power and the ways that success gets recognised. You can then spot some of the bear pits, as well as the likely career accelerators. As soon as you understand the system, you are in a position to decide how you wish to engage with it. You have choices about the groups you join, the committees you engage with or avoid and the relationships you foster.
There is no 'right' way of engaging with a work system, as we all have different desires and values that affect what we want from our working lives. But there is merit in trying to shape circumstances so they align with our ambitions, whatever they may be.

\section{What influence do I have, and how do I want to use it?}

Exercising influence is not just the province of those at the very top of an organisation. A work environment is a human social system where we all impact on one another - sometimes intentionally and often unawares. To this extent we are all role models and the question then becomes, 'What kind of role model do I want to be?' We send messages all the time about who and what we value most and the behaviours we endorse or disapprove of. When we hold ourselves to account for those messages, we become more aware of our potential to influence others.

On a more practical level, job roles have authority attached to them - for example, to hire people, change a policy or set the working practices for a team. If you identify the scope of your influence, you can then ask yourself what you really want to do with it.

\section{What do I want to be known for?}

In talking to women for this project, there was a real ease and fluidity in discussing what they admired about their colleagues, both male and female. It's rarely as easy to describe what we value in ourselves. One way of tapping into this is to imagine overhearing a conversation where others are talking about you. Once you put aside the social awkwardness of the situation, what would you hope they said about you, what adjectives would you be pleased to hear or what achievements remembered? This perspective can shine a light on the sort of legacy we want to leave, the impact we want to have that is bigger than ourselves and perhaps the part we want to play in moving towards a more inclusive workplace.

\section{Summary}

Notions about success are not only intensely personal, but also shape and are shaped by the organisations within which we live and work. The stories we tell about success send messages about who and what we value. They have the potential to limit what an organisation or individual is capable of or to create the conditions for them to excel.

If organisations and individuals are able to engage in a rigorous, sometimes spiky and deeply ambitious conversation about how they view success, then they create the possibility of developing much more inclusive workplaces where men and women can perform at their best. 


\section{A personal perspective}

Most institutions find it difficult to change their prevailing cultures. It is all the more challenging for the University of Cambridge, with roots in a male monastic culture extending back 800 years, and with an exceptional record of success as traditionally defined. So why change now? One simple answer to that question is that the world around us has changed, and is changing, very fast; if we do not respond then we shall be left behind. It would be churlish not to recognise the progress made in recent years, partly in response to external legislative pressures. However, the stories in this book give us more powerful, and more humane, ways of thinking and acting. They show us that if we learn from these, we can do better: we can create a workplace and an environment that encourages and allows a diverse set of individuals to flourish and contribute in a wide range of different ways that enrich the experience for both women and men.

As Pro-Vice-Chancellor for Institutional Affairs, I am responsible for the wellbeing of all 10,000+ University employees. I chair the Human Resources and Equality \& Diversity Committees, ably supported by the staff of the Human Resources Division. So I have formal responsibility for the matters that concern this book and for pursuing the agenda that it sets out.

But I also bring to this role a personal commitment and perspective. Some of the feelings of exclusion (implicitly from a boys' club) that come through the experiences uncovered in this project resonate with me: as a Jew, growing up on a council estate, educated at a comprehensive school in Wandsworth and with no interest in either pubs or sport, I felt an outsider even before I arrived in Cambridge as a PhD student. It is still easy to feel excluded by the casual conversations of senior colleagues about rugby, cricket and rowing. Some who start as outsiders make the (possibly unconscious) decision to become 'one of the boys' as quickly as possible, and that includes some women too. I did not take that route, but I now realise that not conforming actually demands a lot of self-confidence and also usually another support group, in my case my wife and family, and the research group that I lead: my academic family. We have all had experience of being an outsider, or in a minority, in some part of our lives - and whilst we have different ways of coping with this, my hope is that Cambridge will become increasingly inclusive, so that difference is embraced and celebrated and the effort that is expended on fitting in or conforming can be used to more exciting and productive ends.

The natural bonding between those who share common backgrounds and interests need not be criticised, and can be hugely supportive: what matters is that important decisions are not taken informally by a group of insiders, but are the result of rigorous, accountable processes and good governance.
Cambridge is an academic-led university, with excellence in its teaching and research as key priorities. This has - too often - meant that managerial and administrative excellence have been seen by academics as less important. They have not always recognised the key contribution that good management, by them and by their administrative colleagues, makes to enabling that academic success. However, I am clear that it is only through bold leadership, excellent management and administration, and by providing the most supportive environment for all of our staff, that we shall be able to maintain our outstanding academic standards in a rapidly changing world. This means recognising and applauding excellence in all aspects of our activity, and at all levels. This book's open enquiry into an inclusive definition of success is one way we can do this. The Employee Recognition Scheme for members of the United Administrative Service, launched in 2012 by the Registrary, is another great example of this way of thinking.

However, recognising and embedding different types of success is not necessarily easy: as we strive to make our appointments and promotions processes more objective, fair and open to scrutiny, the temptation is to become more quantitative in our assessments. That might lead us to measure more and to feel less. There is clearly much work still to be done in this area; the questions raised in this conclusion provide us - both individually and institutionally - with some direction for our next steps.

I hope that the publication and wide distribution of this book, and the success stories that it celebrates, personal and professional, will contribute towards the changes that are still required, ultimately inspiring women and men to work together to help redefine success - not only in Cambridge, but everywhere.

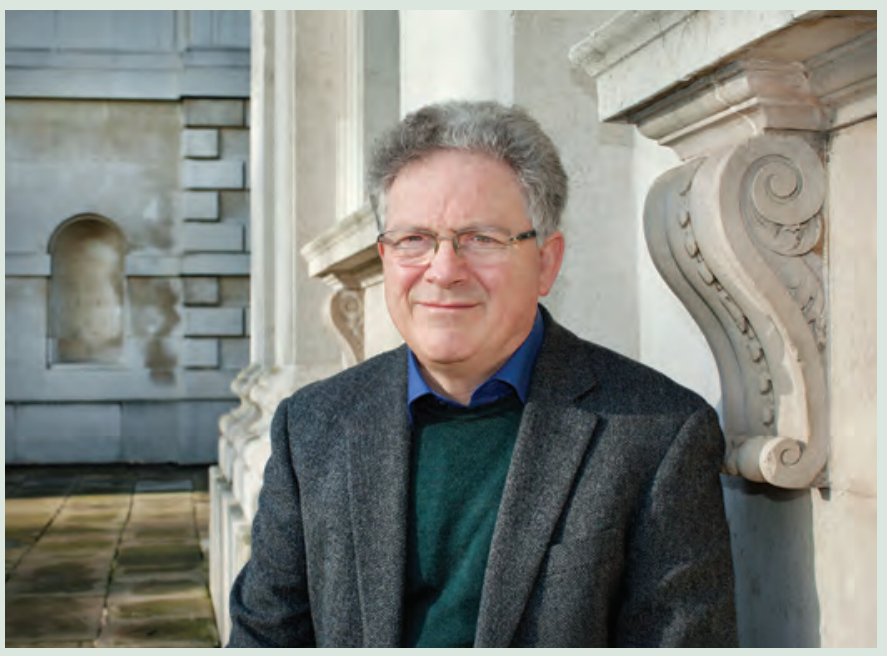

Professor Jeremy Sanders FRS

Pro-Vice-Chancellor for Institutional Affairs University of Cambridge 


\section{The Meaning of Success has been compiled from contributions submitted by 126 women. Some have been featured in the profiles throughout this book; our sincere thanks are also extended to the following women who so generously shared their time, insights and experiences for this project:}

\section{Dr Kirsty Allen}

Principal Assistant Registrary and the Head of the Registrary's Office

Stamina, patience and a sense of humour are amongst the things which get me through. That and building good, strong relationships with colleagues.

\section{Dr Abir Al-Tabbaa}

Reader in Geotechnical Engineering

There are sufficient women in the University for us to work together, make a difference and take on challenges. There is no need to feel alone: many women in the University have had similar experiences.

\section{Dr Terri Apter}

Senior Tutor at Newnham; Affiliated Lecturer in Psychology

I bought into the family structures that set me up as primary carer of our children, and it was very difficult for me to relinquish what that offered me. Children's development and the passions and penalties of parenting then became the focus of my professional interest. So what I had thought was a detriment to my career became its foundation.

\section{Professor Madeleine Arnot}

Professor of Sociology of Education; Professorial Fellow at Jesus College

Being female at a time when the women's movement took off has been wonderful. I have made so many good friends, travelled the world and found like-minded women, I have helped and seen women advance in their careers and worked on wonderful projects that focus on gender. All this has given me a role, a network and an extraordinary link to the era.

\section{Sue Aspinall}

Research Laboratory Manager, Departmental Safety Manager, Department of Plant Sciences

Be positive and don't always believe the system is against you - look at your achievements. For me that means, 'Don't just think I've been lucky!' 


\section{Dr Claire Barlow}

Senior Lecturer and Director of Undergraduate Education, Department of Engineering

Be bold and seize opportunities! But get good at saying 'no' to things where people are actually taking advantage of you. There has to be something in it for you.

\section{Professor Catherine Barnard}

\section{Professor in European Union and Employment Law; Fellow of Trinity College}

I recognise that my own time at Cambridge has benefited from the support given by a number of colleagues - among them some men - who have seen that the gender imbalance needs addressing and that they should assume some responsibility for assisting in that process. In turn, I also feel a responsibility towards women beginning a career at the University. I recognise the hesitancy that some feel about pushing themselves forward and try to provide them with support.

\section{Professor Dame Gillian Beer}

\section{King Edward VII Professor of English Literature Emeritus}

Gender is in the grain of all we do: sometimes it makes one an irritant but it also allows you to contribute fresh experience. I was fortunate to have a female-centred education and to take for granted that women would occupy positions of authority.

\section{Alice Benton}

Head of Educational and Student Policy, Academic Division

Look after your friends and colleagues when they need help. They'll help you when you need it.

\section{Professor Natasha Berloff}

Professor of Applied Mathematics, Department of Applied Mathematics and Theoretical Physics; Fellow of Jesus College

Never sacrifice your dreams just to be convenient.

\section{Professor Serena Best}

Professor of Materials Science, Department of Materials Science and Metallurgy

Much of my success has been because of the support and 'pushing' that a good mentor provides. A good mentor can be male or female, but it is essential to find people who are motivated and who take their role seriously. 


\section{Dr Jane Blunt}

Safety Officer, Department of Physics

I believe that I have made a significant difference at University level since, when I joined, there was almost no guidance literature for staff. I wrote quite a lot of what is now on offer. On a personal note, I am also very pleased to have achieved a black belt in judo (in my thirties) and taekwondo (in my sixties).

\section{Lucinda Bowditch}

\section{M.St Administrator, Institute of Criminology}

I think you get out what you put in - I like to do things to the best of my ability and I believe I have received the rewards (not necessarily financial but in satisfaction and personal commendations).

\section{Professor Carol Brayne}

Professor of Public Health Medicine; Director of the Cambridge Institute of Public Health

Teaching is a privilege and supervising students, bringing people on, is tremendously rewarding, very different from the thrill of research outputs.

\section{Dr Abigail Brundin}

University Senior Lecturer in Italian; Fellow and Director of Studies in Modern Languages, St Catharine's College

Be pushier. Don't hang back and wait to be asked - ask first. If you don't get good advice, seek a second opinion, further afield.

\section{Professor Ruth Cameron}

Professor of Materials Science; Director of Cambridge Centre for Medical Materials; Fellow of Lucy Cavendish College

I have received much support over the years from the University, Department and College in being able to work flexibly and balance outside and work commitments. This has made a huge difference.

\section{Ann Cartwright}

Institute Administrator, Wellcome Trust/Cancer Research UK Gurdon Institute

You should never be afraid of being unpopular for something that you feel is right. Popularity is transient.

\section{Professor Jennifer Clack}

Professor and Curator of Vertebrate Palaeontology, University Museum of Zoology

I don't think of myself as 'a woman'. I think of myself as 'a person'. 


\section{Dr Menna Clatworthy}

University Lecturer in Transplantation Medicine; Honorary Consultant Nephrologist; Fellow and Director of Studies in Clinical Medicine, Pembroke College

It's great to have a job you love, and I am very fortunate to be able to have such an interesting job combining research, clinical medicine and teaching.

\section{Professor Ann Copestake}

\section{Professor of Computational Linguistics, Computer Laboratory}

I've experienced stereotyping and unconscious bias but I can't tell how much it has affected me.

\section{Polly Courtice}

Director, Cambridge Programme for Sustainability Leadership

Combining a full-time career with family life was exciting but also very demanding. It made me all the more committed to supporting other women trying to do the same thing.

\section{Dr Hannah Critchlow}

Content Designer, Editor and Presenter, Naked Scientists, Department of Pathology

I'm still trying to find out what the best answer is to dealing with gender inequality. But for the time being I just try to be myself and be as reasonable, firm and clear as possible.

\section{Sue Davis}

Manager, University of Cambridge Childcare Services

I aim to reach a win/win solution where possible, by being sensitive but also realistic. Dealing with people is not easy, but it is always worth trying to understand their position before responding or reacting to them.

\section{Professor Judith Driscoll}

Professor of Materials Science, Department of Materials Science and Metallurgy

I think it is not a question of how I (or other women scientists) can help other women scientists, as I believe most of us do a lot in this regard, but it is more a matter of the fact that institutional changes are needed.

\section{Dr Caterina Ducati}

Reader in Nanomaterials, Department of Materials Science and Metallurgy

It matters to me to have secured a job that allows me to search freely and discover... permanently. 


\section{Dr Helena Earl}

Reader in Clinical Cancer Medicine, Department of Oncology

There is success in every woman, no matter if they are well known or not. The old classics are filled with 'heroes' rescuing helpless princesses from deadly fates, yet now in the field of modern science the reality of 'heroines' has emerged.

\section{Dr Karen Ersche}

Senior Research Associate at the Department of Psychiatry; Leader of the Human Drug Addiction Group

Never give up!

\section{Dr Patricia Fara}

Senior Tutor, Clare College; Affiliated Lecturer, Department of the History and Philosophy of Science

I think that my generation suffered from trying to match two conflicting role models: we were still expected to behave like conventional women (basically looking attractive and being good wives and mothers), but at the same time we were being told that we were living in a new era of liberation.

\section{Dr Helen Firth}

Consultant Clinical Geneticist, Cambridge University Hospitals Trust; Honorary Faculty Member, Wellcome Trust Sanger Institute; Bye-Fellow of Newnham College

Quite minor changes in work-life balance can have a dramatic effect on your happiness, so it's always worth reappraising this every few years.

\section{Sarah Foreman}

Head of Maintenance, Estate Management

Success is out there for the taking: just grab it with both hands. A successful career requires determination, a firm resolve, dedication and damn hard work, but so does everything worth achieving in life.

\section{Professor Abigail Fowden}

Professor of Perinatal Physiology, Personal Chair; Deputy Head of Department, Department of Physiology, Development and Neuroscience

Being female means you tend to be underestimated, at least it did when my career began. 


\title{
Professor Mary Fowler
}

\author{
Master, Darwin College
}

The people for whom I have huge admiration are the current generation of PhD students, postdocs and early career academics who are managing to combine their academic work with raising young children. There is more childcare available than decades ago and maternity leave, flexible working, career breaks etc, are now seen as mainstream, but nevertheless having the determination to overcome the sleepless nights, juggle the multiple demands on your time and emotions, and still produce high-quality academic work is not easily or lightly achieved.

\section{Professor Sarah Franklin}

Sociology Professor, Department of Sociology

Women face enormous discrimination in the academy. This is most evident in the lack of citation of women's work, in the inability to fully recognise women's achievements, the constant marginalisation of their work and the constant denial that any of this is happening.

\section{Dr Jennifer French}

Research Fellow in Archaeology and Anthropology

I would urge people (especially women, as most of the ones I meet are less willing to do this than men) to realise that a bit of selfpromotion and confidence (as long as it is not at the expense of others) is an excellent thing and a vital tool for getting ahead.

\section{Professor Susan Gathercole}

Director of the Medical Research Council Cognition and Brain Sciences Unit

There are many blind alleys and when you get to these, it can be frustrating and hard to think about fresh approaches. Resilience is the only answer!

\section{Dr Fanni Gergely}

Royal Society University Research Fellow and Research Group Leader at Cancer Research UK Cambridge Institute

Setting up a small yet productive research group has probably been the achievement that mattered to me the most. It has been a long process full of ups and downs (and ups again).

\section{Professor Valerie Gibson}

\section{Professor of High Energy Physics, Cavendish Laboratory}

You CAN do research and have a family. If you decide to go down this route, make sure that you have understanding and support in place from your partner/family/childcare etc. Accept that you will not necessarily have the same career trajectory as others - if the quality of your research is excellent you will succeed. Talk to others and you will find that you are not alone. 


\section{Professor Fiona Gilbert}

Professor of Radiology, Head of Department of Radiology

It's crucial to keep focus on what is important and to keep pursuing your goals. Try to avoid giving up after a disappointment, but learn from your failures and try to find a way to succeed. I have a very strong belief that you can succeed in something if you really want it enough.

\section{Dr Emma Gilby}

\section{Senior Lecturer, Department of French}

In my teaching, I try to be encouraging, because I dislike posturing and hierarchies.

\section{Professor Beverley Glover}

Professor of Plant Systematics and Evolution; Director of Cambridge University Botanic Garden

Cambridge has very many examples of inspiring women, most of whom are very approachable and happy to help their colleagues find their own path.

\section{Dr Jane Goodall}

Research Fellow and Group Leader, Department of Medicine

I think my main challenges are yet to come; supporting my son through his teenage years, achieving a tenured research position and helping my parents as they face increasing disability with age. My last thought comes from experiences from my photography which I think is generally applicable to everything in life: 'You'll never see the sunrise lying under the duvet.'

\section{Margaret Greeves}

Emeritus Fellow, Wolfson College; formerly Director of Renaissance Projects for the Museums of the University

Try to have a reliable mentor within the University and another wise 'critical friend' outside it.

\section{Dr Fiona Gribble}

Professor of Endocrine Physiology; Wellcome Trust Senior Research Fellow; Honorary Consultant in Clinical Biochemistry

Get out there and make yourself known to the leaders in your field around the world, because they will be the ones who will review your grants, papers and career progression applications. 


\section{Professor Gillian Griffiths}

Director of Cambridge Institute for Medical Research; Professor of Immunology and Cell Biology; Wellcome Trust Principal Research Fellow; Fellow of King's College

Like most other women scientists I have the usual stories of being ignored, and it being presumed that I am present at a meeting as a secretary rather than an academic.

\section{Nicola Hardy}

\section{Senior Esquire Bedell}

There are some amazing things for us to achieve together as colleagues in a world-class academic institution, and also some incredible conversations for us to have as friends.

\section{Dr Liz Hide}

University of Cambridge Museums Officer

I work part-time: neither better nor worse than full-time, but different. I have found this approach personally empowering.

\section{Dr Jennifer Hirst}

Principal Research Associate, Clinical Biochemistry

Some of my best ideas come to me in the middle of Jazzercise or karate! Being around my children helps me put a better perspective on life - so a disastrous day at work where nothing has worked is quickly forgotten about. This keeps me fresh for the next day!

\section{Professor Simone Hochgreb}

Professor, Department of Engineering

Being part of a minority brings particular visibility, which can work in one's favour by bringing attention to positive achievements. On the other hand, the small numbers of women mean significant responsibility - performance is expected to be stellar across the board, or risk becoming a poor representative for the minority group, thus validating any prevalent prejudices.

\section{Professor Deborah Howard}

Professor of Architectural History; Fellow of St John's College

It is usually not acceptable for a woman to be seen to be angry, as she is regarded as hysterical and out of control, whereas a man can get away with it.

\section{Isobel Humphrey}

Assistant Registrary, Academic Division

My greatest asset in overcoming challenge is my network of friends and colleagues; the wisdom of others is really important. 


\section{Diane Ingham}

\section{Business Services Administrator, Estate Management}

I will always help other members of staff if they need me (especially the underdog), no matter whether they are within my section or not.

I like to see people happy in their workplace as I am extremely happy in mine.

\section{Dr Lisa Jardine-Wright}

\section{Educational Outreach Officer, Cavendish Laboratory}

My weakness was not feeling able to ask questions - not wanting to show lack of knowledge or understanding. Developing the confidence to acknowledge this weakness and to ask questions became my biggest strength. I have truly learned the lesson that there is no such thing as a stupid question.

\section{Professor Fiona Karet}

Professor of Nephrology; Honorary Consultant in Renal Medicine

The women I admire are those who know how to play well as well as work well.

\section{Dr Linda King}

Director of Studies, St Edmund's College

My view of my career now is that I want a good work-life balance. Success is measured in many ways - the most important of which is how you feel about yourself.

\section{Professor Alison Liebling}

Professor of Criminology and Criminal Justice; Director of the Prisons Research Centre, Institute of Criminology

Be authentic, summon support, find like-minded others, do what you believe in, trust your instincts, take up offers of intellectual and other support/friendship, never compromise your basic values or identity.

\section{Professor Judith Lieu}

\section{Lady Margaret's Professor of Divinity}

There have been moments of invisibility and (often unintentional) marginalisation, but more generally I have been fortunate in the amount of support I have received. Perhaps I have been more determined to challenge attempts to pigeon-hole me.

\section{Debbie Lowther}

\section{Bursar, Girton College}

It's an old chestnut, but I think it's true, that it's amazing what you can achieve if you don't mind who gets the credit. The hard bit is getting the credit that's due to you. 


\section{Dr Sam Lucy}

Admissions Tutor and Financial Tutor, Newnham College

Never, ever, volunteer to make or pour the tea for a meeting if there are fewer than 50 per cent women in the room.

\section{Dr Jane MacDougall}

Consultant Obstetrician \& Gynaecologist and Subspecialist in Reproductive Medicine

I was told at an early stage that I needed to be better than my male colleagues in order to get the good jobs.

\section{Helen Marshall}

Teaching Office Administrator, Department of Physics

When I was at school in the mid 1970s, girls of my age in my school were not given any advice on what to do next. I felt it was assumed that I would become a 'secretary' because that's what a lot of my peers were doing. I don't think that is the case now.

\section{Professor Theresa Marteau}

Director of Research; Director of the Behaviour and Health Research Unit; Honorary Professor of Behaviour and Health

I still find myself in places where one can be forgiven for thinking women have yet to be invented. Pointing this out - with grace and humour, but more importantly attempting to remedy it - is just one small example of the many interventions that senior academic women can make in working towards a 50:50 society.

\section{Dr Helen Mason}

Personal Readership in Solar Physics, Department of Applied Mathematics and Theoretical Physics

My main challenges came when I had children. Good parenting requires time and dedication. I addressed this by working part-time, without compromising the quality of my research.

\section{Genevieve Maul}

\section{Science Communications Officer, Office of External Affairs and Communications}

As the third of three girls, I benefited from a father who made sure we were not limited by our gender while growing up. I always had male friends, and I played on the all-male soccer team in high school because there was not one for women. I truly believed that I could do anything a man could do.

\section{Jessie Monck}

Development Consultant, Personal and Professional Development

Despite ongoing inequalities, I still feel incredibly fortunate to be alive today in this country rather than when women could not vote/work/ own property/study/receive a degree. Or indeed, cannot do these things today in far too many countries. 


\section{Professor Gillian Murphy}

Professor of Cancer Cell Biology; Deputy Head of the Department of Oncology

I feel very fortunate to be one of the first generation of working-class people, post-war, to succeed academically. Despite all the problems of UK education, I have appreciated the excellent teaching that I have received to allow me to do this.

\section{Vicky Neale}

Senior Teaching Associate, Department of Pure Mathematics and Mathematical Statistics

It is better (although not always easier) to be oneself than to try to be someone else.

\section{Rosalyn Old}

Former President of the Cambridge University Students' Union; member of the University Council

As you climb up the ladder, help other women up with you; don't drop the ladder when you get to the top.

\section{Dr Rachel Oliver}

Reader in Materials Science, Department of Materials Science and Metallurgy

What I am currently learning is that there is a way of being a successful female scientist without working twelve-hour days and having no family life. Whether the compromises I am making in order to achieve this are the right ones, I don't yet know!

\section{Dr Rosanna Omitowoju}

Senior Language Teaching Officer, Faculty of Classics

Students will turn to me with problems, both pastoral and work-related, and I think that this is part of very complex gender expectations.

\section{Nicola Padfield}

Reader in Criminal and Penal Justice; Master of Fitzwilliam College

My greatest achievement in my own eyes is that I have been able to have a career which has involved such variety: I love teaching, but have also been privileged to be involved in important research projects, and to take a role on a more public stage. My three children are hugely important to me - they matter most, but are they an achievement?! More of a privilege.

\section{Professor Sharon Peacock}

Professor of Clinical Microbiology

Being self-propelled and interacting with the people around you is more important than waiting for sage advice, since no one will know what is better for you than yourself. 


\section{Karina Prasad}

\section{Head of the Office of Postdoctoral Affairs}

I would say now that my daughter is grown I have a renewed energy to get stuck into projects and initiatives and view this next chapter of my working life with great enthusiasm and vigour; with more than twenty years of working life in front of me it is almost as though I have a new career, which is rather exciting.

\section{Dr Wendy Pullan}

\section{Senior Lecturer and Director of the Martin Centre for Research, Department of Architecture}

Many of my generation have been less confident about our place in academia and demanded less; we were more willing to put up with being a safe pair of hands. Women today have a clearer sense of what they want to do (if not necessarily who they want to be), and they find ways of getting there faster; they expect and demand a more egalitarian workplace.

\section{Dr Julia Riley}

Senior College Lecturer in Physics; Fellow, Director of Studies and Vice Mistress, Girton College; Affiliated Lecturer, Graduate Training Coordinator, Department of Physics

I am me and I have taken life as it comes.

\section{Professor Margaret Robinson}

Professor of Molecular Cell Biology, Cambridge Institute for Medical Research

I don't seem particularly imposing, and I certainly don't play power games, but this hasn't prevented me from doing well in my field.

\section{Dr Corinne Roughley}

Affiliated Lecturer, Division of Archaeology

Supportive colleagues make the impossible possible, and it can be surprising who that might turn out to be.

\section{Dr Corinna Russell}

College Lecturer and Director of Studies in English

The most gendering experience has been motherhood, but this has brought with it some great philosophical opportunities for contemplation: what does a career look like that isn't defined by 'achievement' in the same way as some of my male colleagues' might be? How else might it be meaningful and satisfying? How can I pass on lessons, to students and colleagues frequently hag-ridden by the pressure to succeed, from an episode in my life when my capacity for brilliance and achievement have been significantly reduced, or in abeyance? 


\section{Caroline Saunders}

Head of Clinical Operations at Addenbrooke's Clinical Research Centre

I am often at meetings, on committees and on boards where women are a minority. I don't find this a disadvantage. I think provided you have a clear understanding of your own thoughts, views and plans your voice has equal weight with those of men.

\section{Dr Suchitra Sebastian}

University Lecturer and Royal Society University Research Fellow, Department of Physics

My biggest learning has been to remain myself, and not lose a lightness of spirit and an appreciation of other people as I find a way to survive and succeed in my field.

\section{Professor Alison Sinclair}

Professor of Modern Spanish Literature and Intellectual History, Department of Spanish and Portuguese

Do the things you want to do, rather than simply the things you feel others want you to do.

\section{Dr Ruchi Sinnatamby}

Consultant Radiologist and Clinical SubDean for Cambridge University Hospitals; Director of Studies in Clinical Medicine

Being nominated for this feels like an affirmation in itself - thank you!

\section{Professor Alison Smith}

Professor of Plant Biochemistry, Department of Plant Sciences

Gender is important, but it should not define you. On the other hand it is quite all right to behave like a woman in committees etc - after all, most men behave like men.

\section{Dr Annabel Smith}

Graduate Programme Manager, Wellcome Trust Sanger Institute

I think it would have been useful to have sought out appropriate (female) mentors during my career, especially as this may have helped to give me more confidence. Sometimes you just need someone to tell you, 'Yes, you can do this.'

\section{Sarah Smith}

Business and Operations Manager, Cambridge Institute for Medical Research

Learn all that you can from role models, irrespective of their gender or age. If you have a manager who is ineffective in certain ways, then learn how not to manage. Even if you are in a role that you dislike, learn everything that you can from it and then use those skills for your next move. 


\section{Dr Claire Spottiswoode}

BBSRC David Phillips Research Fellow, Department of Zoology

It seems a good idea to find what it is that you love and do it, and along the way find people you like to do it with.

\section{Meg Staff}

\section{Research and Graduate Education Officer}

The hardest challenge was coming into the University without a degree, having been told on arrival in 1992 that I wouldn't have any career in the University because of this. It has been an uphill struggle to overcome this personally and professionally.

\section{Professor Liba Taub}

\section{Director and Curator, Whipple Museum of the History of Science}

I am comfortable in male-dominated and female-dominated environments, and enjoy both. Increasingly, my department is becoming more gender-balanced, and that's comfortable too.

\section{Elizabeth Tilley}

Faculty Librarian, Faculty of English

It has made an enormous difference to my current working life that I love what I do. I don't think I would have been successful as a teacher because I didn't enjoy the work enough. I work well in a support-service environment such as a library, precisely because it is a 'service'.

\section{Dr Dana Tsui}

Postdoctoral Research Fellow, Cancer Research UK Cambridge Institute

I believe teamwork is the key to success. No one can work alone, and working together with people of differing expertise is the best way to combine different talents to achieve the best outcome.

\section{Professor Megan Vaughan}

Smuts Professor of Commonwealth History, Faculty of History

Being the only woman in the room can be extremely dispiriting. You often feel one of two things: either that you're not being vocal enough in support of female causes, or that you're being labelled as 'strident' for speaking up. 


\section{Nathalie Walker}

Director of External Affairs, Cambridge Judge Business School

From only one occasion do I have a horror story, where someone uttered the immortal line, 'You won't understand that because you are a woman.' I found it such a preposterous statement I genuinely just laughed, and many years later it still makes me laugh to think about it.

\section{Professor Alexandra Walsham}

\section{Professor of Modern History, Faculty of History}

Compromise and diplomacy are important in leadership roles, but never at the expense of integrity. Stand up for your convictions.

\section{Gillian Weale}

Administrative Officer in the Faculty of English

On a smaller level, one achievement that stands out is being awarded Grade 1 piano with distinction aged about ten years old. I am not very musical, and the result was unexpected. I think the achievement is important because it shows how good teaching and preparation can get amazing results.

\section{Susie White}

Deputy Administrator, Faculty of Asian and Middle Eastern Studies

I encourage people to develop themselves and not to be held back by feelings that, first, it's not their place to develop themselves beyond their prescribed role and second, that it's something beyond them.

\section{Caryn Wilkinson}

Administrator and Office Manager to Professor Patrick Maxwell, Regius Professor of Physic and Head of the School of Clinical Medicine Enjoy work and home - and enjoy the satisfaction of doing a good job.

\section{Dr Diana Wood}

Director of Medical Education in the Clinical School and Clinical Dean

Don't be pushed into making important decisions too quickly - take enough time to think through the consequences and be prepared to compromise on some issues in order to get what you want overall. There is nothing more annoying than someone who tries to make their deadlines into yours. 


\section{Professor Sarah Worthington}

\section{Downing Professor of the Laws of England; Fellow of Trinity College}

I've learnt a lot about the importance of relationships, the value of experiences, the randomness of opportunities and the uselessness of adhering to 'life plans' even if the energy and focus they inspire is useful - who'd have thought from the outset that l'd ever be fortunate enough to end up here?

\section{Dr Laura Wright}

\section{Reader in English Language, Faculty of English}

I was unable, biologically, to farm child-raising out to someone else. I needed (and still need) to be home every night to help with homework, cook dinner, get stuff ready for school, hear about the day, help with social problems and so on.

\section{Jocelyn Wyburd}

Director, University of Cambridge Language Centre

One of the points made most often in exercises of this kind is that women are underrepresented in senior roles. It has never occurred to me to feel that I did not deserve to be in a senior role, if I have the ability to fulfil it. I do not know if I am unusual as a woman in this regard.

\section{Professor Magdalena Zernicka-Goetz}

Professor of Mammalian Development and Stem Cell Biology, Department of Physiology, Development and Neuroscience

When I had children, our eldest turned out to be a girl. My father made the comment that perhaps girls used to have less opportunities but he did not believe that was the case these days, and so he expected the most from me and now from her. I think that this kind of parental expectation and encouragement, sometimes quite forceful, has had much more of an influence upon my life than my own gender. 



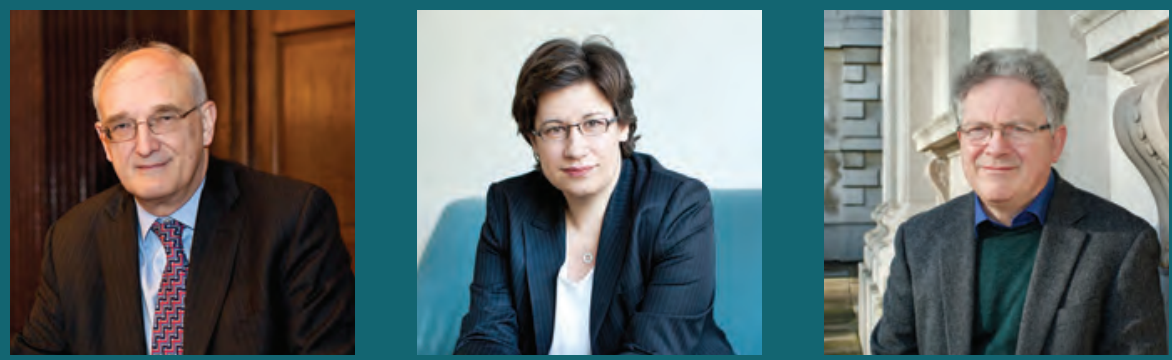

The Meaning of Success: Insights from Women at Cambridge makes a compelling case for a more inclusive definition of success. It argues that the current criteria we use to judge people as successful are both too narrow and create a career advantage for men. In order to recognise, reward and realise the talents of both women and men, a more meaningful definition of success is needed. Practical ways of achieving this are explored through interviews with a diverse cross-section of remarkable female role

models at the University of Cambridge, spanning academic staff, administrators and professors.

These first-person stories bring alive the achievements and challenges women experience in their working lives, and the effect gender has had on their careers. The book stimulates a debate about what it would take to bring about a more inclusive working environment and is relevant to the University and academic sector internationally, as well as the wider workplace. 